\title{
The Illustrated Chicano: \\ Chicano Border Methodology in Practice
}

\author{
by
}

\section{William Franco}

\author{
A thesis \\ submitted to the Victoria University of Wellington \\ in fulfilment of the requirements for the degree of \\ Doctor of Philosophy
}

Victoria University of Wellington

2019 



\section{Contents}

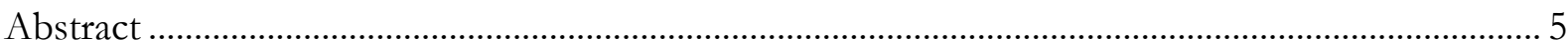

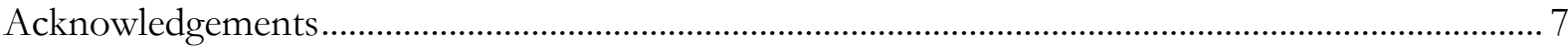

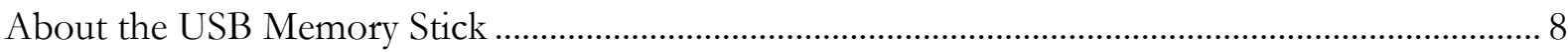

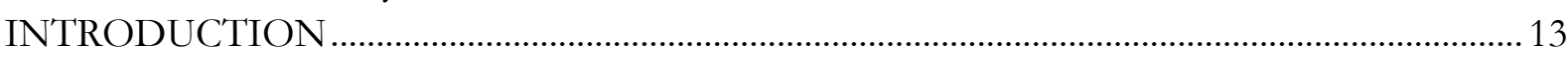

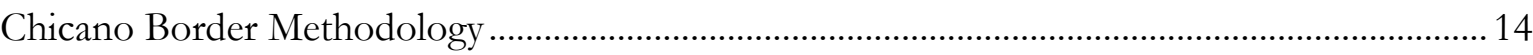

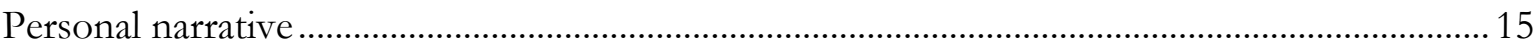

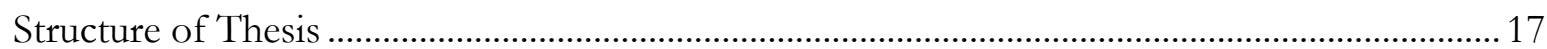

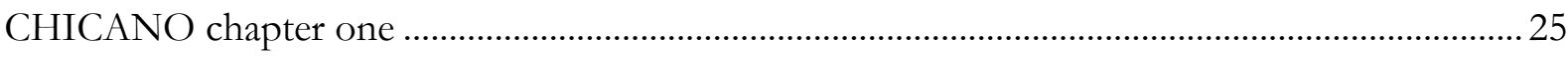

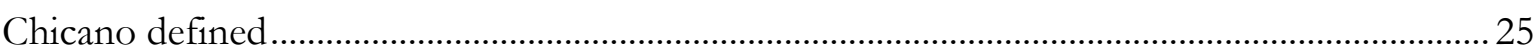

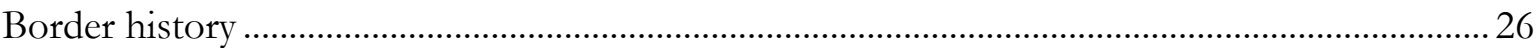

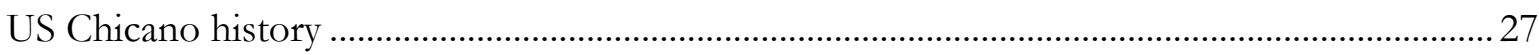

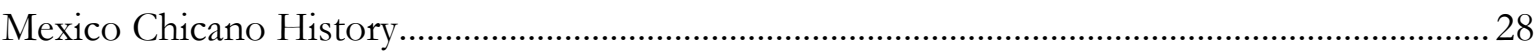

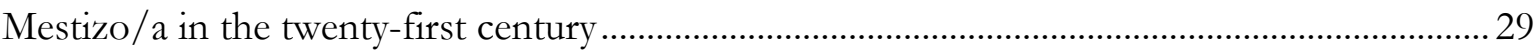

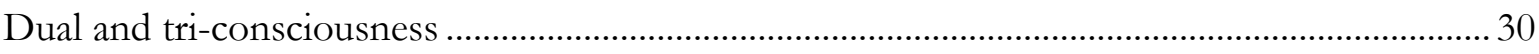

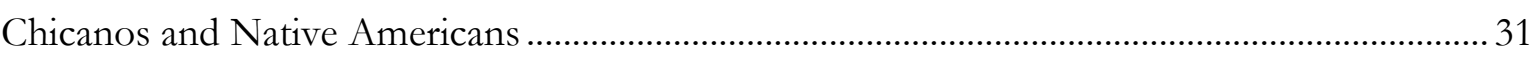

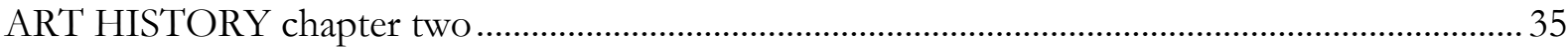

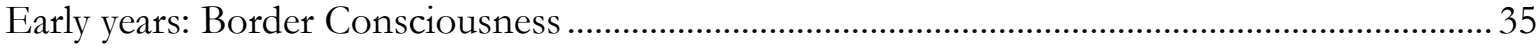

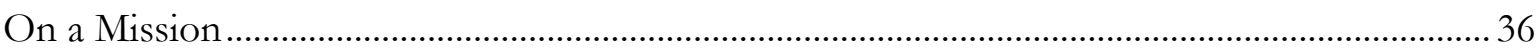

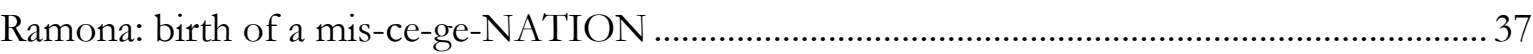

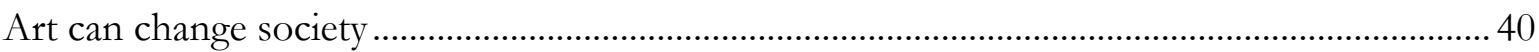

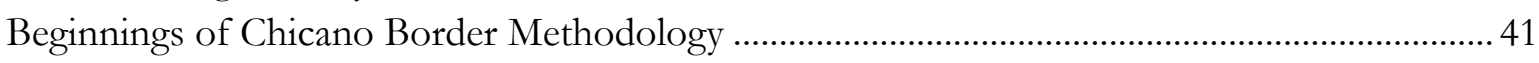

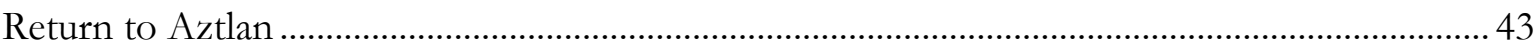

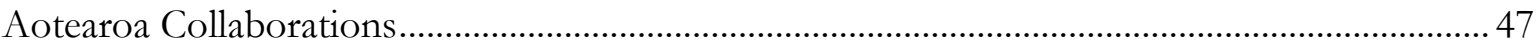

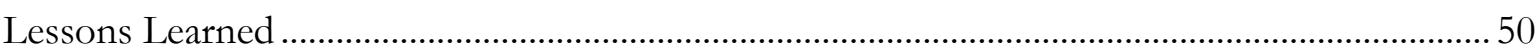

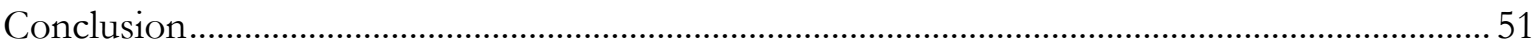

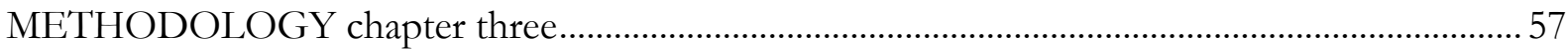

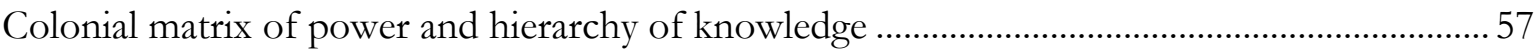

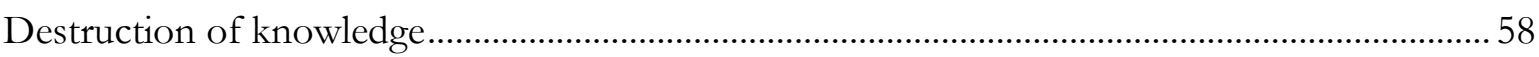

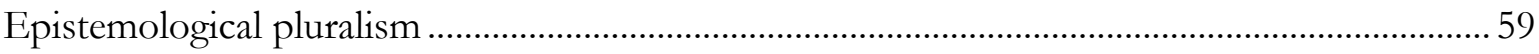

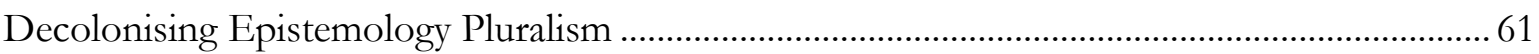

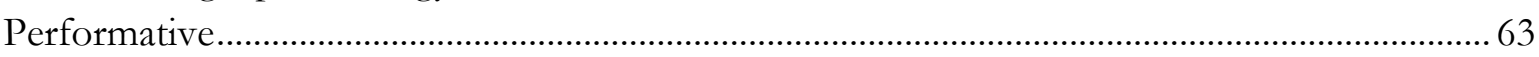

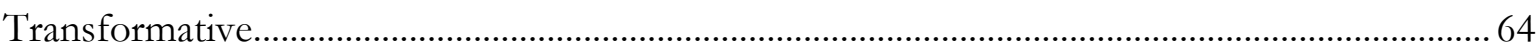

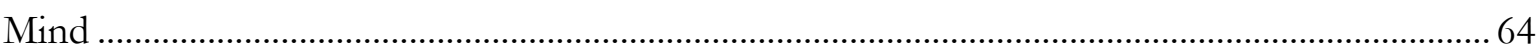

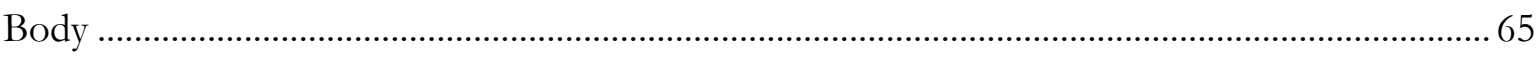

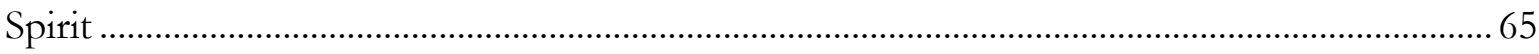

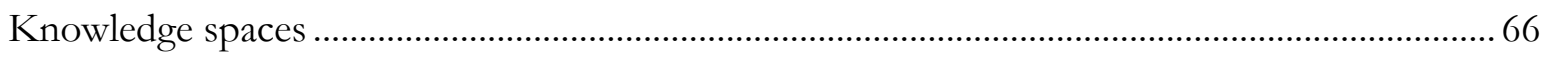

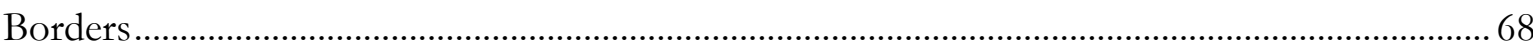

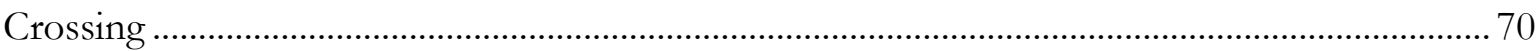

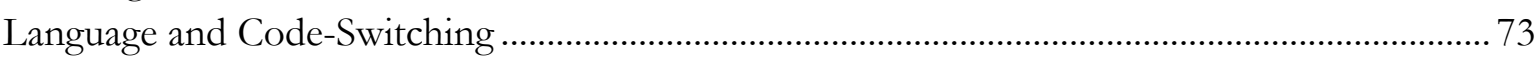

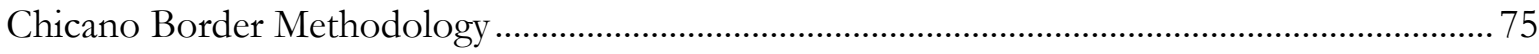

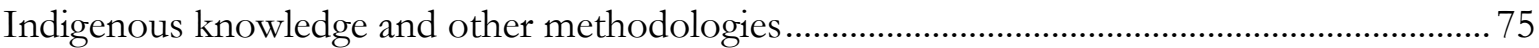




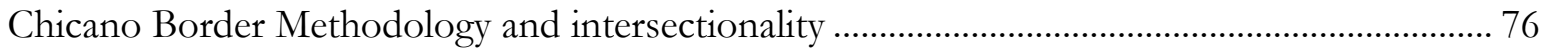

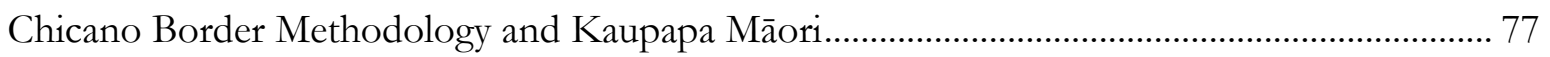

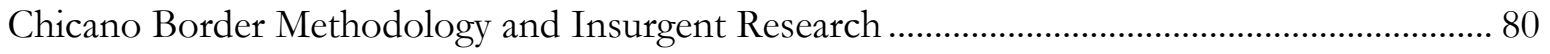

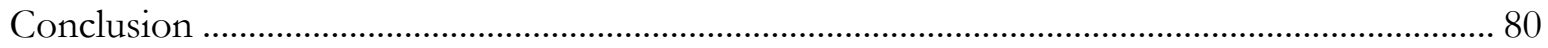

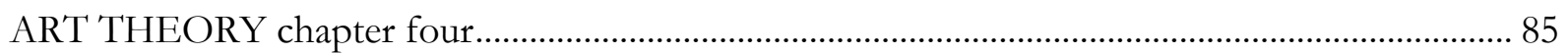

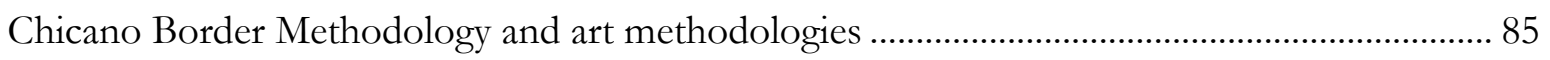

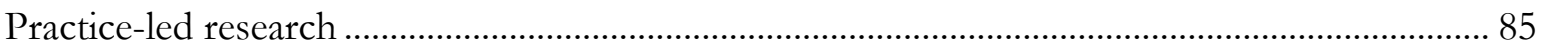

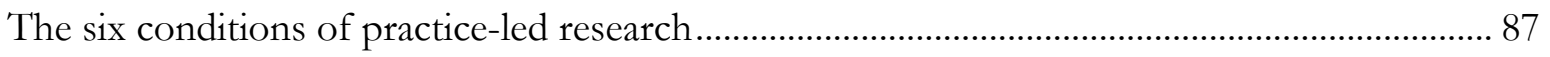

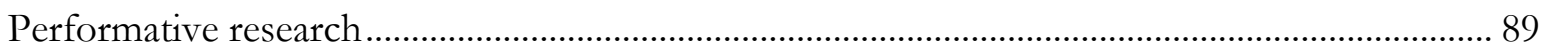

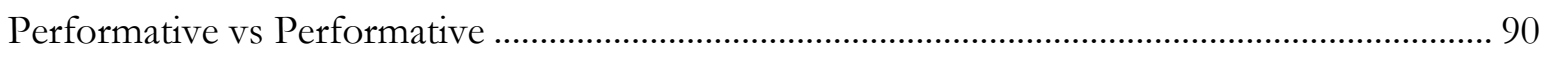

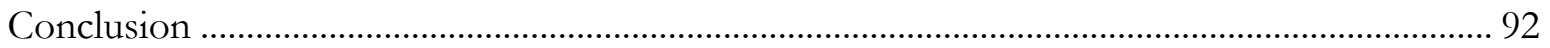

THE ILLUSTRATED CHICANO INSTALLATION chapter five ............................................. 95

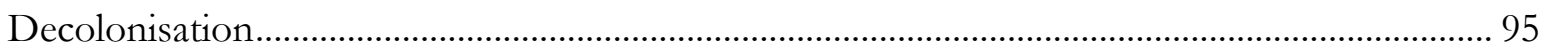

Border Art Workshop/Taller de Arte Fronterizo (BAW/TAF) .................................................. 98

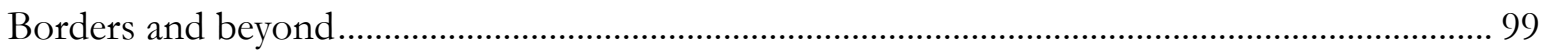

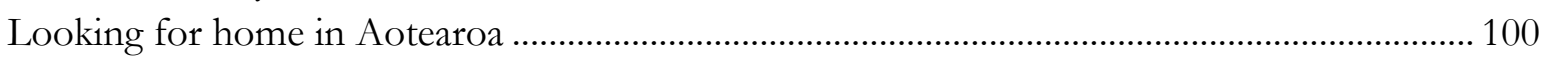

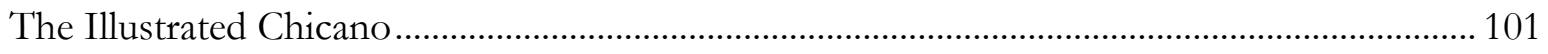

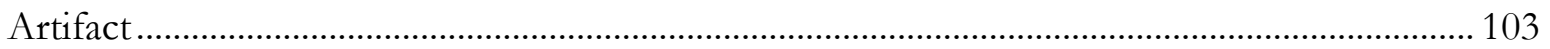

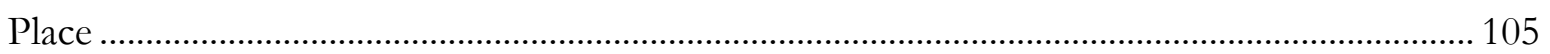

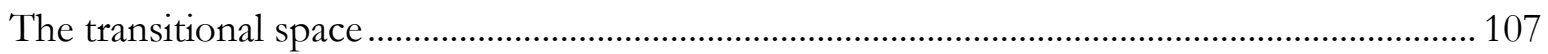

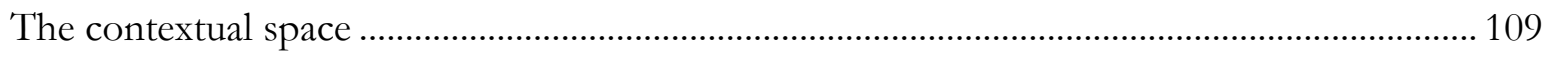

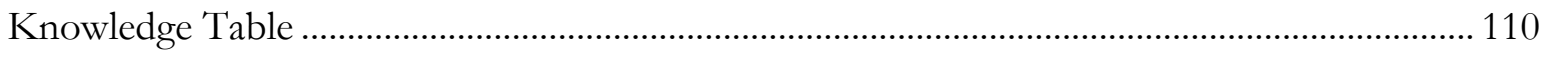

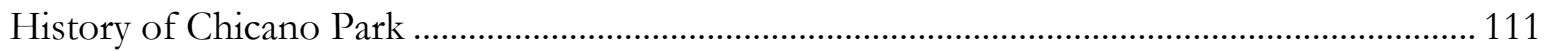

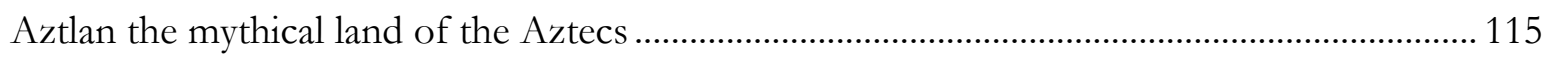

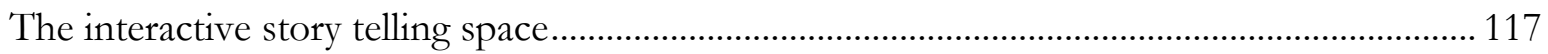

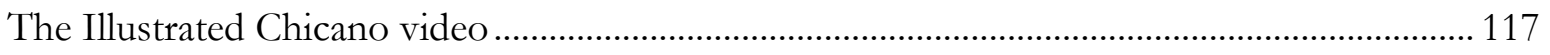

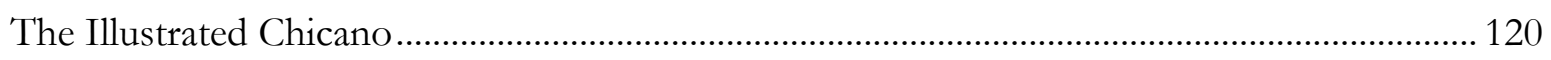

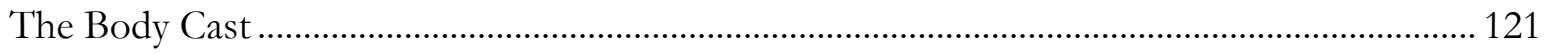

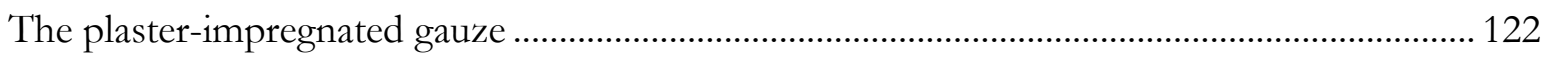

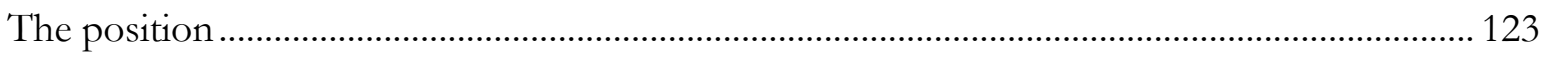

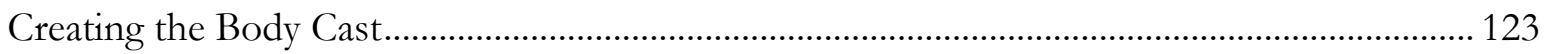

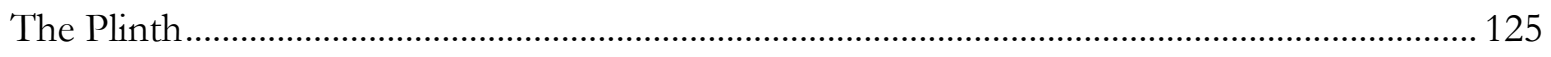

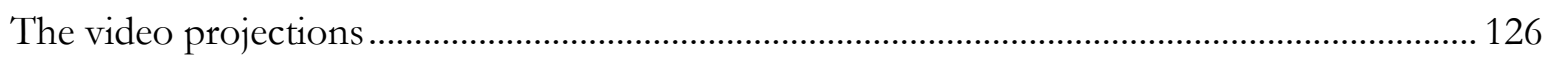

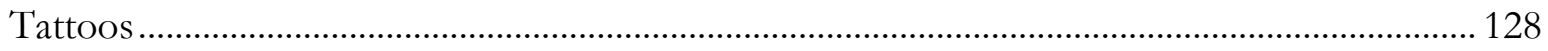

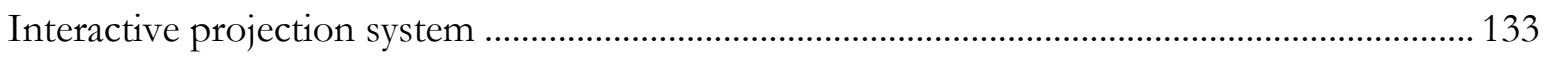

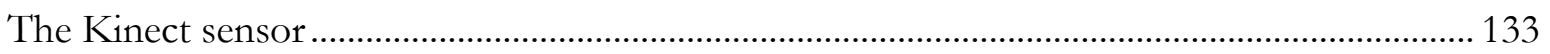

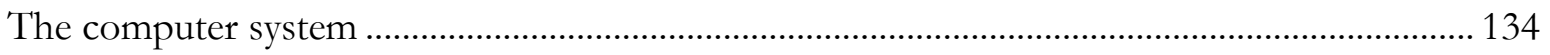

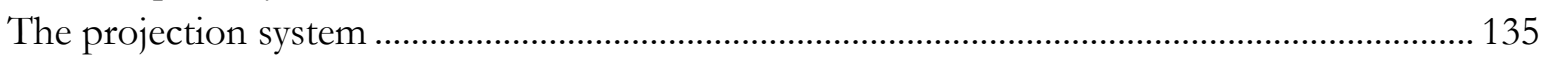

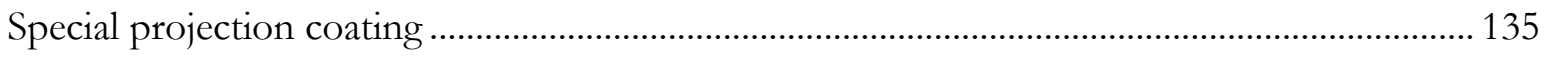

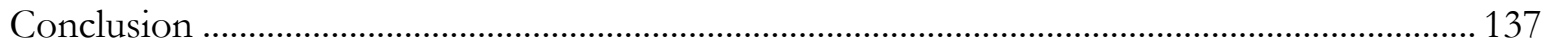

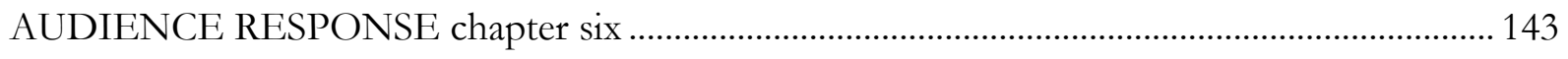

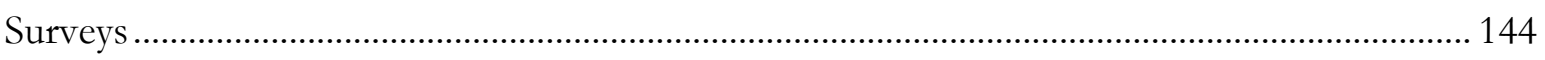

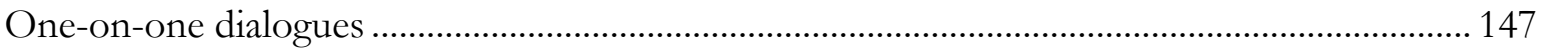




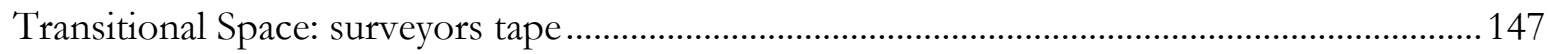

Contextual space: knowledge table and Chicano Park............................................................ 148

Interactive space: the Illustrated Chicano video ........................................................................150

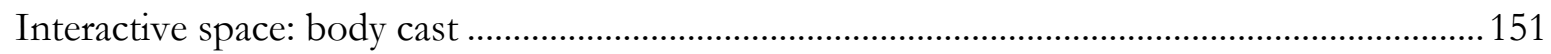

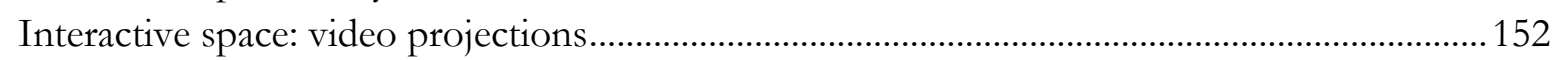

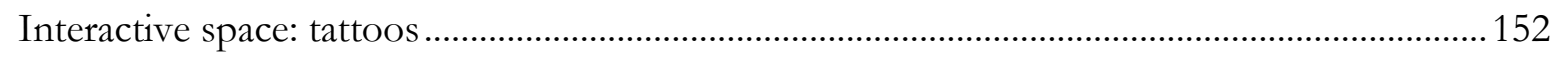

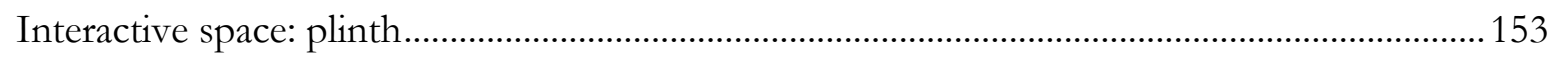

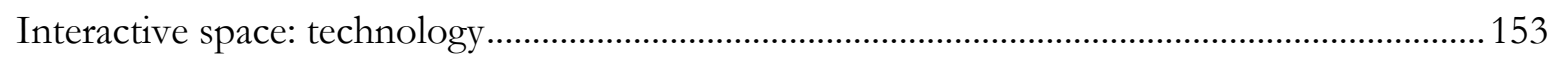

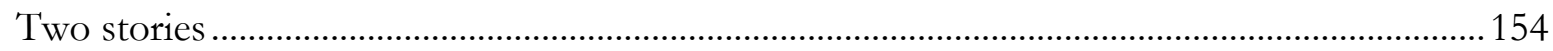

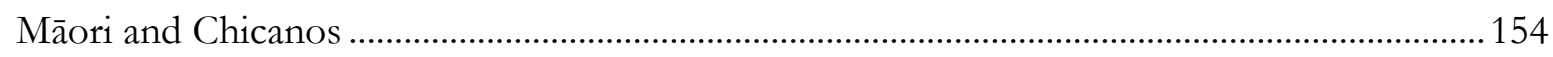

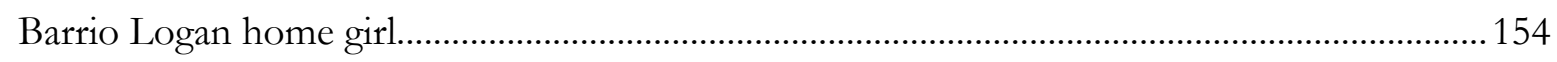

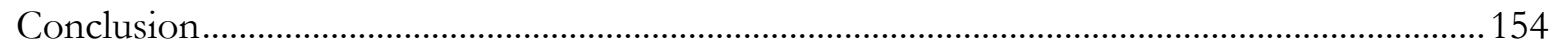

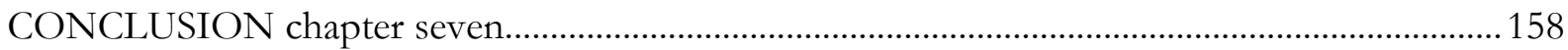

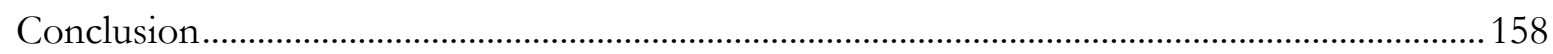

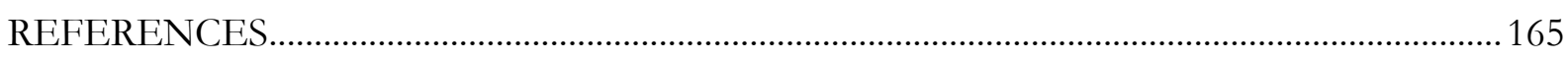

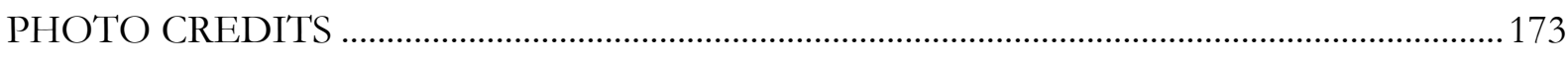

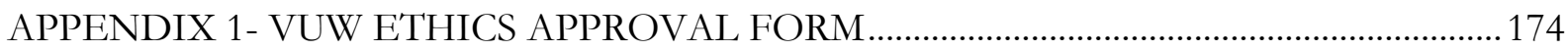

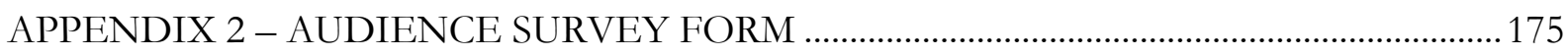

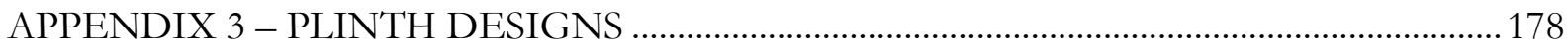

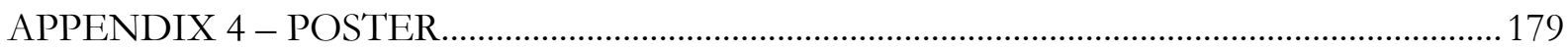

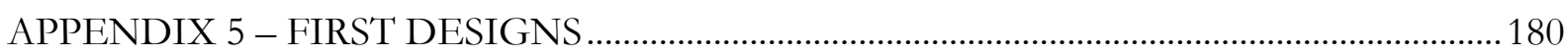

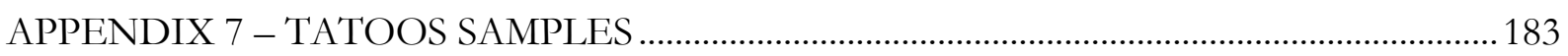

APPENDIX 8 - TESTING AT BANFF CENTRE FOR ARTS AND CREATIVITY ............ 184 
4|P a g e 


\section{Abstract}

What is Chicano Border Methodology? In my thesis I am answering this question by showing that this is a key part of my practice, and revisiting my past work and experiences to re-construct the development of this methodology. Chicano Border Methodology is a living methodology based on lived experience that is constantly in praxis, and not just theoretical. It is rooted in a knowledge space that is specific to a locality, La Frontera/US-Mexico border. I began to assemble the methodology using epistemological pluralism as the framework and modified this framework to produce a decolonising epistemological pluralism. Using the colonial matrix of power, this position questions the assumption of epistemic privilege of western knowledge production.

Using a personal narrative structure, I start the re-construction process by describing the beginnings of my decolonising process with the re-discovery of my Chicano identity. I then describe the knowledge space developed along La Frontera/US-Mexico Border and how it shows up in my art practice. Looking at the concepts of decolonisation process, practice-led research, performative research and Kaupapa Māori, I contrast and analyse the position of my Chicano Border Methodology, highlighting the differences that make my Chicano Border Methodology unique. I go on to describe and analyse how I applied this methodology to the production of The Illustrated Chicano, an art installation that looks at issues of place, home and immigration in Aotearoa New Zealand. The Illustrated Chicano, as a practical application of the Chicano Border Methodology, revealed that this methodology is robust and can be modified by Chicanos to match the specific needs of research areas, where a decolonising approach is required or beneficial to the outcome. I also explore how the community reacted to my installation built through the Chicano Border Methodology lens by documenting and analysing the community's reaction to this work. I conclude with a discussion of the significance of local knowledge spaces, the value of different methodological models, and the flexibility of a decolonising epistemological pluralism framework, such as the Chicano Border Methodology. 
6|P a g e 


\section{Acknowledgements}

I would like to thank my supervisors Ocean Mercier and Edgar Rodriguez-Ramirez. Without their advice and patience, I would not have been able to complete this thesis. I feel honoured to have both of them as my supervisors. Ocean was my guide on my journey through the explorations of my Indigeneity and western academia. Edgar, who is from Mexico, was someone who understood my struggles with the complexities of my Mexican, US and Indigenous identity. Even if he was not in the country, he was always available by email and would respond within two days. Both of them were there for me at the most critical moments of my $\mathrm{PhD}$ journey. Through the many different changes and re-directions that my thesis took, they were there to help me through it. They were very patient with me as I struggled with the transition from visual artist to academic researcher. Their questions and observations were instrumental to the strength and clarity of my thesis.

I would also like to thank Te Kawa a Māui/School of Māori Studies at Victoria University Wellington for graciously accepting an old Chicano into their Māori studies department. They treated me as whanau (extended family), giving me the space and opportunity to look back at myself, my community and my practice; to investigate where I came from and what were and are the influences that govern my life and work today. I cannot thank the staff and faculty enough for all their generosity, support and resources during this time. There will always be a special place in my heart for Te Kawa a Māui. It will always be my home here in Aotearoa.

Also, a thank you to Te Kupenga o MAI/Māori and Indigenous Scholar Network in Aotearoa. Their monthly hui, workshops, writing retreats and conferences kept me energised and focused, especially during the last two years of my thesis. It was a place where I met and made many new friends. It was a place where brown people were doing extraordinary work.

Thank you to Darrell Haddon, Tristan Rodway, Fern Pakamon Karun and Craig Thomson for helping me with the building, creation and documentation of The Illustrated Chicano. Always great to work with you guys.

And lastly a big thank you to my partner and editor for the over thirty years, Dr. Miki Seifert. We share this journey through life, exploring our past and future together while making art, writing, and dancing, trying in a small way to make this a better world for everyone. 
About the USB Memory Stick

The USB Memory Stick attached to the last page of this thesis contains an electronic version of The Illustrated Chicano: Chicano Border Methodology in Practice thesis. Also included on the USB is a five-minute video documenting The Illustrated Chicano Installation at Thistle Hall in Wellington New Zealand in October 2017. As talked about in my thesis this installation is a practical application of my methodology. 
Jntroduction 
10|P a g e 
Tihe mauri ora!

Ko mā raro te waka

Ko Paauw te maunga

Ko otay te awa

Ko Mixteca, Zapotec te iwi

Ko William Franco ahau

cahuaompaca nemi-litzli

no noicxitepozcacalachtli

no paauwteptl

no otayapan

no tlatlacah Mixteca, ihuan Zapotec

ne notoka William Franco ${ }^{1}$

Deje allí ser la vida

Mi coche es mi pies

Mi montaña es Paauw

Mi río es Otay

Mi tribu es los Mixteca, y Zapotec

Mi nombre es William Franco

Let there be life

My canoe was my feet

My mountain is Paauw

My river is Otay

My tribes are the Mixtecas, and Zapotecas

I am William Franco

1 The Nahuatl translations came from several sources http://mexica.ohui.net and the book Genaro Medina Ramos, Nábuatl (: Plymouth State College of the University System of New Hampshire, 1999). 
12|P a g e 


\section{INTRODUCTION}

I greet you and ask you to come along with me on my research journey. I have introduced myself using a pepeha. A pepeha is a Māori way of introducing oneself. It is based on whakapapa (genealogy) and tells one's story, connections to people, places, and also reveals one's relationships to the environment. It addresses questions that are important to one's identity (S. M. Mead 2001: 9). My pepeha shows the context of my thesis: I am an Indigenous from the Americas, conducting research in Aotearoa where Māori are the tangata whenua (people of the land). I have shared my pepeha in four languages: Te Reo Māori, Nahuatl, Spanish and English. This multilingually demonstrates the complexity of my multiple standing places. Aotearoa New Zealand is the last colonised country in the world and I, another Indigenous person from another colonised place, have come into this colonised place to pursue my research. My pepeha represents my past and my future. There is a Māori whakataukī or proverb, "Kia whakatōmuri te haere whakamua, I walk backwards into the future with my eyes fixed on my past"(Rameka 2016: 1). It is the same for me: I cannot see my future without looking through my past. I am pursuing my research as part of my continuing growth as an artist and tlacatl or human being in Nahuatl.

Growing up and being educated in the western academic system in Southern California, I never felt comfortable with the views that were presented in school about my culture. Chicanos ${ }^{2}$ were always described or depicted as uneducated, unmotivated, lazy Indians who spent most of our time sleeping against a cactus. I have always felt a tension from my first days in kindergarten when I was told to speak only English or be punished and ridiculed by the teacher, to now, years later when I am at university, writing my $\mathrm{PhD}$ thesis. How do I resolve this tension? How do I write a thesis from my perspective and my knowledge space? How do I write a thesis that examines this tension without sounding defensive or causing defensive feedback and rejection from the same western academy that I inhabit? How do I stay true to myself? In my research I am looking at these questions through the lens of a border crosser growing up along La Frontera/US-Mexico border. How do I negotiate the borders between my indigenous culture and academia? I am writing my thesis with these questions in my mind.

\footnotetext{
${ }^{2}$ A Chicano is an individual (usually with a Spanish surname) of Mexican parentage or ancestry who lives in the United States. Chicano is often used synonymously with Mexican-American, although many Chicanos presently make an ideological distinction between the two terms. Telodigo Sinmadera, 'The Meaning of Chicano', <http://www.vividhues.com/BSS/chicanomovement.htm>, accessed Jan 42019.
} 


\section{Chicano Border Methodology}

The subject of my thesis is the Chicano Border Methodology that I developed over my years as an artist. Chicano Border Methodology is a methodology that uses a de-colonising epistemological pluralism to do research along La Frontera/The US-Mexico border that is inclusive of different ways of knowing. This thesis captures my journey to explore and excavate my art practice to lay bare the driving mechanisms that lay beneath the surface of my art and give rise to my Chicano Border Methodology. I will describe my history as a Chicano artist and the conditions that enabled the theorising of this methodology. Until immigrating to Aotearoa New Zealand in 2007, I had not unpacked and reflected on my art practice. I just produced artwork. It was here in Aotearoa that I encountered Kaupapa Māori and I will talk about how Kaupapa Māori influenced the development of my methodology. This thesis will tell the story of how I was able to understand the theory that underpinned my art practice and articulate this understanding as a new methodology called Chicano Border Methodology.

I will discuss why I chose to explore and develop a decolonising epistemological pluralism as the framework to build my Chicano Border Methodology. Briefly epistemological pluralism is a methodology that uses several points of view or knowledge spaces to solve problems in a holistic manner that benefits the whole rather than the part or individual. In chapter three I will detail how epistemological pluralism's flexibility encourages the inclusion of Indigenous knowledge and other methods for doing research. Performance theorist Miki Seifert finds that a de-colonising epistemological pluralism "seeks to dismantle the colonial matrix of power and the dualisms that underpin the hegemony of western knowledge and casts a critical eye on power relations as they manifest out in the world and as they reproduce themselves inside individuals" (Seifert 2011: 7).

What Seifert is saying is that by using a de-colonising epistemological pluralism as a framework we can help break up the centuries of western colonial dominance, the colonial matrix of power or coloniality (Quijano 2007), of the Americas. We can do this by changing the way we view knowledge spaces. Since knowledge is power, by changing the way we view and create knowledge, we are able to rethink our views on the way power is structured and how the power affects the individual. By using a de-colonising epistemological pluralism as a framework, I was able to create a Chicano Border Methodology that helps to envision a change in the power structures that are present along La Frontera of the U.S. and Mexico. 
Using my Chicano Border Methodology, I created The Illustrated Chicano, an art installation that recognised and honoured the local Indigenous knowledge, while referencing western art practices, Chicano culture, Indigenous knowledge and art as research, to present a work that represented my ongoing investigations into my Chicano identity and culture while living and working in Aotearoa New Zealand.

I had four reasons for using a de-colonising epistemological pluralism for this project. First, my methodology is about helping to change the status quo by showing alternative ways of knowing to counter the positivist structures in academia. By using a de-colonising epistemological pluralism I am expressing a new way to de-centre the western hegemony (C. Walsh 2007: 225) or "epistemic sovereignty" (Stephen Healy 2003b: 693) that is at the centre of western academia. Second, my methodology is showing that there is more than one way of being in the world. This way is just as valid as the western way of being in the world, and it is a way that is inclusive of other ways of knowing such as Indigenous knowledge. Thirdly, my methodology shows the validity of different forms of reality such as the fluid reality of living and working along La Frontera/Mexico-US border. And fourthly, understanding that universalism does not leave much space for other ways of viewing the world and is challenged to recognise Indigenous knowledge as a valid source of knowledge production, I want to help create a space where using a decolonising epistemological pluralism can be one of the norms rather than the exception within the academy.

\section{Personal narrative}

This thesis will be presented in a critical personal narrative form. "Narrative inquiry has been used by social scientists since the early 1970s. Personal narratives have assumed various forms in social science research---case histories, personal interviews and content analysis (Richardson, 1990; Maines, 1993; Ewick \& Sibey, 1995; Van Maanen, 1988)"(cited in Aguirre 2005: 149) . By using a critical personal narrative, I will be able to articulate the multitude of layers that I, a Chicano $^{3}$, encounter as I explore the complexities that are at the core of my identity as a Chicano. As Denzin states, "Critical personal narratives are counternarratives, testimonies, autoethnographies, performances texts, stories and accounts that disrupt and disturb discourse by exposing the complexities and contradictions that exist under official history" (Denzin et al.

\footnotetext{
${ }^{3}$ In Spanish language ' $\mathrm{o}$ ' generally denotes masculine and 'a' denotes feminine. Chicano usually refers to both genders but is often written as Chicana/o when there needs to be a distinction between genders. Some Chicanos also see themselves as Indigenous/Native American.
} 
2008a: 13). These critical personal narratives "embody a critique of prevailing structures and relationships of power and inequality in a relational context"(Burdell and Swadener 1999: 21). I am exploring the prevailing structures and relationships of power along La Frontera/US-Mexico border and how my Chicano identity fits within this discourse. As a Chicano, who grew up along La Frontera between two nation states, I am physically and metaphorically a border crosser. I am not of a single mindset. By writing in a personal narrative format, I can explore these relationships. As Denzin finds in the writing of Mutua and Swadener, "Critical personal narratives and counternarratives explore the intersections of gender and voice, border crossing, dual consciousness, multiple identities, and selfhood in a...post-colonial and post- modern world"” (Mutua \& Swadener cited in Denzin et al. 2008a: 13).

This process of investigation, using my Chicano Border Methodology and creating an installation that reflects my Chicano identity and its presentation in Aotearoa, is well-suited to the use of critical personal narrative as the waka or vehicle to carry my thoughts and observations during this time.

As a Chicano, I am writing my thesis from my Chicano male perspective. However, I am not representing, or claiming to represent, the views of all Chicanos. I am also not representing the views of Chicanas. However, in my thesis, I drawn upon several Chicana writers who have inspired me and who have articulated concepts that support my argument. ${ }^{4}$ My personal narrative articulates what is means to be a Chicano along the La Frontera, specifically the border area between San Diego, California in the U.S. and Tijuana in Mexico. La Frontera is a volatile and explosive crossroads politically, culturally and economically where the policies of these two nation states collide every day. La Frontera with its constant ebb and flow of humanity across its borders is the setting for my personal narrative but the context in which I am writing my thesis is in Aotearoa New Zealand.

As an Indigenous person from North America, looking back across the water roadways to my homeland and culture, I am looking at the impact my self-imposed diaspora has had on my work. I am examining my relationships with other Indigenous people here in Aotearoa, predominately Māori, who have graciously accepted me into their department at Victoria University's Te Kawa a

\footnotetext{
${ }^{4}$ Gloria Anzaldua, Ana Maria Alonso, Ana Castillo, Cherrie Moraga, Cristina Beltran, Elisa Facio, Irene Lara
} 
Māui/School of Māori Studies. In this thesis, I will be examining the effect of being the "Other" (Tomaselli 2008) in a nation state which has its own Other already. Where does my Otherness fit in with the localised Other? We are both the "Other" in a colonised island at the end of the world. ${ }^{5}$ What does an Indigenous person become when they move to from their locality to another locality where they are part of the colonisation process? How do we negotiate these borders and bridge the gap between two colonised cultures? These are some of the questions that I have asked myself since my arrival in Aotearoa and that I investigated and is the subject of The Illustrated Chicano installation.

\section{Structure of Thesis}

My thesis is constructed around my personal metaphor of re-construction. This re-construction metaphor comes from my personal history of growing up and working in my father's cabinet shop. I always tell people that I grew up under a table saw playing in the sawdust. I worked in construction, remodelling interiors, and building and moving houses, from the age of twelve until my late twenties. In this metaphor, Chicano Border Methodology is the house, and in this thesis, I am Re-constructing the process of building this house. I do not have to de-construct the house since I already know everything about it and I am not looking to change the meaning of the house. I am just sharing my process of how I built it.

My re-construction process starts at the genesis of my Chicano Border Methodology which is when I started my own de-colonisation process. Since I am using a decolonising epistemological pluralism as the framework for my methodology, I chose to focus on those factors that are relevant to decolonisation, such as decolonising myself, decolonising research, decolonising the academy. In my thesis, I look at decolonisation through several different lens, one of them being the colonial matrix of power in which gender is one of the hierarches, where men are privileged over women. In this particular project, I chose not to explore gender because it is a topic that I believe would require its own investigation to do it justice. ${ }^{6}$ Therefore, it is beyond the scope of this thesis. Also, I chose not to look at how my work is perceived by the western contemporary

\footnotetext{
${ }^{5} \mathrm{Oh}$, by the way did you notice what I did a couple of sentences back during my discussion about othering? It may have slipped by a little too fast, "in a colonised island at the end of the world" in a cartographical way, I just othered Aotearoa New Zealand. We are so used to doing this, that is it easy for us to "other" entire nations without realizing it at the time.

${ }^{6} \mathrm{I}$ am aware of the discussions of the fluid ideologies of identity within the Chicanx and Latinx groups. However this, too, is outside the scope of my thesis which is focusing on my Chicano Border Methodology.
} 
art world since the western art world is not looking at my work through the lens of decolonisation, their critique or acceptance or non- acceptance my work would have no relevance to my thesis.

I will talk about this in depth later in chapter five. It was my de-colonisation process that was the catalyst for the development of my Chicano Border Methodology. If I had not de-colonised myself, I would not have had the knowledge that enabled me to create my methodology. To be clear, I could have gone through the de-colonising process and not become a Border Artist who developed a Chicano Border Methodology. Instead I could have become an activist in another capability within my community, but I chose the path of a Chicano Border Artist.

In the following chapters I discuss what I have learned during this re-construction and what were some of the key moments that helped shape Chicano Border Methodology, my world view and artist practice over the years. As a Chicano artist working in Aotearoa New Zealand, I discuss and analyse my previous collaborations in the US where the seeds of my methodology were sown, starting when I was called a naive artist ${ }^{7}$ along La Frontera. From 2007 when I arrived in Aotearoa, I examine my collaborations with Māori artists. These collaborations with Māori artists in Aotearoa added fertile soil which nourished the growth of my practice as a Chicano artist. I finish with the present time in 2018 and how I was able to apply this same methodology that I have been developing for the last thirty years in collaborations to a solo work here in Aotearoa.

I also discuss my experiences in the academy, from my formal education in and rejection of western art practices at California Institute of the Arts (CalArts) to the writing my thesis at Victoria University of Wellington. It was here in Aotearoa at Te Kawa a Māui/School of Māori Studies where my research coalesced. It was here in Aotearoa that I began assembling the pieces of my methodology. It was here in Aotearoa that I formulated my argument for a Chicano Border Methodology.

In chapters one and two, I begin the re-construction of my journey starting with my Chicano identity and my art history. In chapter one, I discuss my Chicano identity. I explain the origins

\footnotetext{
${ }^{7}$ Naïve art is simple, unaffected and unsophisticated—usually specifically refers to art made by artists who have had no formal training in an art school or academy. https://www.tate.org.uk/art/art-terms/n/naiveart
} 
and history of Chicana/os and how my life along La Frontera influenced my perceptions of the world around me. I explain several different terms relating to my Chicano experience, such as mestizo and border artist, and where they came from. I also discuss the complexities of being a Chicano along La Frontera, how I dealt with the issues of living at the intersection of two nation states while trying to maintain connection to my cultural roots. I describe how I am viewed by people from both sides of the border and by my Native Americans brothers and sisters. And I discuss what makes the Chicano living along La Frontera different than the rest of the Chicanos in the US and Mexico.

In chapter two, I re-construct my art history and major influences, which include The Border Art Workshop/Tallér de Arte Fronterizo (BAW/TAF). From the artists of BAW/TAF I learned about Border Consciousness, installation art, performance art and art-as-activism. I revisit my first collaborations with Chicano artist David Avalos, Native American performance artist James Luna and American artists Deborah Small, Louis Hock and my lifetime collaborator Miki Seifert. I analyse what I learned about collaborations across cultures from these experiences. This time period is when the seeds of my Chicano Border Methodology were sown and would grow along with my art practice. As I delve into my work and collaborations, such as Ramona: Birth of a Mis-cege-NATION, To My Sister's Husband, Quecholly-or how I learned to stop worrying and love weapons of mass destruction, No Olvidado/Don't Forget Me, I outline how I began developing my Chicano Border Methodology. I talk about my experience in art school in 2004 where I was exposed to and started my investigations into western concepts of art. After I finished art school, I did my MFA in Aotearoa New Zealand and began to write more about my process. These insights into western art practices were integrated into the work I created in Aotearoa. I incorporated my deeper understanding of my process into my collaborative artwork in pieces such as Nò Näianei and He rawa tona kakahu/She Wore A Becoming Dress. This chapter ends with my decision to do my doctorate and use this methodology on a solo piece called The Illustrated Chicano.

In chapter three, I begin the re-construction of my methodology which is a set of principles and guidelines that grew out of the localised knowledge space at La Frontera/US-Mexico border. I am articulating this methodology so that Chicano and other researchers can undertake decolonising research. One of the key benefits of this methodology is its adaptability that allows other researchers to adjust this methodology to their particular circumstances and projects. I start by looking at the origins of the western concept of universality and how colonisation has influenced the university systems in the world. I then discuss the concepts of knowledge spaces and a Pluri-versity system, alternatives to this system, as put forward by academics, such as 
Boaventure de Sousa, Ramon Grosfoguel, Enrique Dussel and David Turnbull. This discussion leads to the concept of epistemological pluralism and its openness to using different knowledge spaces within its research model. I follow this path to the de-colonising epistemological pluralism developed by performance theorist Miki Seifert. I explain how I used a de-colonising epistemological pluralism as a methodological framework to create my Chicano Border Methodology.

Following this re-construction of the research frameworks I explored, I move to a discussion on how I developed my Chicano Border Methodology and how this methodology fits with decolonising epistemological pluralism. I look at how I reconfigured epistemological pluralism and applied some of the concepts and ideas of Seifert's de-colonising epistemological pluralism (Seifert 2011: 40) to a specific locality, La Frontera/US-Mexico border, and created a new methodological model that I have called Chicano Border Methodology. This methodology uses the difference influences and structures from the border, such as code switching, border thinking, and the colonial matrix of power to name a few.

In chapter four, I discuss and compare how my Chicano Border Methodology, which I applied to the creation of The Illustrated Chicano, comes from a different lineage than the other dominant visual arts methodologies, such as practice-led research and research-led practice that are similar but different. The former stresses practice first and the latter stresses research first. Both are inclusive of different ways of gathering knowledge. I, however, come from an Indigenous perspective - specifically, a Chicano perspective from La Frontera- not an art perspective. I also discuss how I use "performative" to mean performing knowledge whereas practice-led research practitioners use performative as a performance or putting on a performance as part of the research process and/or outcome (Gray 1996) (H. Smith 2009).

In chapter five, I re-construct how I applied my methodology to my research project, The Illustrated Chicano. I show how this methodology takes in account different elements that are usually not referenced in other methodologies. I talk about how I use this methodology to look not only at the physical space of the work but the cultural and spiritual space the work inhabits. For example, I describe how I integrated and honoured the local ways of knowing and created a temporary space that did not impinge on the local community but instead invited the local community to participate with the work. I describe how I searched and found common elements such as the multi-coloured surveyors tape that connected Chicano and Māori cultures to the work. 
In chapter six, I document the community response to the installation by presenting results from a simple survey and the notes gathered during one-on-one dialogues with the community who witnessed the installation. I look at my expectations for the installation and what the visitors experienced and see if my expectations and the visitors' experiences were similar.

In my concluding chapter, I reflect on the major findings of my research and summarise how my research sits within the academic system and how my research can be a bridge between a University and a Pluri-versity system. I conclude with my thoughts on the viability of the Chicano Border Methodology and how the Chicano Border Methodology can be used as a model for research in other research environments, especially those that have an Indigenous component. 
22|P a g e 


\section{Chíano \\ chapter one}


24|P a g e 


\section{CHICANO chapter one}

In this chapter, I will examine where I, as a Chicano, sit within the cultural and political landscape of the Americas.

\section{Chicano defined}

"We need you to accept the fact that Chicanos are different"(Anzaldúa 1987: 107).

A critical part of the re-construction of my methodology, as outlined in my introduction, is my identification as a Chicano. When I was in my early teens-a time of coming of age, a time for rebellion and exploration, a time to forge my own identity, a time to find my place in the worldduring the turbulent times of the late sixties and early seventies, during the rise of the Chicano and Black Power movements, the Chicano movement was at full strength in my hometown of San Diego. Historic Chicano Park, which I will talk about in more detail it in Chapter five, was founded during this time. It was during this time that I began calling myself a Chicano.

Over the years there have been many different definitions of what is a Chicano. I find that Laura Elisa Pérez's explanation resonates the most with me and how I identify as a Chicano. The term Chicano "came into widespread usage in the 1960's as part of the Chicana/o civil rights movement. Unlike the ethnic description 'Mexican American,' these terms signalled a decolonizing political ideology critical of anti-Mexican sentiment and melting-pot ideals of assimilation into Eurocentric culture" (Pérez 2007: 12). The Chicano movement spread to all parts of the US and there are people who identify themselves as Chicano in most states in the US. For my research, however, I am looking at the group of Chicanos who live at La Frontera/USMexico border; more specifically the San Diego/Tijuana Frontera where I grew up and lived for 35 years.

Within the identity politics of North America, the Chicano sits in a unique position. As Rafael Pérez-Torres says in his book Mestizaje, "while the racial order in the United States has at times forced a uniform racial status on Blacks, Asians, and Native American, Chicanos and Chicanas remain distinct among people of colour by virtue of their more ambiguous legal relationships to

\footnotetext{
8 The Spanish word Mestizaje does not easily translate into English. Its meaning and significance have been debated for centuries, since colonisation of the Americans by European powers began. Its simplest definition is "mixing." Stefanie Wickstrom and Philip D Young, Mestizaje and Globalization: Transformations of Identity and Power (University of Arizona Press, 2014) at ix.
} 
race" (Pérez-Torres 2006: xii). This ambiguity has created a self-consciousness within myself when searching for a place within US racial context. To use a Māori word, my whakapapa (genealogy) leads me back to the Zapotecs in the Southern Mexican state of Oaxaca and the Mixtecas in the state of Guerrero. In the greater context of the Americans, I am a Native American. I am an Indigenous person of North America. My family has a long cultural history. My culture has a history that goes back several thousand years before the "discovery" by western European countries in 1492. Both of my cultures have their own language, Zapotec and Mixtec. Before the Spanish arrived, the Aztecs were in power and Nahuatl became the lingua franca, or the trade language. Nahuatl is a group of languages of the Uto-Aztecan language family and has been spoken in central Mexico since the seventh century. Varieties of Nahuatl are spoken by 1.5 million Nahua peoples and is one of 63 Indigenous languages Mexico recognises as lenguas nacionales (national languages)(Terborg et al. 2006). I am from one of the many groups that travelled up and down the Americas, who settled in the area that is now La Frontera/US-Mexico border.

\section{Border history}

This artificial border was created by the European colonisers of the Americas, as they fought for control of the Americas. The fighting ended with the US-Mexican War and the signing of the Treaty of Guadalupe Hidalgo in 1848 (MacDonald 2001: 368). The treaty added an additional 525,000 square miles to United States territory, including the land that makes up all or parts of present-day Arizona, California, Colorado, Nevada, New Mexico, Utah and Wyoming. This treaty created the border that exists today. This border, 2,000 miles long and about 200 miles wide, runs from the Pacific coast along the bottom of California, Arizona, New Mexico, and Texas and ends at the Gulf of Mexico. This border, created by these two new nation states, quickly became a contested place since it was created without consideration of local Indigenous groups who had lived in this area for hundreds of years. Indigenous tribes, like the Tohono O'odham (Cadava 2010; Luna-Firebaugh 2005) whose land is bisected by this border, are still fighting with the US and Mexican governments over the right to cross the border on their ancestral land unencumbered, without the need of a passport or special documents. They are fighting for their right to travel to sacred sites to perform rituals for their community as well as to visit family members who live on the other side of the border. Some of the Tohono O'odham commute daily to work on the other side of La Frontera. They have lived on this land for hundreds of years. In her statement to the United Nations Secretariat of the Permanent Forum on Indigenous Issues, Chairwoman Vivian Juan-Saunders of Tohono O'odham said: 
The Tohono O'odham Nation strongly supports the rights of our people to travel between our communities and is vehemently opposed to any limits placed on this right. We have historically rejected the militarization of our border and will continue to work with all relevant federal and state agencies to seek relief for our members (LunaFirebaugh 2005: 363).

La Frontera has become a focal point because it is one of the few places in the world where first world and the third world collide every day. To keep the third world (Mexico and its neighbours to the South) from encroaching upon the first world (US), the United States is in a continual process of re-enforcing the border between the two countries, building walls and patrolling it with technology and thousands of armed border guards.

Living in the middle along La Frontera, not wanted by either side Mexico or the US, are the Chicanos. The uniqueness of this environment and history is what separates Chicanos from other Native Americans.

\section{US Chicano history}

Throughout their histories, both the US and Mexico have had different ways of dealing with their Indigenous populations. The US tried to eliminate the Native Americans by killing them or putting them on reservations to make way for greater western expansionism, taking Native land through the western court system by writing thousands of treaties that were never intended to be honoured in US courts (Porter 1999: 107-08).

The US government's policies were focused on the assumption that Native Americans were a dying race who would eventually disappear (Strickland 1985-1986). This policy continued into the twentieth century. One example of this is:

On February 8, 1887, Congress ratified the General Allotment (Dawes) Act, making it legal for the U.S. government to reduce the size of American Indian reservations to accommodate homesteaders and to assimilate indigenous nations in the west. The Dawes Act (General Allotment (Dawes) Act, 1887) principally stated that "the President of the United States... hereby is authorized whenever, in his opinion, any reservation or part thereof of such Indians is advantageous for agricultural and grazing purposes, to cause said reservation ... to be surveyed [taken over and cut into pieces] and resurveyed if necessary" (Black 2007: 185) 
Another example is on June 18, 1934 the US government passed the Indian Reorganisation Act that determined who could say they are Native American and who couldn't (Kelly 1975). This became known as the blood quantum law. This law adopted the use of blood quantum as a method to gage the 'Indian-ness' of a person or a tribe before they could apply for government funds. The government's goal was to reduce the number of Native Americans recognised by the US government until there were none. This law had larger consequences than identifying who was a Native American. This law destabilised the Native American communities for years by pitting tribe against tribe as they tried to prove that they were 'Indian enough' to receive limited government funds to survive. This law, along with other laws by the US government, left Native Americans as the poorest of the poor with the worst health care and standard of living of all US citizens (Holm et al. 2010).

\section{Mexico Chicano History}

On the other side in Mexico, the government tried to assimilate Indigenous into a new national identity called Mestizo/a, viewing Indigenous as part of the past but acknowledging their importance as building blocks of modern Mexican nationalist society (Alonso 2004). The Oxford Online Dictionary translates Mestizo/a to mean mixed race (in Latin America), a person of mixed race, especially one having Spanish and Indigenous descent. With the influx of Europeans into Mexico, during and after the colonisation, Mexico realised early on that miscegenation, or race mixing, was a big part of the country's identity and decided that miscegenation "had to play a more productive role than merely marking the decay of the social foundation" (Pérez-Torres 2006: 5) and went on to celebrate miscegenation" as a way of "conceiving a homogeneous national identity out of a heterogeneous population"(De Castro 2002: 9). Spearheaded by the Partido Revolucionario Institucional (PRI) party of Mexico, Mestizaje was introduced into the national consciousness where it "served to effectively erase the presence of a contemporary Indigenous identity in Mexico, relegating the Indian to the mist of a tragic and oblivious past" (Pérez-Torres 2006: 6). One of the major contributors and architect of the topic of mestizaje was Jose Vasconcelos, whose 1925 essay "La Raza cosmica: Mision de la raza ibero American Race"

\footnotetext{
${ }^{9}$ In the context of Aotearoa, I understand that miscegenation is a loaded term and its use is frowned upon, but "Mexico and Brazil have embraced miscegenation as part of their official discourse surrounding national identity. By contrast, Andean nations view the mestizo as either an individual actively denying his own ancestral roots or aspiring to shed himself of a benighted and disempowering primitive past" Rafael Pérez-Torres, Mestizaje: Critical Uses of Race in Chicano Culture (U of Minnesota Press, 2006) at 7.
} 
helped solidify the notion of the positive aspects of race mixing in Mexico. Vasconcelos states in his essay that the many different races of the world "tend to intermix at a gradually increasing pace and [will] eventually give rise to a new human type" (Vasconcelos 1925). Vasconcelos called this new type of humanity "la raza cosmica" (the cosmic race). His essay was very influential in the development of the new Mexican national identity based on the Mestizo.

\section{Mestizo/a in the twenty-first century}

Over the past few decades Chicanos have started to re-embrace and re-interpret the Mexican word Mestizo. Gloria Anzaldúa talks about "Mestiza consciousness" in her book Borderlands La Frontera the New Mestiza (Anzaldúa 1987). In her book Territorializing the nation and 'integrating the Indian', Ana Maria Alonso examines Mestizo and Mestizaje (Alonso 2004, 2005) from a Mexican identity perspective and Rafael Pérez-Torres takes us through a critical analysis of Mestizaje and its connections to Chicanos in Mestizaje: Critical Uses of Race in Chicano Culture (Pérez-Torres 2006). To paraphrase Pérez-Torres, this re-engagement with the Mestizo/a and the identification with the Indian body, which was used in the nineteenth century to dispossess the Mexican in the United States ${ }^{10}$, was used to re-establish claims for identity and place for the Chicano/a in the twentieth century. Up until this point Chicano/as had been portrayed by Indigenous and nonIndigenous as Mestizos, having given up their indigeneity. Chicanos/as have now become Natives. This gave birth to a Chicano/a critical subaltern identity with other Indigenous groups throughout the Americas (Pérez-Torres 2006: 9).

During my artistic journey, I was actively seeking my Indigenous connections in my visual art practice and my research. My current research has helped me reaffirm this position that a Chicano is a Native American. It was a very interesting revelation for me when I found this quote by Perez-Torres, “That the same logic used to disempower nineteenth-century MexicanAmerican populations was used to empower those same populations a century later is one of the ironic legacies inherited by the mestizo body and its role in the ever changing strategies for effecting political viability" (Pérez-Torres 2006: 9). My own growth as a Chicano artist has followed this same path over the last thirty years.

\footnotetext{
${ }^{10}$ even though as part of the treaty with Mexico, Mexican Indigenous were to be considered white, it was easy in the Southwestern US for settlers to ignore this and see the Mexicans as Indians making it easier to take away their land.
} 
For myself and my own research, I see the term Mestizo as just being mixed. Mestizo (mixed) is not just a biological or nationalist or political term to me but is the embodiment of my existent as a Chicano. It encompasses all of these definitions and then some. My existence as a Chicano is played out at La Frontera in an area Chicana writer Gloria Adzaldúa refers to as a:

...liminal space where the border people, especially artist, live in a state of 'nepantla' (ne pant la). Nepantla is the Nahuatl word for an in-between state, that uncertain terrain one crosses when moving from one place to another, when changing from one class, race, or sexual position to another, when traveling from the present identity into a new identity (Anzaldúa 1993).

Mary Louise Pratt calls these places "contact zones", that is, social spaces where disparate cultures meet, clash, and grapple with each other, often in highly asymmetrical relations of domination and subordination, such as colonialism and slavery, or their aftermaths as they are lived out across the globe today (M.L. Pratt 2007: 7). Contact within these zones de-centre established social order and create a place of transculturation.

\section{Dual and tri-consciousness}

The La Frontera/US-Mexican border is a place not just of dual consciousness as conceptualised by Black sociologist W.E.B Dubois (Dubois ([1904] 1995)) which situates dual consciousness as a burden. Dubois finds that dual consciousness is "this sense of always looking at one's self through the eyes of the others, of measuring one's soul by the tape of a world that looks on in amused contempt and pity"(DuBois cited in Taliaferro 1998: 90) However, at La Frontera dual consciousness can be a positive tool of resistance as first expressed by educator Denise M. Taliaferro:

...double-consciousness need not only be a burden, but might be a virtue as well. And it need not be only a situation of blackness, it can also describe, albeit differently, the experiences of... any of America's oppressed. Not only that, but we should all seek to understand it and those who have escaped the pain of splitting soul should surrender to the possibility. (Taliaferro 1998: 90-91)

Seifert finds that “Taliaferro's 'virtuous' double-consciousness is an apt tool to dismantle our inner colonisation, our individual colonial matrix of power-double-consciousness as a personal 
tool of decolonisation"(Seifert 2011: 21). I agree with Seifert and find that double-consciousness is not a limited way of being.

Further, we can have more than two consciousnesses. For example, I have a tri-consciousness worldview. As a Chicano at La Frontera, I navigate between the colonial worlds of Mexico, the US, and my Indigenous world. In the liminal space of La Frontera, I inhabit each of these worlds. This is a place of resistance and dominance within the mind and the body, a place of control and chaos. One side sees us as Mexican, the other as US/American. We are of the land but no longer live on our ancestral our land. We have not moved but the world has moved around us. The Chicano Mestizo body was born of imperial desire at the signing of the Treaty of Guadalupe Hidalgo in 1848 and continues to mature.

Like other Chicanos, I use what the Europeans have brought and I make it my own. Through transculturation, we manifest our identity through our clothing (zoot suits), our cars (lowriders), our music (Tex-Mex, Chicano Rock, Rancherita), our films (El Norte, Like Water for Chocolate, Stand and Deliver, and La Familia), our writing (Borderlands, A Century of Chicano History, Whos the Indain in_Azttlan?), our religious festivals (Dia de Los Muertos) and our food (burritos, tacos). I resist but I am submissive. I am the future of the Americas but I am a constant reminder of my troubled colonial past. My language is a fusion of all three worlds: English, Spanish, and Nahuatl. I live in the borderlands where relationships of conquered/conqueror, invader/invade, past/present, before/after become the medium out of which culture, language, society, and consciousness get constructed (Mary Louise Pratt 1999). I am a Chicano Border Artist.

\section{Chicanos and Native Americans}

As a Chicano I am dispossessed of my homeland. Yet I am disconnected from my Native American cousins who live north of La Frontera and who do not see me as Indigenous or Native American but as part of the Spanish Empire's troubled past that includes the Indigenous genocide in the Southwestern United States. But to say this, is to simplify the issue. It would require another thesis to examine this complex situation and find a small sense of clarity. As an example of the complexity of the Chicano-Native American relationship, when the US signed the Treaty of Guadalupe Hidalgo, "the US government owing to the provisions of the 1790 Naturalisation Act, made ethnic Mexicans legally white. However, socially they were not given the privileges of whiteness and faced de facto segregation" (Chávez 2002: 2). By reason of the 1790 Naturalisation Act all Native Americans who were under Spanish rule became white US citizens. 
Native Americans under US control were never given this legal option. This racial ambiguity is one of the major areas of controversy between Chicanos and Native Americans. Just because our Indigeneity is on the other side of the line drawn in the sand does not make us less Indigenous.

I remember when I was growing up along La Frontera, my mother, who was mixed, would tell us that we were Spanish, not Mexican or Indígena (Spanish for Indigenous). When the US census would come around, my family would always be confused. Which box do we check? We were told to check white but we weren't white. There was never a brown box. Most times we would check 'other'. We would go shopping across the border in Tijuana, Mexico and I remember that I did not look like the people there. Instead I looked like Indígena who were begging for food or money on the street or Indígena who were darting between the slow-moving cars as we crossed the border back into the US trying to sell chicle (chewing gum) to the people in the cars. I remember as a small kid asking my mom for some money so that I could buy some chicle from Indígena or just to give it to them. I would try to talk to them, but they spoke only Nahua and I only spoke Spanish and English. I always felt bad that we could not communicate because I felt that I had a connection with them. When I was older and would travel through Mexico, I always made a point to connect and spend time with the local Indigenous groups that I encountered along the way, sharing food, stories and drink. This is where I felt most at home.

As a Chicano, I embrace my Indigenous, Native American, Zapotec and Mixteca roots. I make a point not to forget our shared colonised past with my Native American cousins. Like our Native American cousins, the world continued to move around us as we were encircled by the West, but we all are still here.

To summarise this chapter, I examined the origins of the term Chicano, the history of the creation of the modern-day US-Mexico border area, shown the complexity of La Frontera and the Chicano experience, how both countries the US and Mexico relate to the Chicano and how complex the relationship is between Chicanos and other Native Americans. In the next chapter, I will continue the re-construction process as I trace the path of my visual arts practice. I will examine the lessons learned from different people and projects that I have worked with and on, that helped to shape my Chicano Border Methodology. 


\section{Art 愐istory \\ chapter two}


34|P a g e 


\section{ART HISTORY chapter two}

To re-construct the development of my decolonising Chicano Border Methodology, I need to go back and review some of my key artworks. Each piece I discuss contains an element that was influential to the development of the methodology. I begin with a brief introduction of how I became a Border Artist.

\section{Early years: Border Consciousness}

After attending at San Diego City College and Cox Cable public access, where I learned video production, my partner Miki Seifert and I began our own production company, Speckled Gekko Productions in 1987, and began to produce our own experimental shorts. At this time, I wanted to contribute to the Chicano political discussions. The Border Art Workshop/Tallér de Arte Fronterízo (BAW/TAF) was at its apex in 1988. I interviewed several of the artists involved in the Workshop for documentation for the Centro Cultural de la Raza, where they were artists-inresidence. The artists I interviewed were David Avalos, Guillermo Gomez-Peña, Sara-Jo Berman, Michael Schnorr and Victor Ochoa.

These artists provided an opportunity for me to learn about border consciousness and the political mechanisms that shaped and governed this area of the Southwestern United States. At this point in my development, I had had no real understanding of the art world, how the border area functioned, or how the BAW/TAF was addressing it. I was just living at the border. From these artists, I learned how the BAW/TAF had a strong commitment to art-as-activism. They recognised the transformative power of art. Their goal was to facilitate dialogue between the United States and Mexico.

The experience working alongside these artists continues to influence my work today. Most of my work deal with the concept of borders, whether they are physical, economic, or cultural borders between countries and people or whether they are mental, spiritual or subconscious borders within our own minds. My work has been about the borders that govern the way we engage with the world around us. Guillermo Gomez-Peña, a performance artist from the DF Mexico City, has said that "the border is no longer located at any fixed geopolitical site. I carry the border with me, and I find new borders wherever I go" (Foster 2002: 49). In a way, this is true but for someone who was born and raised on La Frontera, there will never be another place like La Frontera/US-Mexico border. It is a place, a way of being. It is where I developed my triconsciousness. It will always be special and it will always be home. 
Using what I learned from the artists of the BAW/TAF and other groups such as the Royal Chicano Air force and ASCO, I started to create video art. The first few years I created videos around the policies of the US and Mexican governments and the effects they had on the people along the La Frontera. One of the most important lessons I learned from this group of artists was not to create work that only critiqued the policies I was looking at but to create work that would stimulate public discussion and dialogue. The goal of my videos was to shed light on a problem that was affecting the world around me.

\section{On a Mission}

Early on I was fortunate to be asked to collaborate and create the video components for installations of some established installation artists in San Diego. In 1988, I shot and edited a video for the installation called On a Mission for an exhibition called California Mission Daze. The project addressed the proposed sainthood of Father Junipero Serra (1713-1784), the founder of nine of the 22 California Catholic missions. It was conceived by a group of local artists. The group consisted of: two local Luiseno Indians; James Luna, James Asuna; two Chicanos: William Franco, David Avalos; two European-Americans: Deborah Small and William Week.
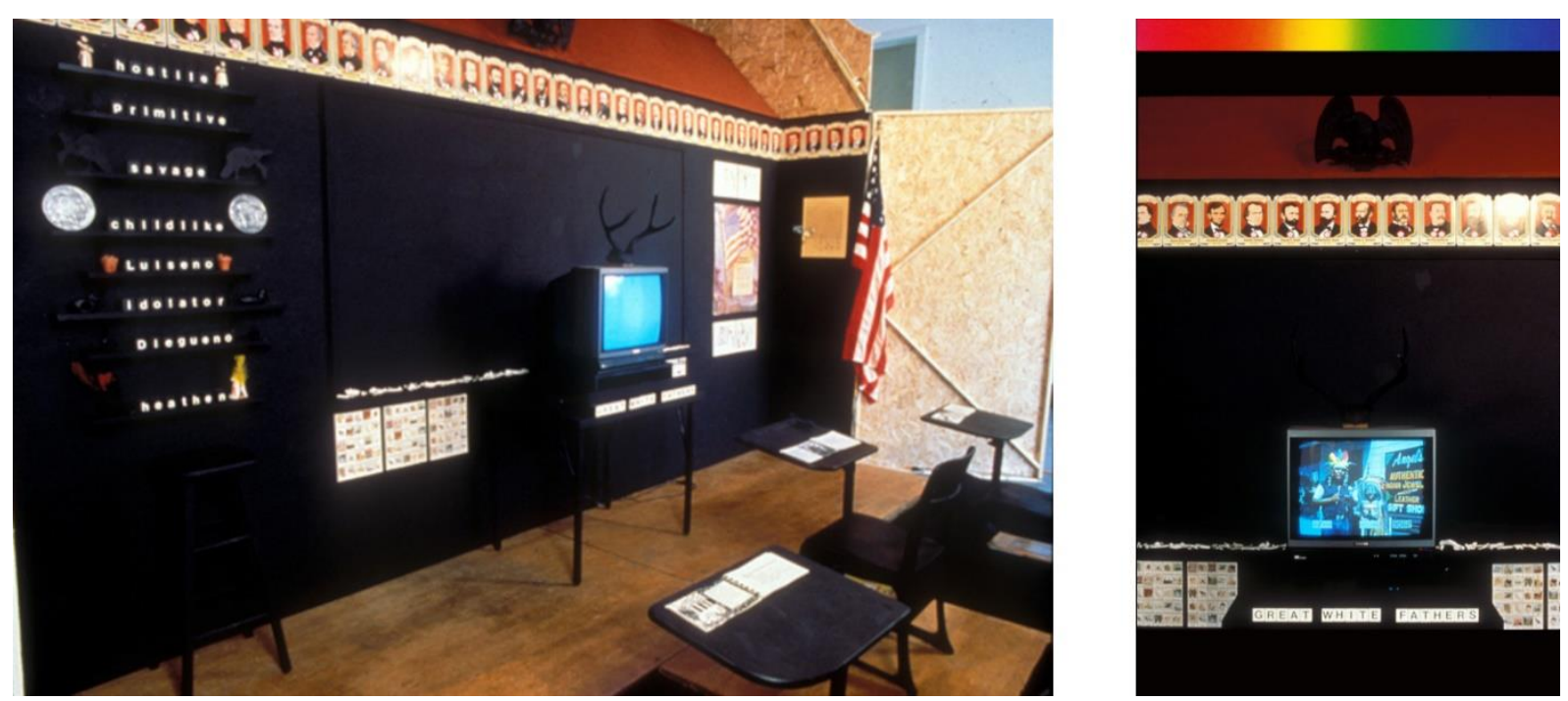

Image 1 On a Mission, (left) wide shot (right) detail (Photo by David Avalos)

The reason I mentioned the racial and gender make-up of the group is because, thinking back in retrospect, it was the first time that I had been made conscious of the fact that I was working in a cross-cultural and cross-gender environment. We were headed toward the multicultural 90s. Everyone in the group was college-educated visual artist, except William Week, who is a historian, and James Asuna and I. All the members of the group were aware of their position within the context of the work and in relation to the subject matter of the project. We self- 
identified as Chicano, Native American, white feminist and white male. We were mostly unified in our vision of what we wanted the work to say and were focused on that outcome. The group was great in the fact that they all helped to educate me on the complexities of working in a multiracial and multi-gender group. They understood that I did not possess the knowledge that they had learned at university but they valued the life knowledge that I had. I watched, listened and learned from everyone in the group. This first encounter with the complex process of working in a multi-racial and multi-gender group collaboration was a great education for me in how the cross-cultural, cross-gender collaboration process worked. This experience gave me the tools that I still use today when working on a collaborative project.

My contribution to this work was to shoot and edit the mini-mocumentary and testimonial by James Asuna, a Luiseno Indian. This video was to be shown on a monitor inside the installation. We looked at the history of the local Indigenous population in California through the eyes of the missionaries. The video that we made examined and critiqued the Spanish priest's version of the events that took place during the period that the mission system was created. The video looked at how the missionaries made slaves of the local Indigenous populations, forcing them to build the missions while converting them to Christianity. If they resisted, they were severely punished or killed. Several of the missions have mass graves on the mission grounds with small plaques with estimates of how many California Indians are buried there. Their deaths became part of the California and American genocide (Phillips 1974). To be recommended for sainthood in the Catholic Church, you had to have performed at least two miracles. Our group could not find any evidence of any miracles during his time in California. On a Mission and the exhibition called California Mission Daze was well-received by the community and brought wider attention to the history of Father Junipero Serra and colonisation in California. It wasn't until the 23 September 2015 that Father Junipero Serra was canonised by Pope Francis. The canonisation of St. Junipero was the first such ceremony to be celebrated in the United States rather than at the Vatican (Wooden 2015).

\section{Ramona: birth of a mis-ce-ge-NATION}

In 1991, I collaborated on another installation where I created a video called Ramona: birth of a misce-ge-NATION for the installation Ramona's Bedroom by David Avalos and Deborah Small. 


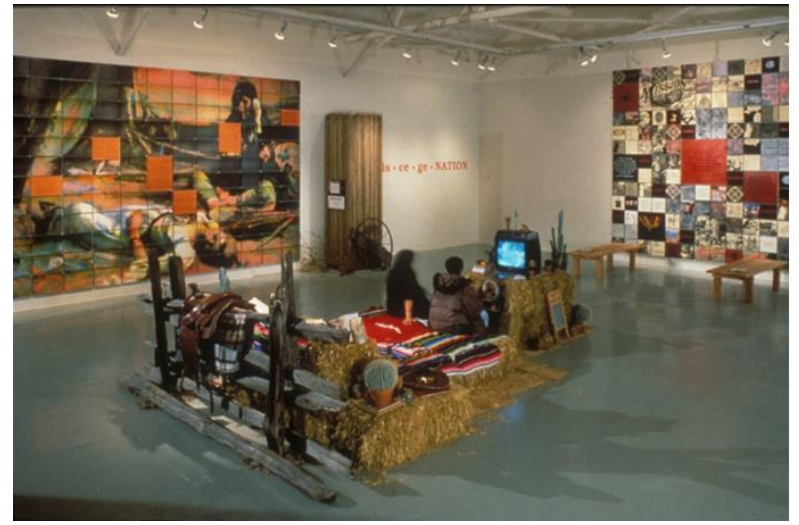

Image 2 Ramona: wide (Photo by Deborah Small)

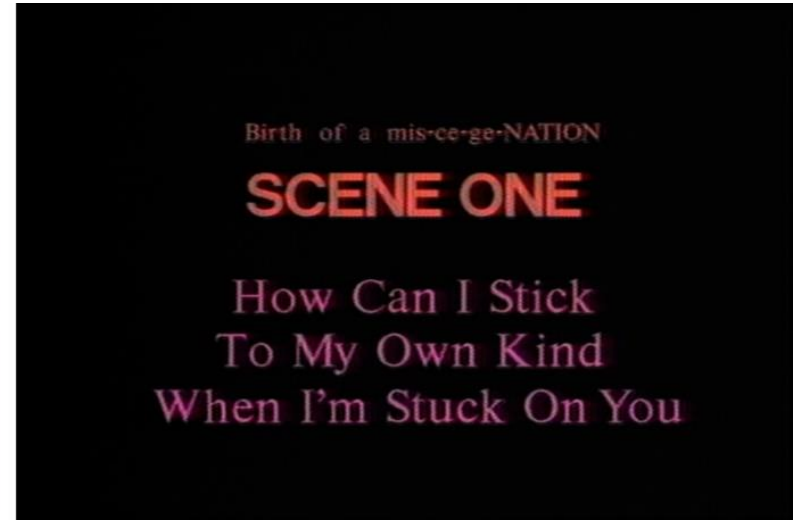

Image 3 Ramona (Still by William Franco)

This time it was Seifert and Small, two white feminists, and David and I, two Chicanos, working on this video. We explored the issue of racial hierarchy and mixed-race relationships and how they were portrayed in Hollywood films. We researched films produced in Hollywood that had cross-racial relationships to uncover what their messages about cross-racial relationships were. During the Chicano and civil rights movements of the 1960s and 1970s, there was a growing awareness of the influence that Hollywood movies had on people's perceptions of race. There continues to be a growing body of work that is looking at race in Hollywood movies. From a Native American perspective, Hollywood's Indian: The portrayal of the Native American in film by Peter Rollins (Rollins 2011), is a good example of this ongoing research. For a detailed list of older articles and publications, there's Gretchen M. Bataille's The Indian in American Film: A Checklist of Published Materials on Popular Images of the Indian in the American Film in the Journal of Popular Film (Bataille and Silet 1976) and Additions to "The Indian in American Film" (Bataille and Silet 1980). Professor Micaela Diaz Sanchez gives a nice description of the Ramona's bedroom installation:

The installation Ramona's Bedroom consisted of a bed made of hay bales covered with Mexican and Indian blankets. Across from the bed was a television 'shrine' running a series of film clips from the movies West Side Story, Duel in the Sun, Flaming Star (starring Elvis Presley) Last of the Mobicans, A Touch of Evil, Giant, Ramona, Broken Lance. On the walls were representations of 18 th century castas (caste) paintings from Mexico, depicting persons born of racially mixed parents. (Sanchez 2010: 117)

Referring to the video component of the installation, Ramona: Birth of a mis-ce-ge-NATION, Small states, "The video demolishes representations of the so-called tragedy of racial mixing" (Callery 1991). Avalos puts the installation into perspective in relation to current American history and how Hollywood and American society still view miscegenation: 
The installation and video present a long history in the Americas of miscegenating families. In 'Flaming Star,' Elvis Presley plays a Kiowa 'half-breed' who experiences an identity crisis at the climax of the movie. In 'Last of the Mohicans,' Uncas and Cora leap from a cliff, as death is portrayed as the only outcome for lovers of mixed races, for whom there is 'no place'. 'misce-ge-NATION' deals with our traditional notions about race, which are based on purity and hierarchy (Callery 1991: 1).

Avalos and Small were great collaborators. Working with them reinforced what I had learned in my previous collaborations as well as deepening my understanding of working in a collaborative space. Questions I didn't know how to articulate were answered in an organic manner through the long discussions as we worked on the project, making decisions on the look and feel of the video as we went along. For instance, how do you have constructive conversations on difficult topics such as class, race or gender relations with someone from another class, race or gender? How to, as Seifert would say in her thesis twenty years later, "perform the hyphen"(Seifert 2011: 1) on a personal level? At this point it was very informal with no explicit answers. What I started to realise was that everyone brings a different sense of awareness with them to the table. This sense of awareness could make things difficult or easier depending on the person. I was learning how to listen to the person in front of me.

Working on these projects served as my apprenticeship, learning the craft of art installation, observing and participating in the process of group collaboration and becoming aware of the power of activist art. In these collaborations, we had to develop a space where other voices and options could be heard and respected, where different ways of knowing the world was accepted and acknowledged, where everyone felt free to express their views. This was not an easy space to create. It took a lot of work and dedication from everyone involved.

Early on during one of our collaborations David Avalos told me an old Mayan phrase, In Lak'ech, translated to Spanish it means "Tu es mi otro yo", in English, "You are my other self". It says so much using very few words. It's a way of looking at the world around me and how I interact with the people I encounter in life. It is the spine of my being and the core of my methodology. Yucatec Maya linguist and philologist Domingo Martínez Parédez translated In Lak'ech,is from Maya writing to mean: 
That manner of conceiving Absolute Being and its mathematical manifestation, as the being of all and of none, avoided those odious racial divisions and had the admirable consequence that the Maya thinker arrived at the genial conclusion that you, is the other me, in the expression In Lak'ech, you are my other self.(Cited in Facio Elisa and Irene 2014: 29)

The importance lessons of collaboration between genders and race and principles like In Lak'ech, 'You are my other self', encountered in these earlier experiences would end up being important in my Chicano Border Methodology. They are concepts and methods that I try encourage while working on de-colonising projects. And from an epistemological point of view, these methods help to foster the creation of new knowledge.

\section{Art can change society}

What I learned from these collaborations and what made them work was the fact that we all had the same goal and the vision: to make art to change society. As Avalos said about the collaborators of California Mission Daze, “There's a belief in this group that art can affect people's consciousness in a way that has concrete benefits for society" (Leval 1992: 72). To give an example of our belief that art can change society and show how other artists were working in the same space, I will describe a piece called Welcome to America's Finest Tourist Plantation created by Elizabeth Sisco, Louis Hock and David Avalos in 1988. The piece addressed the plight of undocumented and low wage workers in San Diego, CA. This work had a national effect on the public's perception of the tourist industry in San Diego, whose slogan at the time was "Welcome to America's Finest City".

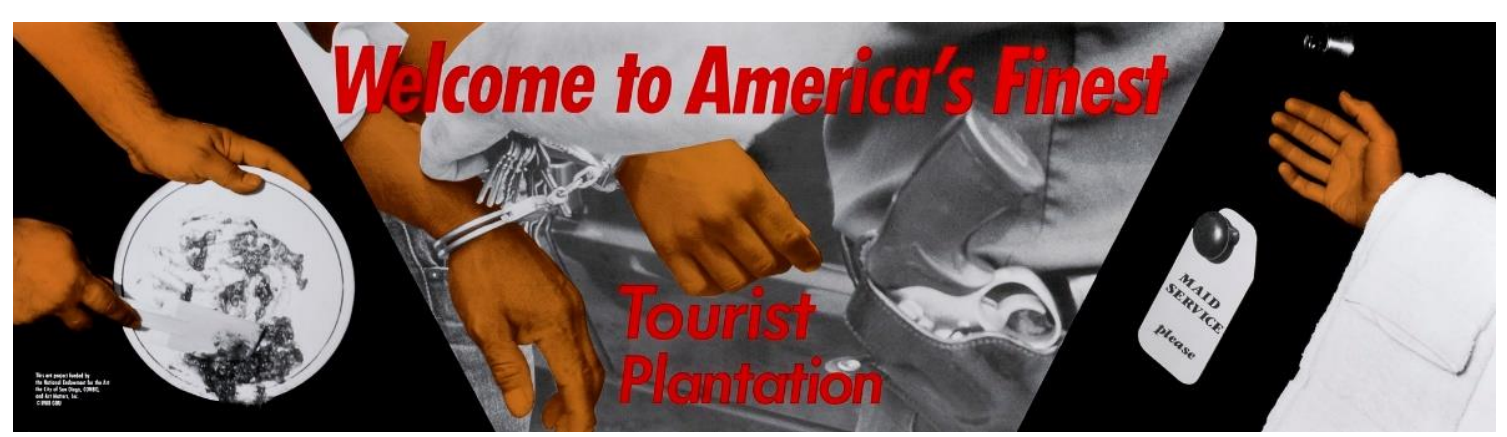

Image 4 Welcome to America's Finest Tourist Plantation (Photo Smithsonian American Art Museum)

The Combined Art and Educational Council of San Diego (COMBO), a San Diego arts organisation, was given a grant to produce a series of bus posters celebrating the city during the 1988 Super Bowl which San Diego was hosting. The Super Bowl was a great publicity 40|P a g e 
opportunity for a city that was promoting itself as a tourist destination around the world to reinforce its image on a world stage.

The Bus Poster Project, as it was called, asked local artists to submit work that reflected life in San Diego. The poster commented on the plight of undocumented and low wage workers in the San Diego and was displayed on 100 San Diego Transit buses.

The $21 \times$ 72-inch poster utilizes both word and image. A set of hands, handcuffed by a Border Patrol agent, is framed to the left diagonally by a dishwasher's hands, scraping off a plate; to the right by a single hand, reaching toward the placard "Maid Service please." On the one hand, only the disembodied hands in these images are "colored"-brown. On the other hand, in red, subvertising business as usual, the found language of the piece's title contributes to its appropriation of San Diego's self-promotion as 'America's Finest City" (Carroll 2017: 205)

The poster was written about in newspapers around the country, profiled on the national TV network news and had articles written about it in major art journals and is now part of the Smithsonian American Art Museum collection. The controversy over the poster shed a national light on the hidden reality behind America's finest city and ignited a heated debate about the issue. While it did not result in a massive change in society, it stimulated debate which could affect people's perceptions of the issue. Even if it changed the perceptions of just one person, it was successful. As Buddhist philosopher Daisaku Ikeda has written, “A great human revolution in just a single individual will help achieve a change in the destiny of a nation and, further, will enable a change in the destiny of all humankind" (Ikeda 2004: vii). This project is a good example of how others were using art to address social issues along La Frontera. Their work still influences my art practice.

\section{Beginnings of Chicano Border Methodology}

After these projects, I went on to continue collaborating with Seifert. At this point, we were still novices at collaboration. The more we worked together, the more we developed our methodology. Our process was that one of us would come up with an idea or topic for a project. We would explain the idea to the other, why we wanted to work on it and why it was important. If the other liked it, our next step would be to individually research the area around the topic and come back and talk about it again. We would listen to each other's ideas on why this was the best way to execute the concept. We would do this until we settled on what we both felt was the best 
way to produce the work. These negotiations were always performed with an understanding that acknowledged and took in account differences between gender and culture, and served as informal laboratories that helped shape my methodology.

We went on to collaborate on work that dealt with other areas of social concern. We investigated childhood sexual trauma. We contributed to the development of a new style of video storytelling, the video poem. To My Sister's Husband was a combination of stills, live action video and spoken word. The poem was about a woman who was sexually abused by her sister's husband when she was ten years old and her journey to come to terms with that history. This video poem was screened as part of the American Film Institute's 13th National Video Festival in 1992 and was part of a tour that travelled the US.

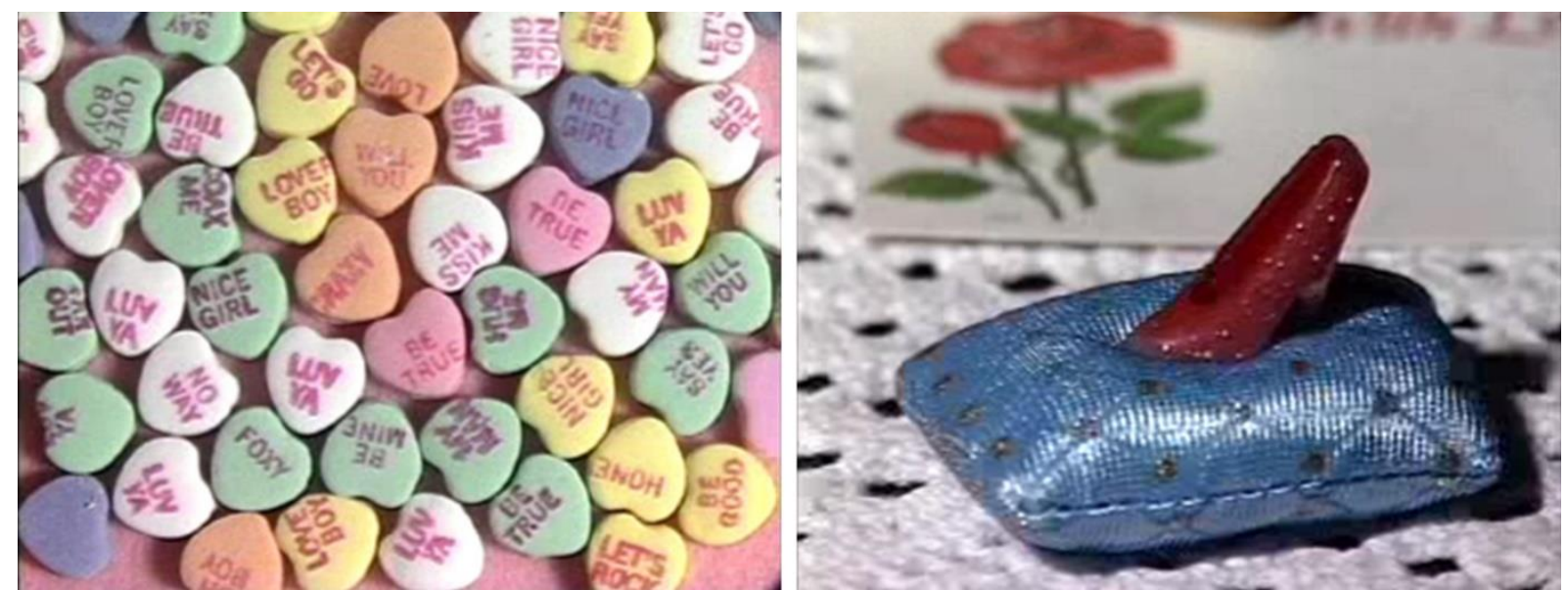

Image 5 To My Sister's Husband (left) Candy Hearts (right) Red Slipper (photo William Franco)

We looked at the AIDs epidemic in Odi's story, a story about a young woman's journey to get tested for HIV, as told through the visual device of a video diary. This video was a precursor of today's reality shows.

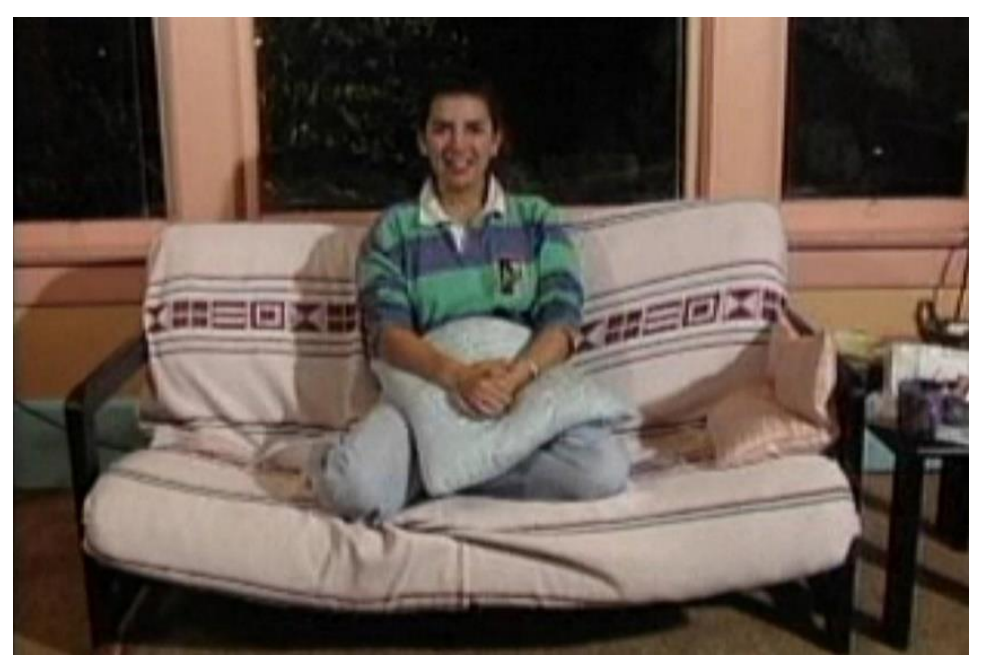

Image 6 Odi's Story (Video still by William Franco) $\mathbf{4 2 | P}$ a g e 


\section{Return to Aztlan}

In 2001, after a decade of working in video production, I returned to my Chicano roots. Seifert and I began to create installations with video components. For the first three years, we created offrendas (altars) as part of the public Dia de los Muertos (Day of the Dead) celebrations held by Art in the Park in the mixed race, working class neighbourhood of Highland Park, CA. Art in the Park sponsored these public celebrations of this Indigenous/Mexican holiday. Anyone could come and build an offrenda. It was art grounded in community, family, culture and history. It was also connected to the temporality of life and shunned the commercialisation of art; the altars were up for only one night and they weren't for sale. They were offerings (Seifert 2011).

While most offrendas were for family members, friends, or public figures, our public Dia de los Muertos offrendas pushed the bounds of the offrenda/altar movement of the previous two decades. The altar movement was a movement led by Chicano artists and contributed to the recovery of a spiritual dimension in contemporary art and culture (Leval 1992: 75). Chicano artists were reconnecting with their Indigenous spirituality by creating offrendas that reflected their cultural roots and interpretations of historical and contemporary icons. They were creating their own mythology by re-interpreting religious icons forced upon them by the Europeans and making them their own.

We pushed the boundary of this offrendas movement by crossing the cultural border into the world of digital technology by reconfiguring the iconography of the Dia de los Muertos traditional offrenda, which was based on Catholic and Indigenous iconology, constructed with materials such as wood, sugar, paper, cloths, fruits and vegetables, and inserting new media such as computers, video projections and sound into the offrenda and addressing contemporary issues. For example, The Virtual Altar (2001) addressed the bombing of Afghanistan, which included a laptop that played a PowerPoint presentation about the anticipated effects of the US bombing on the civilians in Afghanistan as assessed by human rights organisations working in the region. 


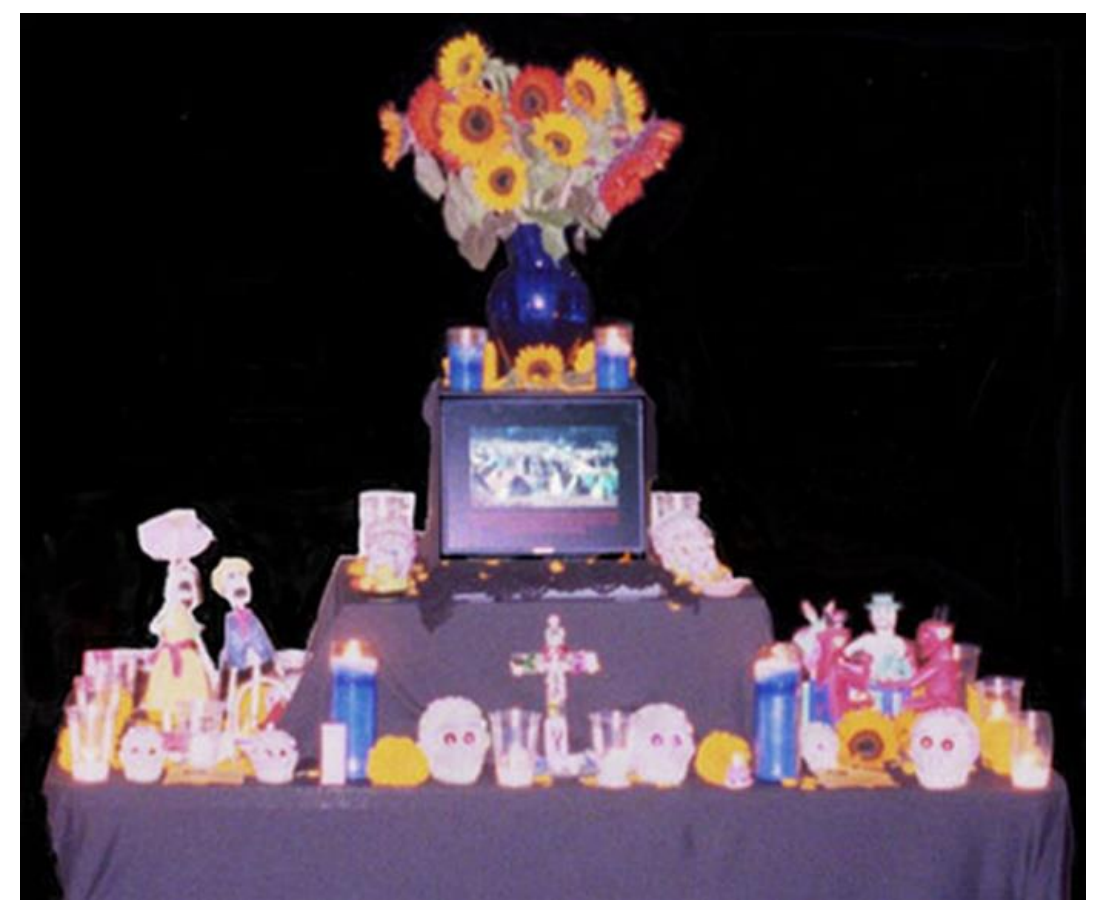

Image 7 Virtual Altar (Photo by William Franco)

Quecholly - or how I learned to stop worrying and love weapons of mass destruction (2002) addressed the new war on terrorism. It was an animated work that included a rotating table top with 300 soldiers painted black with white faces, symbolising the number of American soldiers who could die during the bombing and invasion of Iraq. An audio soundtrack played clips from then-President George W. Bush's speeches talking about weapon of mass destruction.
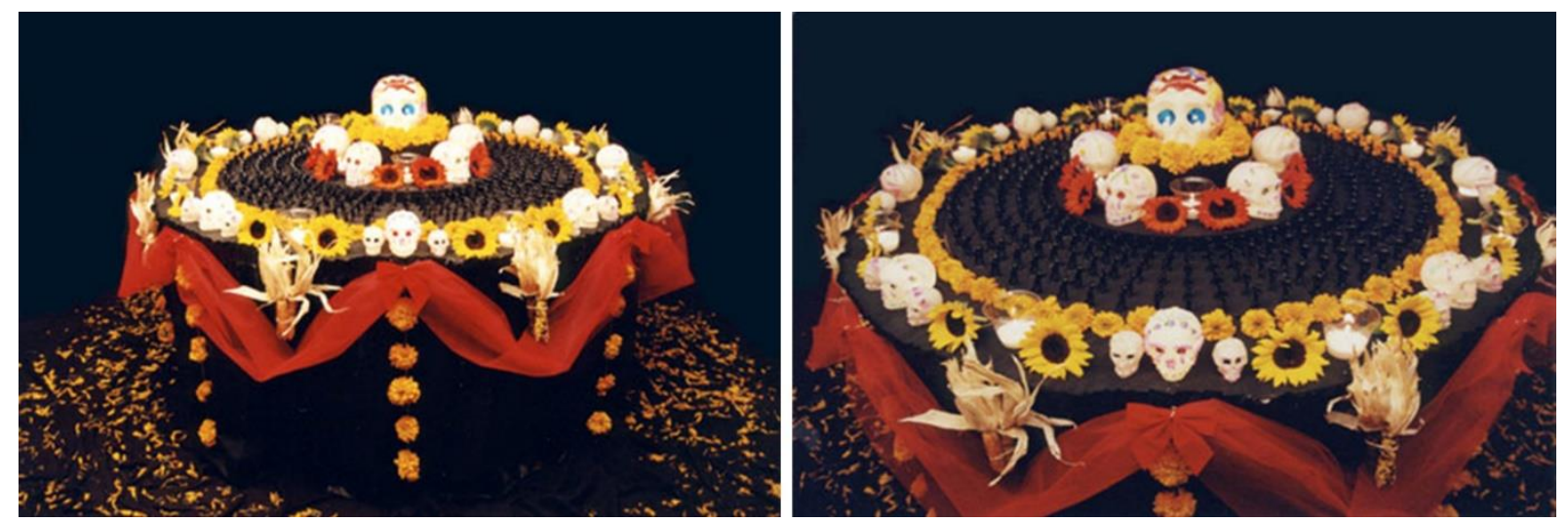

Image 8 Quecholly, (left) wide shot, (right) detail (Photo by William Franco)

By the time we left Los Angeles and moved to Aotearoa New Zealand in 2007, this trend we had started of integrating technology and to address current issues into the Dia de los Muertos offrendas had spread and was becoming common place at the Art in the Park and other yearly public celebrations for Dia de los Muertos in Los Angeles. 
Seifert and I were still developing our system of working together, unaware that we were developing a collaborative methodology. It was an organic process born out of our shared histories in the border area. At the time I was considered a naive artist by people in the greater arts community. Other than the occasional community art class and my collaborations with the BAW/TAF, I had no formal arts training.

In 2003 I was accepted and attended the California Institute of the Arts (CalArts), where I received my BFA in Film and Video in 2004. It was at CalArts where I was asked to analyse and articulate my practice for the first time. This was when I started to bring my unconscious processes to the surface. I started to express my process in papers and classroom discussions. I began to realise that my method was very different than the methods that were being taught in art school. I was beginning to understand how my border upbringing had affected my perceptions of the world around me and how I used these perceptions to create my work. This caused tension with some of my lecturers who were trying to convince me to see art through their western eyes.

The lecturers pushed their concepts of western art and the White Cube, the gallery as the place for Art (Sheikh 2009). I am not saying that contemporary art was only in the gallery spaces because there were artists doing work outside of the gallery space. Artists like Robert Smithson and Dennis Oppenheim back in the sixties and seventies were creating what was called Land Art (Ginsburgh and Penders 1997: 1), but their reasons for doing work in these places is very different than my reasons working in alternative spaces. Their reason was to break away from the conventions of the white cube in western art context. My reason for working in unusual spaces was to connect with my local communities_communities that didn't usually frequent galleries.

These discussions with staff actually pushed me further away from the western way of looking at art toward my Border Art thinking which was context, location, and community. Staying true to my Chicano Border Methodology, which uses knowledge from different sources, I held onto the bits of art theory and practice that I saw as relevant to my work. Because of my art school experience, my practice has become a mixture of Indigenous border art and contemporary art practices. This can be seen in my collaborations and solo work during and after CalArts.

In the first work No Olvidado/Don't forget me that I did at CalArts, I explored (im)migration and the U.S.-Mexico border. 

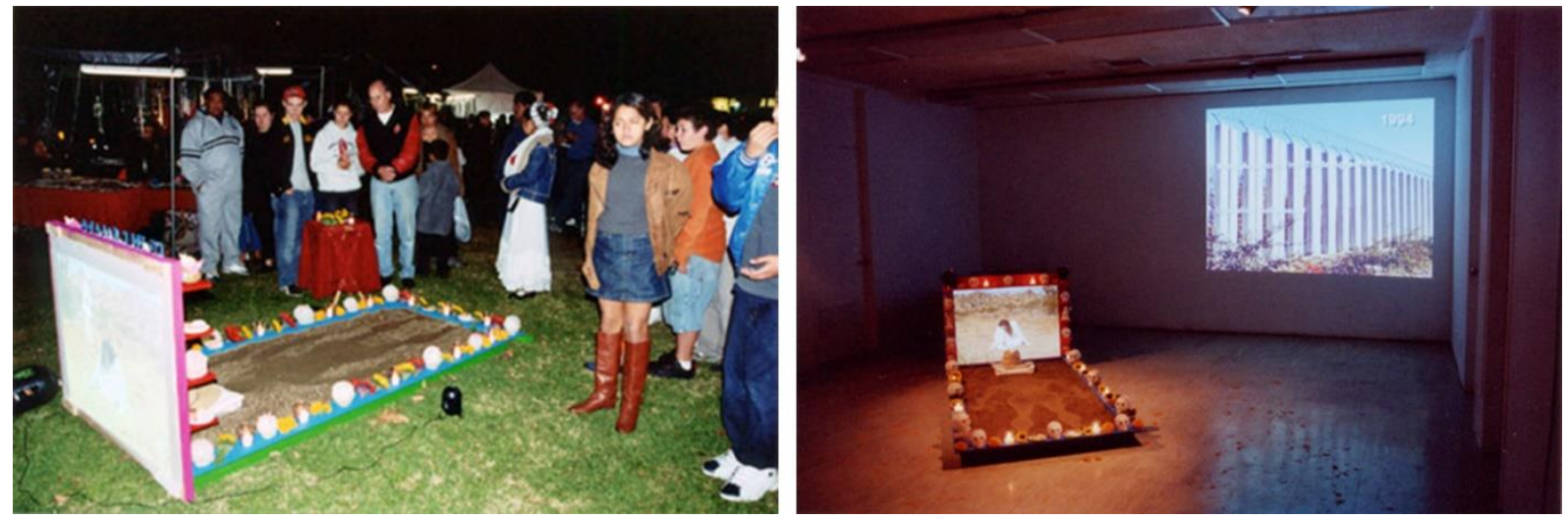

Image 9 No Olvidado (left) Art in the Park (right) Calarts (Photo William Franco)

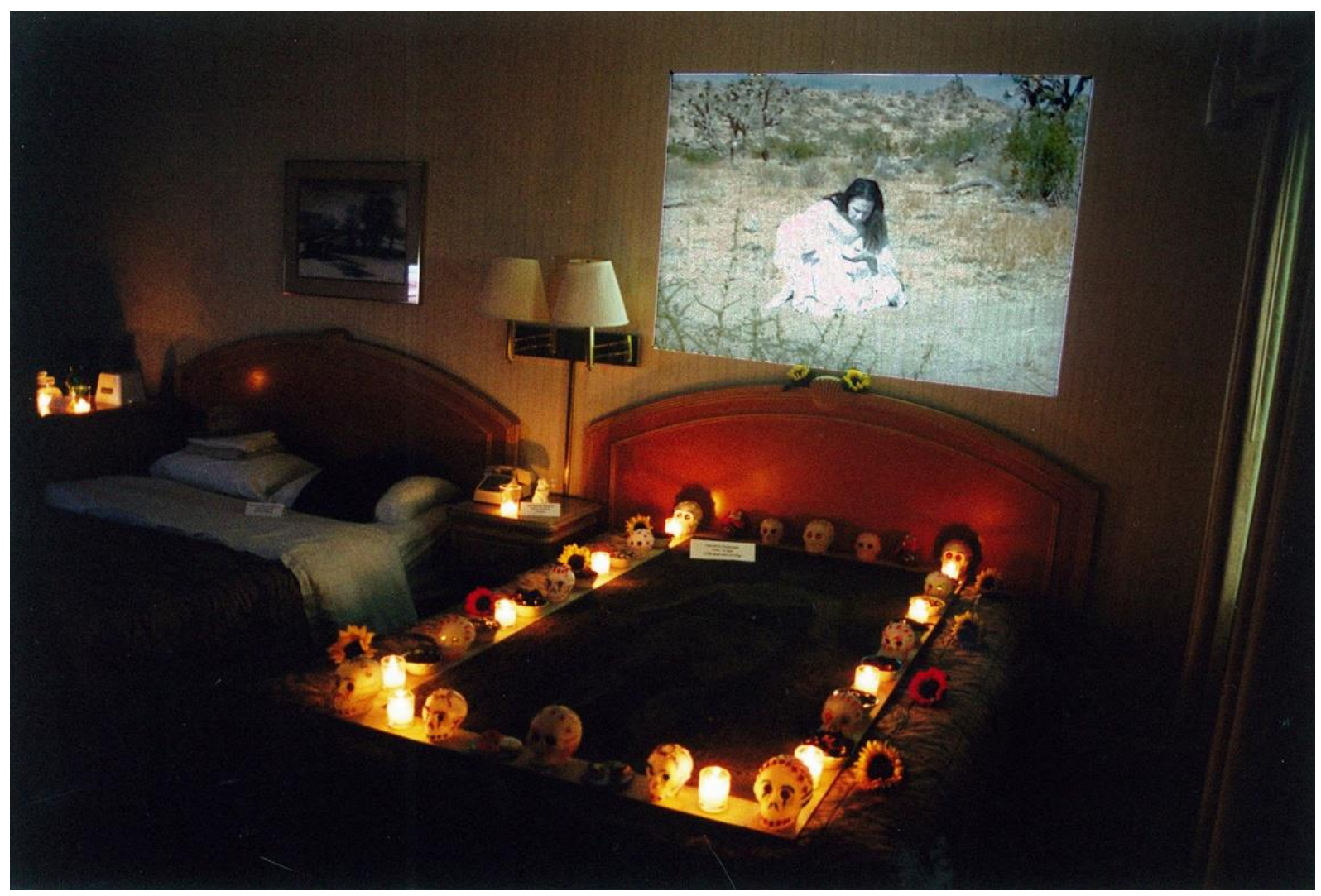

Image 10 No Olvidado Hotel/Motels (Photo by William Franco)

No Olvidado highlighted the plight of the undocumented workers and their struggle to enter the US to work. It was dedicated to the many who died along the way. The installation was built around the tradition of a grave site offrenda. It was a rectangular box filled with earth. In the soil was an imprint of a human body. At the top of the grave was a set of neatly folded clothes. The perimeter of the grave was covered by Mexican sugar skulls, candles, marigolds and food. 
The headstone was a rear screen projection of a video of Seifert and I performing a Butoh ${ }^{11}$ dance honouring the many who had fallen during the journey across La Frontera. There was a sound track of Chicano poet Ruben Mendoza reading a list the names of the people identified by the US government who were found dead at the border. Seifert summed up the importance of these pieces in our development as artist:

What we learned through these experiences was the importance-to us-of the context in which our work is presented. There had to be a dialogue between the location, the people who lived in the location, the people who came to see the art, the artwork and the artists. During these events, we did not merely present our altars. We talked with the people as they came and looked at the offrendas. We not only discussed the work, but more often than not, the conversations veered into other topics as well. A personal connection was made between us and our audience (Seifert 2011: 71).

For me, this acknowledgement of people and place and connection with the surrounding community is an important concept of my Chicano Border Methodology. The recognition, validation and importance of the local people, knowledge, customs and the way of being grounds my work in the community and helps the community connect with the work on a level that is different than just coming in and hanging a picture on the wall. There is a synergy that takes place when the local context is acknowledged. The work morphs into something bigger and more important than the individual pieces alone. The work comes to life. And that's where change takes place. That's one of the main differences I see between my work and that of most contemporary artists: for me it's about community; for contemporary artists it's about concepts, ideas and self-promotion.

\section{Aotearoa Collaborations}

In 2007 I was awarded a Fulbright Fellowship to Aotearoa New Zealand to do an art project on colonisation from the perspectives of Māori and Chicano. Again, I collaborated with Seifert on this project. When we arrived in Aotearoa, we sought out Māori collaborators who were

\footnotetext{
${ }^{11}$ Butoh is a form of performance that is part dance and theatre developed in Japan in the early 1950s as a way, to externalise and transform the pain and suffering Japan experienced in World War II. Seifert in her thesis He rawe tona kakabu/She Wore A Becoming Dress has a chapter on how we developed a Critical Butoh for our performance work.
} 
interested in a cross-cultural exploration of the Indigenous colonisation experience. Our collaborators were Anahera Gildea, a Māori writer and a performer from the iwi (tribe) of Ngāti Raukawa ki te Tonga, and Eugene Hansen, a VJ (video deejay) and time-based installation artist from Ngāti Mahuta and Ngāti Maniapoto. The project became Nō Nāianei (from this moment). Nō Näianei was a ten-month cross-cultural collaboration that, within the context of colonisation, explored the question: How can the artist be a catalyst for change in a society by fostering dialogue and discussion? The outcome was a three-part project that consisted of a Butoh hikoi (march/procession), Butoh/VJ performance and multimedia installation.
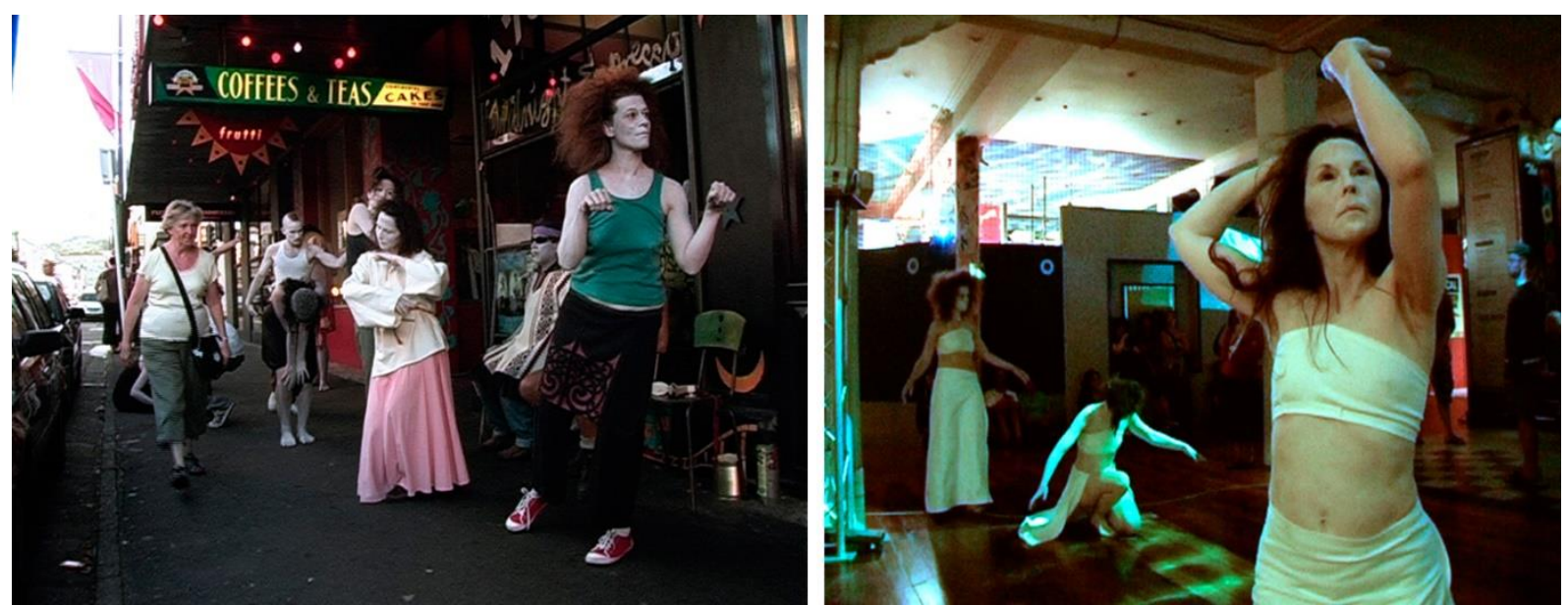

Image 11 No Nāianei (left) Butoh Hikoi (Right) Indoor performance (Photo William Franco)

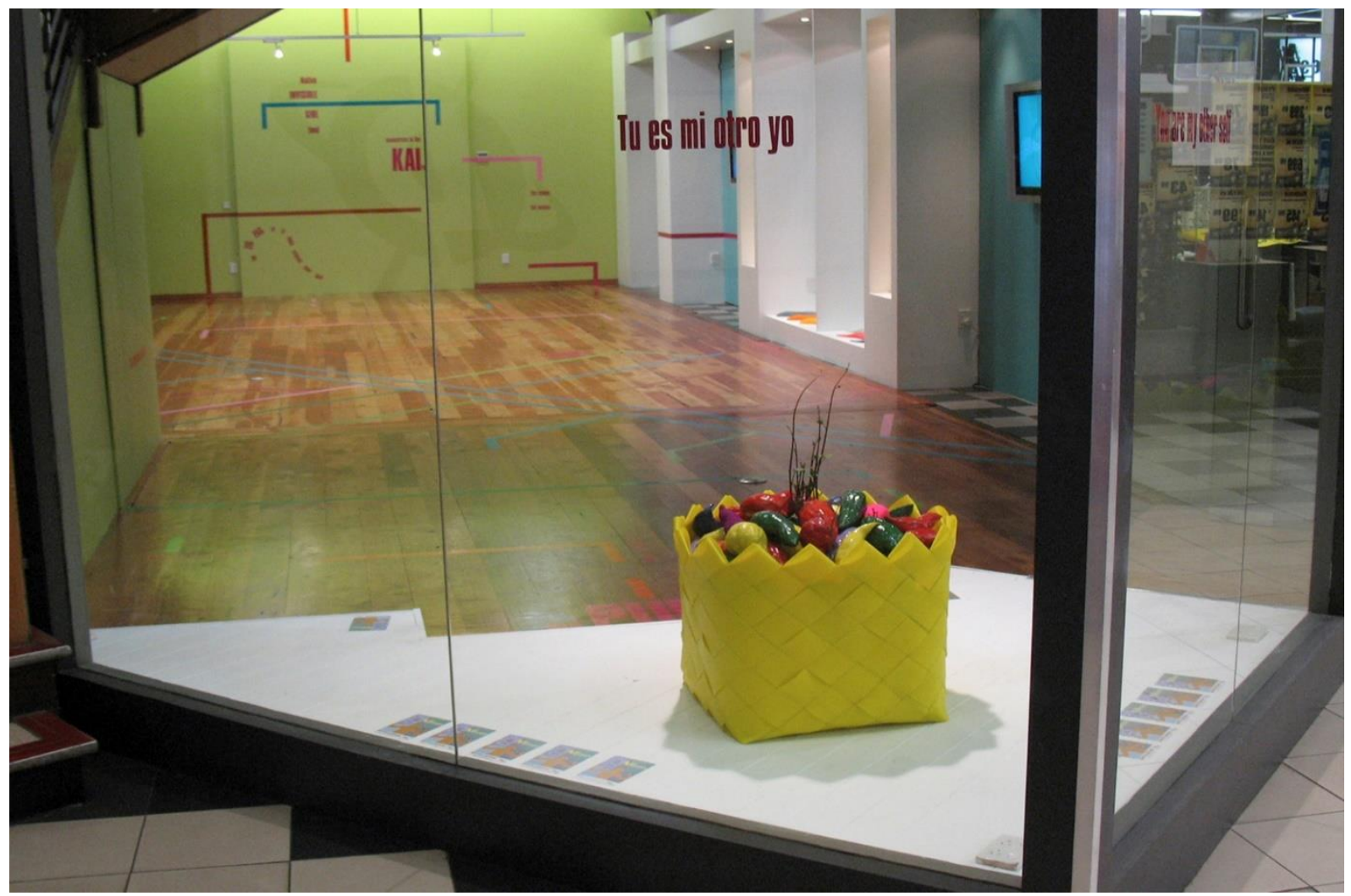

Image 12 No Nāianei Installation (Photo by William Franco) $48 \mid \mathrm{P}$ a g e 
As part of my Fulbright Fellowship I had to be attached to a local university, so I enrolled in the Masters of Fine Arts program (MFA) at Massey University in Wellington. For my MFA program I had to write an exegesis about my collaborative art practice, my history and the influences on my work. I wrote about the cross-cultural collaboration and the Nō Näianei project. This was the first time collaborating with another indigenous group, while living in another country. In this scenario, I was the Other, a settler in Aotearoa where Māori were the tangata whenua (people of the land). It was very different than working the coloniser-indigene hyphen that I had become used to while working with Seifert in the border area of the US.

Here in Aotearoa was the first time I was able to look back from afar at my culture and country — looking at my world from a distance and seeing it through different eyes. Rather than being in the heat of the moment fighting for a voice, I was in the position to be able to sit back and analyse what I had been through as a Chicano artist. My exegesis was the beginning of my retrospective and introspective process. Just starting that deeper exploration into my process, I still had not given my practice a name.

In 2009 Seifert and I collaborated again with Gildea on Seifert's doctoral research project, He rawe tona kakahu/She wore a becoming dress, a multimedia Butoh performance about colonisation and gender from the perspective of a white woman (Seifert) and a Māori woman (Gildea). He rawe tona kakahu was performed for two nights at the Film Archive in Wellington.

On this collaboration I had a producer-production designer-technician role. Since the work was from the point of view of the two women, my part of the collaboration was to assist with the technical and stage presentation of the piece. For the most part I was an observer of their process but contributed to the discussion when we all felt it was appropriate, such as set design, video projections and lighting schemes that set the atmosphere for the performance and general producer responsibilities.

There were times when I would be in the same room working on part of the project while Seifert and Gildea were working on another element of the project. It was interesting to watch and listen as the two artists talked and worked. Both took great pains to focus on that edge between the two cultures, a white American and a brown Indigenous person. The closest connections they had was their gender and religion, both being women and SGI Buddhists. Seifert states, "As a collaboration that worked across the hyphen, we both engaged with critical and decolonising 
theory from our respective positions on the hyphen, as well as brought our respective world views_-I, white American and Anahera, Te Ao Māori”" (Seifert 2011: 7).

\section{Lessons Learned}

These collaborations deepened my understanding of my practice. It highlighted the differences I encountered working the coloniser-indigene hyphen vs indigene-indigene hyphen. Working with Māori, we shared similar worldviews about the land and the world around us. We also shared our cultural differences; for instance, my Māori collaborators explained the Māori concepts of tapu and noa (sacred and normal). My culture does not have such a formal designation for what is sacred and what is normal, or the rituals that can change one to the other. This sharing of ideas and cultures gave us material that we could build upon to create a relationship. There was a freedom of sharing of experiences without worry about having to look over our shoulder for the social structures that could be uncomfortable with the cross-cultural discussions we were having. We all brought knowledge to the table and we all valued that knowledge. These collaborations in Aotearoa could not have been as successful without the tools I developed during the many years of collaboration in the US with other Chicano, Indigenous, and non-Indigenous artists.

One of the most important lessons I learned from these collaborations with Māori and being in a Māori department is the way of articulating who am I, where I came from, and what are the principles that governed my everyday life. Māori have a strong sense of who they are and have ongoing discussions about what it means to be Māori and how it is constantly evolving. When Chicanos/as first meet we always ask ¿De donde es? (where are you from?) as an informal way of finding commonalities between each other. Because of several factors, such as of the sheer size of the Americas, the hundreds of years that we have been here, and the effects of colonisation, we usually answer with the part of the Americas we are from. I usually say La Frontera. From this information we can get a general idea of the person. If we want to know more, we can ask more questions, for instance tribal affiliations.

When I first came to Aotearoa and asked a Māori ¿De donde es? or the Māori equivalent, Nō hea koe? (where are you from?) (Walsh-Tapiata 2002). Knowing that I was not from Aotearoa, they responded with their iwi and what part of the island they came from. If a Māori were to ask another Māori, Nō hea koe? The Māori person would have responded differently because they are having a dialogue with their ancestors, and endeavour to 'see that person' within their familial and celestial totality (Rua et al. 2017). A Māori would reply by saying their mihi (introduction) 
about where they come from or their whakapapa (genealogy) if it's a more formal setting. They would include their waka, iwi, hapū, marae and whanau. Most Māori can recite their family history all the way back to the first waka that came to Aotearoa.

When they ask me about my whakapapa, I can go back three or four generations. Because of the extended history of our presence in the Americas, it is impossible for us to go back more than a few generations in our whakapapa. If we knew every one of our ancestors, it would take several weeks to present it. Because of the enormity of the Americas, there is not as much direct contact with my Chicano ancestors as the Māori have with their ancestors here in Aotearoa. But because of these conversations with Māori, it made me question myself more about who am I, where do I come from, and how do I fit in this world and in Aotearoa. It was because of these conversations that I decided to dig deeper into my myself and my past to write a thesis about what makes me who I am and drives my art practice. This led me to the re-construction of my Chicano Border Methodology.

\section{Conclusion}

As part of my western art education at CalArts I was told not to add any cultural signifiers to my work. My work would be viewed more as folk art then contemporary art. My work is filled with cultural signifiers. In No Olvidado there are Mexican sugar skulls, Indigenous food, flowers, candles and the colour scheme reflect the colours seen in communities in Mexico. Sometimes this will lead to discussions about what is fine art or folk art. There is no one definition for either of these. In general, if there are cultural signifiers, the work can be considered as craft or folk art. Contemporary art is about stripping away culture and identity and replacing them with concepts, ideas, and abstractions. My work is grounded in place, the here and the now, and uses techniques and technology that normally are not used in what some would call folk art practices. If the artwork does not fit within that idea of the western fine art paradigm, it is not considered fine art but instead called folk art, which usually includes Indigenous art and naïve art. This means that the work will be valued less and not regarded as serious art in the art world. Which also means that it will not be shown in any of the major galleries or museums in the world and would sell for much less than other art works. I have been engaging with the aesthetic of western art practices, adapting some of these western art practices and techniques and incorporating them into my work. By doing so, I am crossing back and forth between the border of folk art and fine art, blurring and sometimes erasing the line between folk art and fine art. Thus, I am making it more 
difficult for the western art institutions that are the gatekeepers of the art world to call it folk art and fine art.

The artworks mentioned in this chapter illustrate the natural development of my visual arts practice and the methodology behind the work. In the beginning years, I learned my art from some of the best practitioners of installation art in the US-David Avalos, James Luna, and Deborah Small. They were well-educated from major universities in the US and were well established in the art world, but they also understood the position of Indigenous art within the art world context and believed that art can have a positive effect on societal change. They instilled in me the importance of this concept and the importance of research, context and execution in the development of work. The aesthetic of the work, making sure that it is presented well, and in a manner to give space for people to feel comfortable but having a strong enough point of view to generate discussion. They believed in the importance of giving voice to people who feel they have no voice. As Avalos has said, "the belief.... that art can affect people's consciousness in a way that has concrete benefits for society" (Leval 1992: 72).

I learned how to work in a collaborative environment with people from other cultures, races and religions, to work in the space what Seifert refers to as "across the hyphen" (Seifert 2011). Collaborations are difficult places to inhabit. It takes commitment from all involved to make it work. Sometimes it doesn't work. Sometimes a collaboration works well on the big over-arching concepts but has problems with the small micro-borders between collaborators that may need to be crossed during the process. I learned to try to work with these kinds of issues on a one-to-one basis as well as through group discussions and group exercises. But sometimes it doesn't work out, a mutual parting happens, and a new collaborator for the project needs to be found. We are all human beings. We each view life through different lens.

The lens that I was learned through was the lens of La Frontera. That lens influenced my art practice and would later become my Chicano Border Methodology. In my collaborations over the years, I applied what I had learned from previous collaborations on each successive collaboration, slowly building a methodology and framework. I had been unconsciously, and now consciously, finessing and developing this methodology for almost thirty years. No Olvidado/Don't forget me (2004), Nō Näianei/From this moment, (2007), He rawe tona kakahu/She Wore A Becoming Dress (2011) were deeper explorations into my methodology. 
Now with The Illustrated Chicano (2018), I have taken a different path with my methodology. This new path illustrates the malleability of this methodology as I apply it on a project that looks inward rather than outward. For The Illustrated Chicano, rather than work in a collaboration, I have decided to work without a collaborator and use my Chicano Border Methodology to create a solo work. During the creation of The Illustrated Chicano, I used all the concepts and practices that I developed over the years to create a project that reflects the core principles of my practice. In the next chapter, I will discuss why and how I came up with the methodological framework for my Chicano Border Methodology and how I apply it to my work. 
$\mathbf{5 4 | P}$ a g e 
Atlethodalougy

chapter three 
56|P a g e 


\section{METHODOLOGY chapter three}

In the previous chapters, I discussed the experiential foundation of my methodology; my life as a Chicano and a Border artist. In this chapter, I will discuss the conceptual foundation of the Chicano Border Methodology. I am writing about this methodology, which incorporates a plurality of knowledges, including local indigenous ways of knowing, to show the rigour and robustness of this methodology and how it can be used as a decolonising tool in research.

\section{Colonial matrix of power and hierarchy of knowledge}

In recent years, the concept of epistemological dominance has generated a large amount of discourse. in the social sciences, giving rise to decolonising, critical race, feminist and postmodernist theories and frameworks(C. Ahenakew 2014a; Aldama and Quiñonez 2002; Anzaldua 1993; Castro-Gomez 2006; Denzin et al. 2008b; Denzin and Lincoln 2008; Walter D. Mignolo 2007b; Quijano 1995; L. T. Smith 1999; J. C. Walsh 2001). Indigenous researchers and scholars, like Linda Tuhiwai Smith (1999, 2005; 2016), Cash Ahenakew (2014b; 2014a) and Martin N. Nakata (2007; 2012), have been looking for new ways to engage with research that represents alternative perspectives of the world and that recognises the multiple ways of knowing, and embraces and values those differences. Through the destruction of other knowledge systems during the European period of conquest of the New World, European or western knowledge assumed its position of epistemological dominance or "epistemic privilege" (Grosfoguel 2013: 74, Dussel 1995).

This epistemic privilege is part of a system Peruvian sociologist Anibal Quijano called “"coloniality' (the invisible and constitutive side of 'modernity')" (Cited by Walter D. Mignolo 2007a: 451), and later the “colonial matrix of power"(Walter D. Mignolo 2007a: 476). Mignolo goes on to describe Quijano's basic components of the colonial matrix of power as coloniality of power (economic and political), of knowledge and of being (gender, sexuality, subjectivity and knowledge) (Walter D. Mignolo 2007a: 451). Quijano argues that these colonialities are the under-structures of the systems that govern our world today. "What is new in the "coloniality of power' perspective is how the idea of race and racism becomes the organizing principle that structures all of the multiple hierarchies of the world-system" (Quijano 1995). Building on Quijano, Grosfoguel states that he conceptualises the coloniality of power as an entanglement of multiple and heterogeneous global hierarchies ("heterarchies") of sexual, political, epistemic, economic, spiritual, linguistic and racial forms of domination and exploitation where the racial/ethnic hierarchy of the European/non-European divide transversally reconfigures all of 
the other global power structures (Grosfoguel 2011: 11). There is the other side of epistemic privilege that Grosfoguel calls "epistemic inferiority. Epistemic privilege and epistemic inferiority are two sides of the same coin. The coin is called epistemic racism/sexism" (Grosfoguel 2012). Examples of this epistemic racism/sexism can be encountered in textbooks:

In the schools, the colonisation of the mind is continued through the instilling of a historical amnesia that renders Latino/indigenous peoples as "immigrants," foreigners who have no claim to the Americas, while European Americans are constructed as the natural owners and inheritors of these lands. The rich knowledge, beliefs, and worldviews of Latino and Mexicano/Chicano communities are not validated, let alone taught (Villenas and Deyhle 1999: 421)

A full analysis of the structure of the western education system and Indigenous knowledge is beyond the scope of this thesis. For more in-depth analysis, see (Aldama and Quiñonez 2002; Barnhardt and Kawagley 2008; Battiste 2008; George Jerry Sefa Dei et al. 2000; Grosfoguel 2012, 2013; Hutchings 2002; Lee-Morgan 2016; McKinley 2005; N. M. N. Nakata, Victoria; Keech, Sarah; Bolt, Reuban 2012; L. T. Smith 1999; Villenas and Deyhle 1999).

\section{Destruction of knowledge}

The dominance of epistemic privilege was accompanied by the destruction of the Indigenous knowledge that was encountered during the conquest as the Spanish, English, Portuguese and French slashed and burned their way through the Americas. The end result was what Boaventure de Sousa Santos calls "epistemicide", the murder of knowledge, the extermination of knowledge and ways of knowing (Santos 1998: 103). An example of this was the mass destruction of the codices of the Aztecs of the North American continent by the Spanish conquistador Hernán Cortés in the 1500s (Martínez 2015: 5).

Thousands of artefacts of knowledge were destroyed in the name of Christianity, empire and settlement under the pretence of civilising the 'savage' natives of the Americas. For example, Dussel (2006) talks about how Spain used the Spanish philosopher Ginés de Sepúlveda’s and Scottish Scotist Juan Mayor's arguments that the natives were natural slaves and needed to be ruled to rationalise their war and destruction of the New World. To fulfil their belief that the people of the Americas were uncivilised barbarians, the Spanish needed to destroy as much of the Indigenous knowledge that they could find. That way when asked about the peoples of America, they could say there are no written laws or any other signs of social order that could be 
considered a civilisation. It would then fall to Spain to rule them and give them culture, so that they can become part of the western god-based world order. Dussel has responded to de Sepúlveda's argument thusly: “...the most serious part of this philosophical argument is that just war against the indigenous peoples is justified for the very fact of having impeded the 'conquest', which to the eyes of Ginés is necessary 'violence' that needed to be exercised in order to civilize the barbaric, because if they were civilized there would no longer be any cause for just war" (Dussel 2006: 12).

Through this mass destruction of knowledge during the conquest of the Americas, western knowledge was able to supplant the local Indigenous knowledges and, in conjunction with the hierarchies of the colonial matrix of power, establish the system of western schools and universities in the Americas.

\section{Epistemological pluralism}

When I started my research, I searched for a model that spoke to my particular situation, a Chicano and Native American living along La Frontera, the border between two settler nations, the US and Mexico. I found that none of them had the strategies and flexibility or fluidity needed to address the particular issues that I encounter at La Frontera. I felt that none of them offered a place to hang my methodological hat until I revisited the writings of Gloria Anzaldúa. I had first encountered her writings when I was part of an art show called La Frontera/The Border: Art about the Mexico/United States Border Experience in San Diego. It was then that things began to come together. Her discussions on Chicana/os in her book Borderlands: La Frontera the New Mestiza (Anzaldúa 1987) resonated with me. Mignolo says "Her discussions about the body politic and the geo-politics were deepening and enlarging the decolonial shift" (Walter D. Mignolo 2007a: 488-89). As Grosfoguel states:

The hegemonic Eurocentric paradigms that have informed western philosophy and sciences in the modern/colonial capitalist/patriarchal world-system for the last 500 hundred years assume a universalistic, neutral, objective point of view. Chicana and black feminist scholars (Moraga and Anzaldua 1983; Collins 1990) as well as Third World scholars inside and outside the United States (Dussel 1977; Mignolo 2000) reminded us that we always speak from a particular location within power structures (Grosfoguel 2009: 168).

It was from my research into Anzaldúa and Borderland Theory that led me to Dussel, Mignolo, Grosfoguel, Miller, Healy, and Ahenakew among others. This research helped me formulate the 
concept of Chicano Border Methodology, a methodology based on using epistemological pluralism as its core. The difference between Borderland Theory and Chicano Border Methodology is that Chicano Border Methodology is an on-the-ground tool for collaboration between different groups of people as a way to create decolonising art and to give people the opportunity to decolonise themselves.

When I encountered epistemological pluralism, I realised it contained the key elements that I was looking for in a methodology:

It is an open system.

- It can be tailored to fit many different situations.

- It is a mix and match system depending on the research subject.

- It can include other ways of knowing into the equation.

- It values other knowledge spaces.

- It is a system that values each knowledge system equally.

- It is accepted in the academy as a legitimate form of research methodology.

- It can be a vehicle for de-colonisation.

Epistemological pluralism is a methodological concept for research that uses a plurality of knowledges to solve a given problem (S. Healy 2003a: 693). It has been used as a methodology in science, championed by environmental scientists Stephen Healy and Thaddeus R. Miller who realised that looking at a problem from only one perspective was problematic. Understanding that one solution might create another problem that makes the situation worse, Miller realised that a more holistic approach was needed to find long-term solutions: "Epistemological pluralism recognizes that, in any given research context, there may be several valuable ways of knowing, and that accommodating this plurality can lead to more successful integrated study" (T. R. Miller 2008: 1). Healy and others researched alternative methods to tackle problems. Healy saw epistemological pluralism's potential for change in the way scientist and researchers process complex problems: "Epistemological pluralism serves to illuminate potential futures and open up choices they involve for deliberation rather than dictate them. Such a 'politics of choice' is predicated on not just the recognition but the positive encouragement of difference" (S. Healy 2003a: 297).

While the plurality of knowledges has often referred to using other western knowledges, e.g. geology, anthropology, etc., it has generally not included Indigenous knowledge or other localised 
knowledges. However, its encouragement of difference opens the door for the inclusion of Indigenous knowledges and other localised ways of knowing into what normally would be a western science-based research projects. The research projects that employ an epistemological pluralist framework present the opportunity for Indigenous researchers to become involved in multi-knowledge space projects. It provides a space to collaborate with scientists and conduct important research in an area where localised knowledge is welcomed and encouraged.

First Nations scholar Cash Ahenakew states, "Epistemological pluralism is an under-explored inherent feature of some indigenous cosmologies that can be used productively to enhance research processes and transnational spaces of dialogue in order to support international efforts to Indigenize the academic spaces as a form of creative contention (of continuous forms of neocolonialism), resistance (to imperialism), and (indigenous) resurgence" (C. Ahenakew 2014a: 1). Kahnawake professor Taiaiake Alfred defines this movement as a spiritual revolution which is "a culturally rooted social movement that transforms the whole of society and a political action that seeks to remake the entire landscape of power and relationship to reflect truly a liberated postimperial vision" (Alfred 2005: 27).

\section{Decolonising Epistemology Pluralism}

To use epistemological pluralism alone does not guarantee that the research will be de-colonising. To include Indigenous or localised knowledge in a research project does not mean there will be a de-colonising outcome. What needs to happen for a project to be considered decolonised? A good conceptual model of what the process of decolonisation looks like for an Indigenous person was developed by Michael Yellow Bird and Waziyatawin. They define decolonisation as both an event and a process:

Event - As an event, decolonization concerns reaching a level of critical consciousness, an active understanding that you are (or have been) colonized and are thus responding to life circumstances in ways that are limited, destructive, and externally controlled.

Process - As a process, decolonization means engaging in the activities of creating, restoring, and birthing. It means creating and consciously using various strategies to liberate oneself, adapt to or survive oppressive conditions; it means restoring cultural practices, thinking, beliefs, and values that were taken away or abandoned but are still relevant and necessary to survival; and it means the birthing of new ideas, thinking, 
technologies, and lifestyles that contribute to the advancement and empowerment of Indigenous Peoples (Waziyatawin and Yellow Bird 2012: 3).

It is a high-level understanding of the decolonising process and is directed toward Indigenous people and Indigenous communities. My own decolonising process was similar to Hawaiian sovereignty activist Poka Laenui's five phases of decolonisation which deals more with the actual process of decolonisation and Laenui gives an example of the process in action (Laenui 2000: 27). In chapter five, I describe in more detail his five phases and how they relate to the reconstruction of my Chicano Border Methodology.

What is the different between these two views of the decolonisation process and my Chicano Border Methodology? They both come from the Indigenous need to decolonise themselves whereas Chicano Border Methodology, using decolonising epistemological pluralism, is designed as a methodology that can be used by Indigenous as well as non-Indigenous to decolonise themselves.

I believe that to de-centre the western hegemony Indigenous people are not the only ones who need to be decolonised. The settlers themselves need to be decolonised. This decolonising epistemological pluralism was designed as a tool for collaborations with non-Indigenous collaborators as a way to decolonise both parties. This means that the decolonising process needs to be accessible to non-Indigenous people.

Coming from a visual art perspective, my decolonising methodology is informed by the years working with my white non-Indigenous partner, performance theorist Miki Seifert who states that the core tenets of a decolonising epistemological pluralism are that it needs to be performative, transformative and needs to include mind, body and spirit (Seifert 2011: 196). This model gives space for Indigenous and non-Indigenous to work in a decolonising research project and as part of the process of working on the project will go through a decolonising process. I have adapted Seifert's decolonising epistemological pluralism methodology and applied it to my research to create a Chicano Border Methodology. I use this methodology to create decolonising art that questions social assumptions and illustrates issues at La Frontera and in Aotearoa New Zealand. 


\section{Performative}

Performative has been used in different ways and has different interpretations. Postcolonial critic Homi K. Bhabha deployed the term "performative" to refer to action that incessantly insinuates, interrupts, interrogates, antagonises, and decentres powerful master discourses, which he dubbed "pedagogical" (Cited in Dwight Conquergood 1995: 178). For Seifert performative means that something needs to happen, that knowledge has to be active or performed. She created a decolonising Butoh performance titled He rawe tona kakahu/She wore a becoming dress. American philosopher and gender theorist Judith Butler writes of three uses for performativity: "1) it seeks to counter a certain kind of positivism according to which we might begin with already delimited understandings of what gender, the state, and the economy are, 2) performativity works, when it works to counter a certain metaphysical presumption about culturally constructed categories and to draw our attention to the diverse mechanisms of that construction' and 3) performativity starts to describe a set of processes that produce ontological effects, that is, that work to bring into being certain kinds of realities or 4) that lead to certain kinds of socially binding consequences." (Butler 2010: 147).

Butler's descriptions of the three uses of performativity are critical to my research because they articulate several reasons behind the development of my research methodology. First, my methodology is about changing the status quo, presenting different ways of knowing to counter the positivist structures in academia. Second, my methodology is showing that there is more than one way of being in the world other than the western way. Thirdly, my methodology shows the validity of different forms of reality, an example being the fluid reality of living along La Frontera/Mexico-US border.

For my research, the actual writing of the thesis is a performative act. I am performing the methodology on paper and demonstrating the performative aspects of the construction and exhibition of an interactive art installation. Another performative aspect of my research is the documentation of the project in video and still photography. This archival footage will be used as a way to visually interpret the work at a later time and place, and allow for different responses to the work from people who were not able to attend the exhibition in its original setting. This material will also be available for public lectures. The exhibition itself was performative as the public became part of the performance. They were able to watch the installation and testing of the work, asking me questions while I was installing the piece. This created an opportunity to share, or perform, knowledge and created a more communal sense to the work rather than the 
individual solo work. As a result, the installation had the spiritual energy imprint of the local community who were present during the installation of the work.

\section{Transformative}

Transformative means something needs to change. It could be laws, policy, a change in the academy, the way one looks at the world, how someone process new information, or how people view one another —as long as something changes.

My research is transformative in the way I have articulated my process for creating art work, the way that I have transformed an interior process to one of externally recording my process in a digital and material form as a $\mathrm{PhD}$ thesis. It is the way my installation transformed the visitors for a brief time as evidenced in audience responses in chapter six. When they entered the exhibition space, they were taken into another space, a space that was transformed into a Chicano space, a space where a different type of knowing took place. This is particularly important here in Aotearoa New Zealand where the tangata whenua is Māori, who have a very specific worldview and the Pākehā ${ }^{12}$ settlers who are still developing a sense of what it means to be a New Zealander in Aotearoa.

\section{Mind}

Using a decolonising epistemological pluralism requires an openness to viewing the world from a different space and a willingness to communicate with one's collaborators. This means to engage with the mind and reflecting on what happens when entering this space. For me the process of writing this thesis is a self-reflective engagement, as I articulate what has been my decolonising journey over the last thirty years. Using Laenui's five phases of the processes of decolonisation (Laenui 2000: 2-7), the turning points of my journey can be summed up like this: The rediscovery and recovery of my Chicano identity, the mourning of the lost homeland and sense of place, the dreaming of what a world could be like, the commitment to moving my world forward towards my dreams and the continuing action on a mental plane toward these possibilities. I will discuss my process of decolonisation further in chapter five.

\footnotetext{
12 "It just means a New Zealander of non-Maori and non-Polynesian heritage...'Pakeha' is mostly used to describe white non-Maori, as they were the original colonists, but it can apply equally to Asian, etc...It gives the term Pakeha a more inclusive and less pejorative tone" Jodie Ranford, "Pakeha', Its Origin and Meaning', (2015) at 64.
} 


\section{Body}

The body also needs to be a part of this process. The body holds memories (Fuchs 2017: 333; Koch et al. 2012) that the mind may not recall. When I am part of a collaboration, we work to access these body memories and use them as part of the decolonisation process. We do group exercises that help release these body memories from simple touch exercises to exhausting physical workouts. At times I have found that someone may say something that represents their thoughts and feeling toward a certain situation, but by involving the body, something else can happen. This usually surprises the person as their body reacts to that situation differently than they thought it would. Through these exercises past body experiences may come to the surface These explorations are then used enhance the work by discussing and analysing these reactions and by incorporating these reactions into the work.

Or the body can be included in the work like I did—my DNA is actually part of The Illustrated Chicano installation. My body memory was transposed onto an object that represented my physical presence in the space. I will talk more about this in chapter 5.

\section{Spirit}

Spirit means that research is not only based in western science but inclusive of other beliefs systems which do not separate the material from the spiritual. For this research project, the spiritual knowledge I used is from the belief system of my Chicano/Native American/Zapotec culture. We believe that life is circular. We use the metaphor that we are children of the corn.

Maíz (corn) is like a human being; it cannot grow without human care and human beings cannot grow without maíz. It is our Indigenous belief. We are men and woman of maíz. The trunk of the maíz is the dual spiritual force of ometeotl. It is female and male. It is father and mother. The ear is the pollen that falls into the cob to give life to the kernels that are wrapped in the leaves of the maíz the way a baby is protected in her mother's womb (Olivares et al. 2014).

We grow from seeds up to the sun. When we are strong and tall and our corn is ripe, it is harvested, then we are burned and our ashes return to the earth to start the cycle of life again. "In this worldview, there is an intimate link between the human and nonhuman worlds, and between all the phenomena of the universe. This concept of reciprocity and interdependence generates indigenous peoples' moral responsibilities to the environments they inhabit" (Day 2015: 2). 
In the previous sections, I have outlined how I developed my Chicano Border Methodology by looking at the structure of coloniality and the colonial matrix of power and epistemic privilege/inferiority, which led into my decision to use the epistemological pluralism as a framework for my methodology. By adding the core tenets of being a performative, transformative methodology that includes mind, body and spirit, I changed epistemological pluralism into a decolonising epistemological pluralism. The next step is to apply my locality of La Frontera/US-Mexico border to create a Chicano Border Methodology. This methodology uses a knowledge space that is specific to this locality which is what I explain in the following section.

\section{Knowledge spaces}

A multitude of methodologies have been and are being developed to give space and to establish a place within the academy for the different ways of knowing.

The emergence and expansion of a discrete academic discourse called Indigenous knowledge internationally, and mātauranga Māori in Aotearoa New Zealand, presents some wonderful and substantive challenges to conceptions of knowing and being, of knowledge creation, knowledge work and the making of meaning. These challenges engage us across philosophical, disciplinary, institutional, inter-generational, territorial and community boundaries and present an exciting opportunity to imagine this old/new field and the theories and methodologies that inform contemporary Māori and/or Indigenous Studies (L. T. Smith et al. 2016: 1).

Indigenous scholars and academics are searching for ways to "de-colonise the academy" (George J. Sefa Dei 2000; Denzin et al. 2008a: 21; Mihesuah and Wilson 2004; L. T. Smith 2005). For the academy to be de-colonised, Grosfoguel says that the academy needs to change the core values it currently adheres to by:

1) acknowledging the provincialism and epistemic racism/sexism that constitute the foundational epistemic structures as a result of the genocidal/epistemicidal colonial/patriarchal projects of the 16th century;

2) breaking with the uni-versalism where one ("uni") defines for the rest, in this case, the one is Western man epistemology; 
3) bringing epistemic diversity to the canon of thought to create a pluri-verse of meanings and concepts where the inter-epistemic conversation among many epistemic traditions produce new re-definitions of old concepts and creates new pluriversal concepts with "the many defining for the many" (pluri-verse) instead of "one for the rest" (uni-verse) (Grosfoguel 2013: 89) .

I see this epistemic diversity or pluriversity as a place that can be built around what David Turnbull calls a third space “...where Western science and localized knowledge spaces can work together, an interstitial space. A space that is not only the representational side of knowledge but a space where the performative side of knowledge is included" (Turnbull 1997: 560). He goes on to say, "If knowledge is recognized as both representational and performative it will be possible to create a space in which knowledge traditions can be performed together"(Turnbull 1997: 561). This space Turnbull is talking about is very similar to the principles of a decolonising epistemological pluralism.

There has been a growth in knowledge spaces for the Chicanos in the academy starting in the late 1960s. A major breakthrough for the formulation of Chicano knowledge spaces occurred during the Chicano Rights Movement with the establishment of the UCLA Chicano Studies Research Center (CSRC) in 1969. Since its inception CSRC has consistently published research on Chicano knowledge and culture in its journal AZTLAN: A Journal of Chicano Studies. In the same year the first Chicano Studies department was created at California State University, Northridge in Los Angeles. Now most universities in the United States have a Chicano Studies department on campus.

For those who see themselves as Native Americans, according to a list put out by the National Indian Education Association (NIEA)(Lechusza 2015) there are now 150 colleges or universities that have AA, B.A or PhD programs in Indian Studies in the USA. In Canada, out of the 96 universities listed, the University of Toronto, University of British Columbia, York University, Wilfrid Laurier University, University of Victoria, University of Alberta, Trent University, and Queen's University each have First Nation, Native American or Indigenous doctorate programs.

In Aotearoa New Zealand seven of the eight mainstream universities have a Māori Studies department which have undergrad and postgrad programs. My department is Te Kawa a Māui/School of Māori Studies at Victoria University in Wellington 
New research is being published in books, journals and electronic publications like MAI Journal: A New Zealand Journal of Indigenous Scholarship, NAISA: Native American and Indigenous Studies Association and AlterNative: An International Journal of Indigenous Peoples in Aotearoa New Zealand, highlighting the latest and newest research methodologies and viewpoints.

\section{Borders}

Each culture has its own localised knowledge that is grounded in its locality. It is built around the environment, history and the social structures of a particular group in a particular area. An example of this localised space is Mātauranga Māori, the knowledge that was developed by the Māori in their homeland of Aotearoa and their long history in Oceania. They developed a cosmology that started when they arrived to Aotearoa around 1350 (Howe 2006: 89), long before Abel Tasman sighted Aotearoa in 1642 (Wilson 2016: 2) that reflects the local knowledge that Māori use to guide their everyday lives.

My local knowledge is from La Frontera/US-Mexico border. We have our cosmology, legends and creation stories. This knowledge can be seen in practice, from the mixing of languages, murals, clothing and even the cars as discussed in chapter one. All of these items are influenced by the border region and could not have developed in this way anywhere else in the world.

My local knowledge gave rise to my Chicano Border Methodology that I developed at the "Cultural Interface" (M. N. Nakata 2007: 198) of the Mexico-US border. Martin Nakata describes the Cultural Interface as not as an intersection, “...but as a much border interface... but this is not restricted to cultural specificities"(M. N. Nakata 2007: 198). The Cultural Interface is multilayered and responsive to the collisions of intersecting points of the political, economic, gender, historic and time of a place, which are contested on the spiritual, conscious and subconsciousness levels of difference between the competing interests that are encountered in this space at any given time. This is how I experience La Frontera/US-Mexico border.

I began my journey in life as a border crosser. My work reflects the political, cultural and economic realities of life along La Frontera/US-Mexico border. Modern-day borders are not naturally occurring spaces. They are artificial constraints created "in the very constitution of the modern/colonial world"(W. D. Mignolo 2006: 208) by the powers that shaped the regions over the last five hundred years, delineating ownership and control of the geological, economic, 
environmental, social, and political space. These borders were documented on maps that ignored the already established pathways and boundaries developed by the local Indigenous populations over hundreds of years. These colonial borders control the rivers of people, materials and culture that flow back and forth across these regions and are driven by the forces of the two nationstates who control the flow, which share an ambivalence to the Indigenous populations that inhabit these border spaces.

My experience of La Frontera is the border that exists between San Diego, CA, my place of birth, and Tijuana, Mexico. This is the space where I, a Chicano Native American, grew up and lived in. One moment I'm in a world of consumerism and waste, where everything has an expiration date, advertisements constantly touting new stuff to buy, people driving expensive cars filled with cheap fuel, having the latest electronic gadgets, wearing the latest fashions, eating like kings, consuming a large portion of the world's food and resources, a country that prides itself as a world leader, a country where immigration policies are sometimes implemented with a decided lack of compassion and reason.

With a step in the other direction, I'm standing on the other side of the border, where many are struggling to find food and work, living in cardboard houses on the sides of hills that sometimes wash away during the winter storms, where some places have power and water while in others people have to walk a long distance to get water or to use power, where people never see darkness because of the spotlights on the border wall are shining into their homes, where the drug war is fought on a daily basis with casualties mounting daily, where migrants and refugees from Central America, Africa and the Middle East, fleeing from wars, violence and poverty, gather hoping to make it to the other side.

I am not the first person to write about this space, a space full of contradictions. Anzaldúa writes about these same issues and expresses some of the same feeling that I have. It is in her writings that I, a Chicano male, can get confirmation/validation of my experience and existence in the borderlands. We are all kindred spirits living our lives in this liminal space.

This border of my childhood and adult life in the twentieth and twenty-first centuries is a border different than the border first created in the 1840s, which was just a line drawn on a map across a vast desert. In the beginning there were a few soldiers and people scattered along the 2,000-mile border (John 2012). Now there are millions of people living and working on both sides of this 
border. This border now has walls, lights, armed security, checkpoints, and a thriving economy on both sides. A border that has its own culture, language and worldview.

Borders' will be in the twenty-first century what 'frontiers' were in the nineteenth.

Frontiers were conceived as the line indicating the last point in the relentless march of civilization. On the one side of the frontiers was civilization; on the other, nothing; just barbarism or emptiness. The march of civilization and the idea of the frontiers created a geographic and body-graphic divide. (W. D. Mignolo 2006: 205)

To live in this space Chicanos/as developed “Border Thinking”(W. D. Mignolo 2006: 206) which is grounded in our experiences living in a place that has many different names. Pratt calls this a "contact zone"(Mary Louise Pratt 1991: 34), the contested space between different colonising forces. Anzaldúa refers to it as the Borderlands, where we live in a state of "nepantla", the Nahuatl word for an in-between state, that uncertain terrain one crosses when moving from one place to another (Anzaldua 1993). We adapted to living in this contested space and developed the decolonising tools that enabled us Chicanos/as to survive along La Frontera.

San Diego - Tijuana is my particular border, my cultural interface, my contact zone, where I first became consciousness of living in a state of nepantla, where I developed my border consciousness, where I organically began thinking of borders. This is the Border Thinking that Mignolo talks about and refers to as an epistemology: "that this Border Thinking is the epistemology of the future, without which another world will be impossible" (W. D. Mignolo 2006: 207). These borders are not natural occurrences. They are the conceptual and physical constructs of the colonial world we live in. La Frontera is where the different knowledges and cultures merge, blend and question the hegemonic discourse of the colonial world, where "people refuse to be geographically caged, subjectively humiliated and denigrated and epistemically disregarded" (W. D. Mignolo 2006: 208). This is where decolonisation, empowerment, and liberation happen every day.

\section{Crossing}

There is a no man's land that I have travelled through many a time during my life, a space that is the condensed physical representation of the liminal space that I carry inside me as a Chicano. It is the San Ysidro border crossing which goes from San Ysidro, the southernmost part of San Diego, to Tijuana, Mexico. 
Most of my life crossing into Mexico was simple. We would come flying off a five-lane super highway down to four lanes across a few topes (speed bumps) through a couple of barricades where we would come to four toll booths. Each one would have a stop signal. As we approached the light, the light would flash either green or red. If it was green, we would drive right through without stopping, wave to the customs officer and be in Mexico. If the light turned red, we would stop and be directed toward to an area called secondary. In secondary, a Mexican customs officer would be waiting to ask a few questions, like "What is your business in Mexico?" We would say we are doing some shopping and then he would let us through. I have only stopped in secondary twice in my life.

For most of my life this is what would happen: we would drive through the toll booths whether or not the light was green or red. As we passed the booth, the Mexican customs officer would franticly wave us into secondary. We would pretend that he was waving hello and wave back and keep going into Mexico. A hundred meters later, we would be in downtown Tijuana. It was a friendly experience as you transitioned from the US to Mexico.

Coming back into the US from Mexico was very different. As we left Tijuana, we would enter a transition zone about one kilometre before reaching the US border. We would drive down a twolane, concrete road down to the Border Zone. If we were crossing during rush hour (4pm to $7 \mathrm{pm})$ or on the weekend, traffic would come to a stop, and we would crawl along in stop and go traffic as two lanes turn into four, then into eight then into 22 lanes. On the right side we would see a series of small shops selling every imaginable piece of Mexican souvenir available to humankind, the last chance for tourists to buy something as a memory of their adventure in Mexico. There would be men carrying selected items from the shops, running around the cars, hawking their wares. These could be large Mexican blankets with tigers, ceramic monkeys, toy cars, Winnie the Pooh banks, velvet paintings of Elvis, pots and pans, hammocks, ceramic Mexican calendars, Bart Simpson banks, necklaces, bed frames and mattress plus a million more bargains that couldn't be missed. Often, we would be moving so slow that we would have conversations with the salesmen, who, as soon as they saw we were looking in their direction, would come over and bring the objects of our desire for us to look at while we would haggle about the price.

Roaming between the slow-moving vehicles waiting to cross the border would be an army of small two-wheeled carts selling Cokes, water, chips, dulces (Mexican treat), churros (fried pastries), and chicharrón (fried pork rinds). Also, amongst the noise, smog and heat of the 
vehicles, walking with boxes of chicle (Mexican gum) for sale, would be the Indigenous women of Mexico, most carrying a small baby strapped to their chest and maybe two small children with them. We would watch the little kids darting and running between the slow-moving traffic, as their mother walks between the cars trying to sell her chicle.

The lanes of traffic would converge and expand at different points depending on how many custom officers were working at the time. There could be anywhere from 16 to 22 lanes of traffic. We would see people fighting to get into the fastest moving lanes only to have that lane come to a stop further down the road because of a stalled or overheating car in the lane.

About 50 meters before the border, we would see men wearing CBP (Customs and Border Patrol Agency) vests, walking among the traffic letting their dogs sniff the cars as they go by looking for drugs. We would try not to make eye contact with them. Ten meters before we would reach the border, we would cross a speed bump which indicated that we were now in US territory. We would enter a section separated by concrete barriers and yellow painted steel poles with signal lights indicating whether we could enter or not. When we would stop to wait for the border agent, cameras would automatically take photos of us and our vehicle. This information would be sent to the national police database to see if we or our vehicle were wanted by state, or federal law enforcement agencies.

When we are cleared, the light would turn green and we'd move forward toward the border patrol officer in the booth. He would ask, "Can I have your ID? Are you a US citizen? Are you carrying any drugs or guns? Would you like to declare anything?” That would be a good day. If he's having a bad day, he would grill us for five to ten minutes, trying to get us to admit to something illegal or to find a reason to send us to US secondary for a thorough search of our vehicle and our persons, whether or not we have done anything wrong. An hour or two later we would take what's left of our vehicle and our dignity, go through the border and into the US to do what we want. This has happened to me many times.

(Note: these are my memories of crossing the border over many years. A few years ago, the vendors were unionised, and for safety reasons the Indigenous women and their children were forbidden to walk within the moving traffic. As of June 2009, with the enactment of the Western Hemisphere Travel Initiative, US citizens are required to have a passport to enter and return from Mexico. Before a state driver's license or ID was all that was required.) 
I don't know exactly how many times I have made this journey between these two countries, crossing that border from one world to another and then back but I can estimate the number from my birth until the time when I turned 50 years old when I arrived in Aotearoa New Zealand. I made that crossing an average of once a week with my family to go shopping. Fifty years multiplied by 52 weeks equals 2,600. I take 104 weeks off or two years for when I was out of town. This equals 2,496 times. Rounding that down to make up for other miscellaneous times when I could not go, that makes it an even 2,400 times I've crossed La Frontera, and every time was different.

By my estimation, the average time to cross into Mexico equals 0.25 hour and the average time to enter the US equals 2.25 hours. This means just to cross La Frontera and return home would take me two and a half hours round trip. Multiply that by 2,400 to get 6,000 hours, divided by 24 hours in a day and I have spent 250 days of my lifetime crossing La Frontera.

That was 250 days of my life that I witnessed the cold hard physical reality of the new twentyfirst century frontier, the geographic and body-graphic divide of colonialism.

To do this border crossing I experienced a microcosm of each of the intersecting points of contention that one encounters when one enters a contested space or when one enters a cultural interface. I experienced the political, economic, cultural, gender and social dynamics of intersecting points of dominance and subjugation that are at play in these spaces.

As mentioned in the previous chapter, as a result, the Chicanos living in this liminal and contested space have developed a tri-consciousness that uses a plurality of knowledges, the localised indigenous knowledge, the colonial Mexican knowledge and the colonial United States knowledge. As a Chicano I live this tri-ality of everyday life on a physical, mental, and spiritual plane at the Cultural Interface, coming to grips with our shared history as Indigenous people surviving the European genocide/epistemicide of the Americas.

\section{Language and Code-Switching}

One of the ways I express my Chicano tri-consciousness is through Spanglish. Spanglish is a simplified word to explain a braiding of languages but is not limited to just Spanish and English. Spanglish fuses Spanish and English and local Indigenous languages of North America, such as Nahuatl. Spanglish developed along La Frontera for generations and is one of the distinct ways we can identify ourselves to one another. Spanglish (also known as Border Spanish) is said to 
have originated in the Southwestern United States and Northern Mexico in the 1840s as the Western expansion of the US was in full speed (Logan 2005: 391). Spanglish is a natural outgrowth of people living at the intersection of nation-states and cultures, as Mignolo finds "languages are not something human beings have but they are part of what human beings are. As such, languages are embedded in the body and in the memories (geo-historically located) of each person" (W. D. Mignolo 2006: 207).

At any given moment night or day at La Frontera, Spanish, English and Nahuatl can be heard to be spoken in a single sentence. This switching between languages is called code-switching (Martin 2005: 404) and has been studied for years by sociolinguistics around the world. When Spanglish is spoken to people from La Frontera, they will not even notice; it is so common place. But when spoken to someone who speaks only Spanish or English, they will often be confused and have a hard time understanding or following the conversation. In both the US and Mexico, Spanglish is looked down upon. Mexicans refer to Chicano code-switching with the derogatory term pocho. Fernando Peñalosa, in his book Chicano Sociolinguistics explains that the word pocho originally meant discoloured, faded or referred to a horse whose mane and tail had been clipped. It came to be used by Mexicans to refer to their Americanised compatriots in the United States, particularly with reference to their habit of substituting English words in their Spanish speech (Penalosa 1980: 73).

However, this braiding of languages allows for a more complex view of the world and allows for the expressions of ideas and concepts that would not be possible or would be harder to define or would lose their meaning when translated into another language. This tri-culturality is the back bone of the Chicano perspective. Both Alfred Arteaga and Gloria Anzaldúa address the importance of this code-switching in Chicano culture and the need to embrace it as a legitimate and vital mode of communication. Arteaga writes in particular about Chicano/a authors who must span the differences not only between their Spanish and Indigenous ancestry, but also between their Mexican and Anglo identities: "Their use of the heterotext expresses the split they struggle with in their identity as Chicanos and as US Americans" (cited by Martin 2005: 405). In her book Borderlands, Gloria Anzaldua talks about the important of Spanglish and code-switching for Chicanos and the pride and respect that Chicanos should feel toward it as part of their Chicano identity:

...the switching of 'codes' in this book from English to Castillian Spanish to the North Mexican dialect to Tex-Mex to a sprinkling of Nahuatl to a mixture of all these, reflects $\mathbf{7 4} \mid \mathrm{P}$ a g e 
my language, a new language---the language of the Borderlands. There, at the juncture of cultures, languages cross-pollinate and are revitalized; they die and are reborn. Presently this infant language, this bastard language, Chicano Spanish, is not approved by any society. But we Chicanos no longer feel that we need to beg entrance, that we need always to make the first overture---to translate to Anglos, Mexicans and Latinos, apology blurting out of our mouths with every step. Today we ask to be met halfway (Anzaldúa 1987: viii).

This braiding of languages is not just a replacement of words but a way of conceptualising thoughts and processes that could not be expressed in just one language. One language may not have the correct word to convey an idea but another language may have the perfect word to express it, but it does not stop there. We sometimes combine words together making new words, like luncheria (a place to have lunch), se renta (to rent something), mofles (muffler of a car). This new way of expression can only occur in a space where the understanding, acceptance and validation of different knowledge spaces exist. In the context of La Frontera, a space where a plurality of knowledges takes place, Spanglish is an example of the norm.

\section{Chicano Border Methodology}

To summarise, my Chicano Border Methodology uses epistemological pluralism as a framework to create a decolonising epistemological pluralism that is performative, transformative and includes mind, body and spirit. It is based on the local knowledge space of La Frontera that uses a tri-consciousness that has been developed by Chicanos at the cultural interface between US and Mexico.

\section{Indigenous knowledge and other methodologies}

In this section, I explore how Chicano Border Methodology fits within the Indigenous knowledge paradigm and how it compares with other methodologies such as intersectionality, Kaupapa Māori, and Insurgent Research Methodology.

Chicano Border Methodology and Indigenous knowledge

Ahenakew articulates the difference between empirical knowledge and Indigenous knowledge production by citing Ermine and adding to his description. Empirical knowledge searches for certainty, predictability, and control of the natural environment while Indigenous knowledge, which involves interactions with a constantly changing reality consisting of human and nonhuman relations (Ermine et al. 1995), is based on the understanding that the creation of meaning 
about this life force will always be provisional, contextual, and subjective (C. Ahenakew 2014a: 12). "It is part of a dynamic system, it's an integral part of the physical and social environment of the communities and it is for the collective good" (Viergever 1999). In this light Chicano Border Methodology shares many of the same principles as other Indigenous methodologies. It is the dynamic, physical and social environment of the community of people along the US-Mexican border. Chicano Border Methodology works to change "“[e]pistemic sovereignty” that produces 'representational perspectives that both maintain their authority and deny legitimacy to rival perspectives"' (Stephen Healy 2003b: 693) by creating a space where different knowledges can co-exist on an equal and balanced platform.

By the nature of its structure, Chicano Border Methodology is a political and resistive epistemology that rejects the notion that there is only one true view of the world, arguing for a multiplicity of knowledges to understand a given situation. Chicano Border Methodology was not based on or created by an individual; it functions through a collaborative model created by the people who live and work along the US-Mexico border. This means that it is not an "I" but a "We" model of interaction that uses knowledge that is locally produced.

Chicano Border Methodology is crossing over from what Boaventura de Sousa Santos calls "the other side of the line [italics in the original]", where "there is no real knowledge; there are beliefs, opinions, intuitive or subjective understandings, which, at the most may become objects or raw material for scientific enquiry" to "this side of the line [italics in the original]" (Santos 2007: 47) the western scientific world using some of the same tools that western science uses to continue to change the boundaries of what is considered to be true knowledge in the world. Chicano Border Methodology is not based on the western scientific model of research, but it can utilise western science as one of a group of knowledge spaces to use in research as well as use western science to critique western science from an Indigenous perspective.

\section{Chicano Border Methodology and intersectionality}

The term "intersectionality" was first coined by Kimberie Crenshaw (Crenshaw 1989) and developed during the 1990s by women of colour who were dissatisfied with the feminist movement that was focused on the position of white women in society and was not inclusive of women of colour. For women of colour, feminist theory did not account for the difference between the experiences of white women and women of colour. Women of colour brought to the forefront not only the difference in gender to men but also highlighted the differences 
between each other's social, racial and economic positions, stating that a white woman's experiences are different than a woman of colour's experiences, and a rich upper class, black woman's experiences is different than a middle or lower economic class black woman's experiences. Intersectionality is a methodology that takes in consideration not only race but also gender and economic status when looking at issues of discrimination whether in the courts, in the education system, or in society in general. "Intersectionality underscores the 'multidimensionality' of marginalized subjects' lived experiences" (Crenshaw, 1989: 139).

Several Chicano researchers have used intersectionality as a method for Chicano/a research, Elvia Ramirez (2013), Patricia A. Jaramillo (2010), and Jennifer G. Correa (2011) to name a few. However, they used intersectionality in conjunction with other methodologies. Similarly, intersectionality could work within the framework of Chicano Border Methodology for researchers who are looking at specific issues that could benefit from an intersectional perspective and the inclusion of intersectionality could generate valuable knowledge for the appropriate project.

However, intersectionality's focus on static markers to determine its results limits its ability to compensate for the liminal existence and fluidity of La Frontera. The uniqueness of the locality and the constantly changing intersection between the two nation-states over an Indigenous population would be difficult to reconcile with intersectionality alone. In my research I am looking at not just one culture in a static environment but several cultures that clash all the time and whose cultures have different attitudes toward race, gender, economics and religion- a place where attitudes ebb and flow. So, I, a Chicano male, find intersectionality is not as good a fit for my particular research.

\section{Chicano Border Methodology and Kaupapa Māori}

In Aotearoa, Māori have been at the forefront of Indigenous methodology development around the world since the 1990s with seminal writers like Linda Tuhiwai Smith, Mason Durie, and many more developing Kaupapa Māori. How is Chicano Border Methodology similar or different from Kaupapa Māori?

I developed Chicano Border Methodology on Turtle Island (North America), living at the intersection of two settler nation-states, a non-static area moving at any given moment to another space or situation. Kaupapa Māori is a methodology that was developed at the intersection of an 
Indigenous population, the Māori, and the European coloniser/settler on the last colonised island in the South Pacific as they wrestle with the complexities of a bi-cultural society.

Kaupapa Māori is a research process designed to guide Māori researchers doing research with Māori, for Māori. At the beginning, Kaupapa Māori had a strong set of recommended guidelines from a culturally specific viewpoint for every Māori researcher who planned on pursuing a Māori research project (L. T. Smith 2000a). These guidelines were expected to be followed in order to be considered valid Māori research. One of the guidelines was the researcher had to be Māori to use Kaupapa Māori. This guideline was a response to the history where most research on Indigenous cultures was done through the eyes of the western colonist. Western researchers were looking in from the outside, using their western perspective to analyse non-western cultures. As the people with the local knowledge, Māori feel they are the best people to research and write about Māori. Māori need to tell their own stories and give context and meaning to their stories.

Other guidelines for research using Kaupapa Māori are listed in Fiona Cram's Rangabau Māori: Tōna tikea, tōna pono - The validity and integrity of Māori research (Cram 2001):

1. A respect for people: about allowing people to define their own space to meet on their own terms. Kathy Irwin sets out guidelines for this that she calls the 'rituals of first encounter' (1994: 36).

2. He kanohi kitea: About the importance of meeting with people, face-to-face.

3. Titiro, Whakarongo... Korero: About the importance of looking and listening so that you develop understandings and find a place from which to speak.

4. Manaaki kit e tangata: About collaborative approach to research, research training, and reciprocity.

5. Kia tupato: About being politically astute, culturally safe and reflective about our insider/outsider status.

6. Kaua e takahia te mana o te tangata: don't trample the mana of the people.

7. Kaua e mahaki: Don't flaunt your knowledge (2001).

Similarly, Linda Smith puts forth a set of questions for Māori researchers to ask before they begin their research: "What research do we want to carry out? What is the research for? What difference will it make? Who will carry out the research? How do we want the research to be done? How will we know it is a worthwhile piece of research? Who will own the research? Who will benefit?" (2000b: 239). 
These questions and guidelines are very important to the Māori researcher. The guidelines show the strong ethics and moral consciousness embedded in Māori research. Kaupapa Māori is addressing a lot of the same issues as Chicano Border Methodology. My proximity to Kaupapa Māori research here in Aotearoa influenced my thinking about the structure of my Chicano Border Methodology. Locating my research in Te Kawa a Māui/School of Māori Studies gave me the opportunity to learn about this framework and how I could adapt some of its principles for my Chicano Border Methodology. However, I have a slightly different set of questions that are directly relevant to my work along La Frontera.

In chapter two, I talked about how I was involved in several projects that used a form of Chicano Border Methodology under the banner of multiculturalism. I then discussed how in later projects I made the conscious decision to use a form of Chicano Border Methodology as the base of my collaborative process. As a result of this work, I find that at the beginning of every project, there needs to be a conscious decision whether or not to use Chicano Border Methodology. Below are some key questions I have developed that should be asked when contemplating using Chicano Border Methodology:

- What is the purpose of this project?

- Who is the project for?

- What are the issues that the project needs to address?

- Who are the people involved in the project?

- Are the participants willing to commit to an epistemological pluralism process?

- What is the project's participants' connection to the community?

- Does the project involve the local community?

- What is the perceived impact that the project will have on the local community?

- What are the potential benefits for the community?

- How will the project be connected with the location?

- Why is the location important to the project?

- What does this project expect to solve, change, or illuminate?

These questions are the core of my methodology. They are a basic framework under which I work. These are the questions I ask myself before I decide to use a de-colonising epistemological 
pluralism in a collaborative project. I then ask each potential collaborator the same questions, and if we can all come to a consensus on the answers to these questions, we start the project.

\section{Chicano Border Methodology and Insurgent Research}

Is Chicano Border Methodology an insurgent research methodology? In his article "Insurgent Research", Adam J.P. Gaudry, outlines the four key principles for such a methodology:

1. Research is grounded in, respects, and ultimately seeks to validate Indigenous worldviews.

2. Research output is geared toward use by Indigenous peoples and in Indigenous communities.

3. Research processes and final products are ultimately responsible to Indigenous communities, meaning that Indigenous communities are the final judges of the validity and effectiveness of Insurgent research.

4. Research is action oriented and works as a motivating factor for practical and direct action among Indigenous peoples and in Indigenous communities” (Gaudry 2011: 117).

In Chicano Border Methodology, each step is geared toward our communities in that they will be able to use the research and findings from our project to further the needs of our community. Chicano Border Methodology is always responsible to its community. Chicano Border Methodology is based on the principle that we take an action. That action can take many different forms depending on the project, but action is a critical part of the methodology. According to these principles, Chicano Border Methodology is an Insurgent Research Methodology. Everything above fits within the epistemological framework of Chicano Border Methodology. It is about creating a space for Indigenous worldviews, geared toward and judged by Indigenous communities and is action-oriented by finding solutions to problems rather than waiting for them to be solved by someone else.

\section{Conclusion}

In this chapter, I discussed the major components that contributed to the creation of a Chicano Border Methodology: the uniqueness of the location of an Indigenous group at the intersection of two nation-states, living in a liminal and contested space; the development of code switching and the ability to go from one thought process to another in a single moment; how we externalised this process with the creation of our Spanglish and other demonstrations of culture 
and identity; and acknowledging that these are positive responses to the forces being applying to the border area.

I talked about how Chicano Border Methodology is working within an Indigenous knowledge space. This Indigenous knowledge space has been created by Indigenous academics and scholars within universities, using various methodological models that reflect our ongoing struggle to break away from the western point of view. I have shown that my Chicano Border Methodology, using the framework of a decolonising epistemological pluralism, is another tool that can be used in this struggle. I also discussed Chicano Border Methodology in relation to Kaupapa Māori research, intersectionality, and insurgent research. In the following chapter, I will take a step sideways across another border and position myself in relation to the current state of art theory. 
$\mathbf{8 2 | P}$ a g e 
Art $\mathbb{T h e o r y}$

chapter four 
$\mathbf{8 4}$ |P a g e 
ReSIS--tance art, )art as resistance(, IN-surGENT re- Search,

installation art. ArT as research, re-search as Art,

HCI(Human Computer interface) art

Political ArT, Performance art,

New media art :-, COllaboration art,

ACTION---- art [solo] art

FIIM AR'I', sound art, computer art, electronic arts

\section{ART THEORY chapter four}

\section{Chicano Border Methodology and art methodologies}

As a visual artist, why did I choose not to use any of the art methodologies I learned in art school for my thesis project, especially since I used the creation of an interactive installation as an example of my methodology in practice? In this chapter, I talk about the relationship between my Chicano Border Methodology and the practice-led art research, highlighting the crossovers as well as the differences between my Chicano Border Methodology and the practice-led art research.

In chapter three, I discussed how I developed my Chicano Border Methodology using a decolonising epistemological pluralism framework. I explained how that methodology was conceived at La Frontera/US-Mexico border, how this methodology uses Border Thinking, and how this Border Thinking is in each Chicano/a who grew up along La Frontera. I have also shown that this Border Thinking differentiates us from other Chicanos/as in the rest of the US. So how does my Chicano Border Methodology sit with practice-led art methodology? Very rarely are there clear-cut delineations between methodologies where one methodology is completely different than this other one. Generally, there are intersecting points, crossovers and border crossing which blur the lines between which aspect belongs to which methodology.

\section{Practice-led research}

Practice-led research is a framework that many artists use and adapt for their research. As a result, there are numerous art methodologies depending on the artform, e.g. painting, dance, theatre, etc., that the artist uses to conduct her/his research: practice-based research, practice-led research, creative practice as research, practice as research, or research as practice. 
What is practice-led research? "Practice-led research has been developed by creative practitioners, partly for political purposes within higher education, research and other environments, to explain, justify and promote their activities, and to argue - as forcefully as possible in an oftenunreceptive environment" (H. Smith 2009: 2). Practice-led researchers are arguing that their research models are just as valid for producing new knowledge as other research models used in other disciplines. This pursuit of acceptance is similar to Indigenous researcher but the big difference is that art and art education is already part of the western education system. This is one of the places where my research deviates from the practice-led research method in that my focus is from an Indigenous point of view, not from a western art viewpoint.

Carole Gray, a leading practice-led researcher, has defined practice-led research as: "Firstly, research which is initiated in practice, where question, problems, challenges are identified and formed by the needs of practice and practitioners; and secondly, that the research strategy is carried out through practice, using predominantly methodologies and specific methods familiar to us as practitioners" (Gray 1996: 3).

Practice-led researcher Brad Haseman believes that Gray's practice-led research is an effective and serviceable term. Haseman further clarifies Gray's definition by saying:

It describes what practitioner-researchers do, captures the nuances and subtleties of their research process and accurately represents that process to research funding bodies. Above all, it asserts the primacy of practice and insists that because creative practice is both ongoing and persistent; practitioner researchers do not merely "think" their way through or out of a problem, but rather the "practice" to a resolution (B. C. Haseman 2007: 147).

Practice-led research practitioners tend to get an idea or concept and then start to make it happen. These artist researchers are not sure where their idea or concept is going to take them, but they just go ahead and do it, solving their problems as they go until they finish the project. This happens whether the researcher is developing new technology or designing with new materials or creating a new performance. As Haseman says:

...many practice-led researchers do not commence a research project with a sense of 'a problem'...Practice-led researchers construct experiential starting points from which practice follows. They tend to 'dive in', to commence practicing to see what emerges. 
They acknowledge that what emerges may be individualistic and idiosyncratic" (B. Haseman 2006a: 100).

\section{The six conditions of practice-led research}

Haseman has outlined what he calls the six conditions of practice-led research (B. Haseman and Mafe 2009: 4-7). Chicano Border Methodology has similarities to some but not all of these conditions. As I go through the conditions, I will highlight the differences between practice-led research and Chicano Border Methodology.

The first is "resolving the 'problem' of the research problem" (B. Haseman and Mafe 2009: 4). Contrary to the usual approach to research, i.e. identify the research problem or question at the outset, practice-led researchers generally do not know what the problem or question is at the outset of their research because their question or problem arises during their research practice. A key aspect of their research is encountering problems or questions during their research and resolving them to the best of their ability. This is different than my research because I already have a research question: what is Chicano Border Methodology? In my thesis I am answering this question by visiting my past and reconstructing the development of my methodology.

The second is "repurposing methods and languages of practice into the methods and language of research" (B. Haseman and Mafe 2009: 5). This is very important because what it means is that what artists use in their art practices become their research materials. Such items as sketches, video documentation, writings about ideas, experiments with different materials and interviews with audience members would be considered as valid research materials to be written about and used in theses. My thesis is repurposing different materials as research materials such as video documentation, interviews with audience, and installation art to demonstrate my methodology in action.

The third is "identifying and deploying emerging critical contexts which are networked out of his or her practice" (B. Haseman and Mafe 2009: 6). Context, context, context, e.g. doing a dance performance about immigration in front of a detention centre. Practice-led researchers need to identify and explore the various contexts of their work by writing about the different contexts where their work may sit and finally settling on one context and writing their thesis from that contextual position. For me there is no searching for context. I already know the context where my work sits, La Frontera/US-Mexico border from an Indigenous Chicano point of view. 
The fourth is "identifying and engaging with the 'professional' frames within which practice is pursued" (B. Haseman and Mafe 2009: 6). Practice-led researchers need to relate their methods to established methods in academia. Because their research is redefining the edges of pre-existing research frameworks, practice-led researchers must ensure that their research is seen as valid in the eyes of academia while still remaining true their practice. This is a similar position to my research project. I am using as a framework a pre-existing western methodology, epistemological pluralism, and changing it to a decolonising epistemological pluralism and applying it to a specific locality, La Frontera/US-Mexico border to create my Chicano Border Methodology.

The fifth is "anticipating and deciding on possible forms of reporting" (B. Haseman and Mafe 2009: 6). Practice-led researchers are faced with a dilemma to represent their work for consideration and evaluation. Is it in written form as in an exegesis or is it in the presentation of the work to an audience? Or a combination of both? How do practice-led researchers write about their work? Where do their research findings lie in relation to similar work? And is it in a form that is within the established framework of their academic institution? There is no set formal response to these questions; it all depends on the subject matter, the researchers' points-of-view and their ability to negotiate the terms within their institutions. My thesis, too, is negotiating these waters. What is the best way to present my research/story to the academy? The way I decided to present my research was to write about it, using a personal narrative format and using some photos to help tell the story.

The sixth is "deliberating on the emerging aspirations, benefits and consequences that may flow from the demands and contingencies of practice" (B. Haseman and Mafe 2009: 7). In practice-led research projects the initial benefit may be outweighed by future benefits that were not anticipated in the original research outputs. It may take time for the consequences or benefits of any practice-led research to be realised. How can researchers address this in their theses? I think that this is the situation with any form of research; the initial goals and aspirations of any research project can only be articulated from the present moment and if these goals can be articulated by the researcher in their thesis outcomes so much the better, but the future impact of research cannot be fully anticipated. It is for others to determine the future benefits of any research. In saying that, the present goals for my thesis were known at the beginning of my research project. The main goal is to widen the scope of the academy in relation to what it regards as valid research methodologies and knowledge, methodologies that are inclusive of other ways of knowing, such as border knowledge. 
Of the six conditions of a practice-led research, three have similarities to my Chicano Border Methodology, only using a different terminology to describe similar ideas. One is the repurposing of a framework to create a new methodology. The second is engaging with professional frames. In my thesis I am using epistemological pluralism as a framework to create a decolonising epistemological pluralism named Chicano Border Methodology. The third is the importance of the presentation of the work for consideration and evaluation by examiners. I want to make clear that this thesis is not seen as a practice-led research project but is an Indigenous research project using a methodology that I have developed over the course of nearly thirty years. This is because there is a key difference between practice-led research and my Chicano Border Methodology. It is the use of the word "performative" in my methodology. In the next section I will look at how practice-led researchers look at performative in their research and then contrast that with the way I use performative in my Chicano Border Methodology.

\section{Performative research}

Within the context of practice-led research, performative research is an emerging research paradigm. Here, research is perceived as being enacted through the creative process and presentation outcomes and in this way, "they not only express the research, but in that expression become the research itself” (B. Haseman 2006b: 102). In practice-led research projects researchers talk about how their performance, e.g. movie, dance, song, or text, is a research outcome and that the performance itself is research. Practice-led researchers argue that since the performance is their research, the performance is a component of their thesis and should be graded as part of the thesis.

An example of performance in practice-led research that is similar to how I use performance in my research is Maria Adriana Verdaasdonk's thesis Living Lens where she describes her performative research: "The study sites itself within the context of practice-led research, more specifically as performative research, a model that allows for practice to perform its outcomes and processes. Here, the research slips between creative and design research for it includes the development of digital media tools in the overall creative production"(Verdaasdonk 2007: 22). Verdaasdonk sees her development of the software for her installation, writing of the code for her application the design of research as part of her performance outcomes. She argues in her thesis that by using a performative research methodology she can turn this "grab-bag" of disparate theories into a coherent and academically acceptable practice that can stand up to the rigour of academic scrutiny. Whilst her constructs may appear to be a "grab-bag" of disparate 
theories, they form a cognitive process by which to help craft a language and thus articulate the practice. In this way, the study combines an analysis of the work from both a research viewpoint and a personal journey in an interweaving of academic and experiential styles (Verdaasdonk 2007: $6)$.

My thesis project The Illustrated Chicano has some similar elements as Verdaasdonk: my performance recorded in a video, the creation of a body cast, the design portion, the development of interactive software, and the use of touch sensor technology, projection technology and a soundscape. However, there are also key differences. My perspective and framework is from an Indigenous viewpoint. My development and use of technology is not to pursue a technological end but to allow technology to assist me in telling my story.

\section{Performative vs Performative}

"...practice-led research, an approach that is characterised by the tendency for research to flow from experiences arising through practice rather than from questions, problems or issues defined at the outset; and by research outcomes being made through symbolic 'material forms of practice" (B. Haseman 2006b: 100-01). This is where the main difference between a practice-led research thesis and my thesis differ.

My thesis is not about the performance as outcome of my research or part of my research. The thesis is the performative aspect of my research. It is the performance of knowing. My installation The Illustrated Chicano is an example of that knowing in action. When I say that my work is performative, it is coming from a different lineage and contains a different interpretation of the word "performative". Performance theorist Miki Seifert's states that as one of the tenets of a decolonising methodology is that it needs to be performative (Seifert 2011). Seifert is coming from the view of performativity that is detailed in D. Conquergood's paper Performance studies: Interventions and Radical Research (D. Conquergood 2002a: 152) where he quotes Amanda Kemps' book This black body in question, where she says that "performance both as a way of knowing and as a way of showing" (Kemp 1998: 116), in others words performing knowledge or knowledge as performance. "Performative that uses the aesthetic and imagination to create spaces of resistance and intervention; is adaptive and improvisational in order to be grounded in and responsive to the local; and does not separate knowing from its context, knowing from doing and doing from done" (SeifertI 2018: 401). Conquergood sees performance as (1) as a work of imagination, as an object of study; (2) as a pragmatics of inquiry (both as model and method), as an optic and 
operator of research; (3) as a tactics of intervention, an alternative space of struggle (Dwight Conquergood 2002b: 152). This difference of definition of performative is different than the way a practice-led research project views performance. A thesis that is working under the banner of practice-led research is documenting the actions of doing research and that the final outcome or conclusion of that research is the performance and documentation of that performance.

My thesis is performing knowledge, the knowledge of a Chicano who was born and grew up along La Frontera, the border between Mexico and the US., the generations of knowledge of the people who have traversed and lived along this border. Michel de Certeau states in The Practice of Everyday Life "what the map cuts up, the story cuts across" (Certeau 1984: 129). What Certeau is referring to is the cutting up of the world by western colonisation and the building of borders between people and cultures. However, our stories and knowledge have no borders; it constantly traverses these borders. Conquergood says that:

...de Certeau's aphorism, 'what the map cuts up, the story cuts across', also points to transgressive travel between two different domains of knowledge: one official, objective, and abstract--- 'the map'; the other one practical, embodied, and popular- 'the story'. This promiscuous traffic between different ways of knowing carries the most radical promise of performance studies research. (D. Conquergood 2002a: 145)

This is what Chicano performativity is about; it is all about the map and the story. The knowledge that is present is about every day events that make up our existence at the cultural interface, which is La Frontera. "Chicano performativity emerges as a more complex phenomenon than either nationalist withdrawal or cultural hybridization. It is, instead, an identity predicated on the dynamic interaction of those two impulses" (Belgrad 2004: 264).

The outcome of my research is not the production of the installation The Illustrated Chicano but the writing of my thesis. The creation of The Illustrated Chicano is just an example of this knowledge in practice. As Conquergood says, "Performance studies struggles to open the space between analysis and action, and to pull the pin on the binary opposition between theory and practice. This embrace of different ways of knowing is radical because it cuts to the root of how knowledge is organized in the academy" (D. Conquergood 2002a: 145-46). In this thesis, I am discussing how I used my Chicano Border Methodology to create The Illustrated Chicano and The Illustrated Chicano is an example of how this methodology works. 


\section{Conclusion}

In this chapter, I have investigated what are the commonalities and differences between practiceled research and Chicano Border Methodology. I have shown that the key differences between the two methodologies are the Indigenous knowledge perspective of my methodology and the concept of performative. Performativity is a key component to a decolonising methodology and this explains why my Chicano Border Methodology is not an art methodology but can be used in an art context as a research tool. This chapter also points to the benefit of using a flexible research model that provides space for research projects to conduct research using more than one methodology, to allow methodologies to flow across borders. This further validates my Chicano Border Methodology—as a legitimate research methodology. 


\section{Uhe Zllustrated Chicano Innstallation chapter fíve}


$94 \mid \mathrm{P}$ a g e 


\section{THE ILLUSTRATED CHICANO INSTALLATION chapter five}

In the previous chapters I talked about Chicano Border Methodology, which is an internal process that I have externalised as a collaboration tool to work with other researchers on decolonising projects. I also mapped out my re-construction of this methodology. Since this is an internal process developed along La Frontera by Chicanos/as, this Chicano Border Methodology can also be used by a single Chicano/a on a project as a means to do individual research. This chapter is a discussion of how I used my Chicano Border Methodology to create The Illustrated Chicano, an interactive installation talking about place and home from my Chicano perspective. This installation was a demonstration of my Chicano Border Methodology in a sole researcher context. I begin this discussion with revisiting Laenui's phases of decolonisation and how this relates to me and my work.

\section{Decolonisation}

In chapter three, I discussed the decolonising process articulated by Hawaiian sovereignty activist Poka Laenui. His five phases of decolonisation are: Re-discovery/Recovery, Mourning, Dreaming, Commitment, and Action. As Laenui notes, this is not a linear process, "Each phase can be experienced at the same time or in various combinations. Like the steps of colonisation, these phases of decolonisation do not have clear demarcations" (Laenui 2000: 2). In this chapter I discuss how my journey relates to these phases, sometimes they are distinct phases while other times they are braided together. I begin with my re-discovery and recovery of my Chicano identity,

My purpose in creating art has always been to expose the injustices and to help not just Chicanos but any oppressed people to foster change. This sensibility was developed during the 1970s. Growing up as a Chicano in Southern California, I was exposed to and experienced racial prejudice from an early age. I watched as the civil rights era unfolded in front of me. I watched as El Movimiento (Chicano Rights Movement) took off. El Movimiento created a lot of changes in its time that made life better, but there was still a lot of work that needed to be done. For instance, a lot of the same racial prejudices are still in existence as the 2018 US immigration laws targeting the people south of the US-Mexico border attest to (NOLO 2018: 1).

The seventies could be considered my re-discovery phase as well as my mourning phase. I was forming my identity as a Chicano by standing up and taking part in the protest marches against racism and inequality. I was recovering from the forced loss of my native identity by the 
educational system in the schools that I attended. At the same time, I was lamenting my own victimisation as a brown person in Southern California. I can still remember how it felt to be on the street, feeling the presence of a police car before I could see it rounding the corner, and knowing that walking/driving while brown had very real consequences. Unlike Chicanos from other parts of the country, I lived in the Borderlands and was fortunate enough to still be connected to my culture. It was part of my everyday life. I did not have to relearn most of my culture and "risk the danger of playing the foreigner's concept of the Indigenous person"(Laenui 2000: 3). I just had to learn to not feel afraid and bring it forward in public view.

Despite my participation in protests, I did not feel that I as an individual possessed the skills to help make a change. The turning point came in 1986 when I started to get involved with the Centro Cultural de la Raza (Centro) in my hometown of San Diego, California. There I was educated in the arts and activism. This was also when I entered my dreaming stage but was also still in my re-discovery and recovery phase.

I was asked by my friend David Avalos to visit the Centro to see a show he was in. David was friends with my brother and my cousin. He was also a Chicano activist and artist, being one of the founding members of the Border Art Workshop/Taller de Arte Fronterizo (BAW/TAF) which I discussed in chapter 2. I went to see the show and was amazed to see all the artwork that was addressing the different issues and thoughts that were going through my head at the time in relation to my identity as a Chicano. As we went through the exhibition, David and I discussed the meaning behind the different artworks that were on display. I described my visceral response and David described the conceptual and social meaning in the works. This was the first time I heard about the mechanisms that governed the culture of La Frontera and how these artists were responding to it.

This was an awakening for me. These discussions and many more began to give me the language of decolonisation to frame and express what I had been experiencing as a Chicano. I had visited the local museums in San Diego and thought I had a basic understanding of art. Yet upon seeing the work that was being presented at the Centro, I was blown away. This was the first art that really spoke to me a person of colour and a Chicano. These artists were talking about my life now, in the present, not about what happened two centuries ago in Europe. Europe was a place to which I have no connection but I was constantly told in school that this was the birth place of civilization, where all knowledge and all the great thinkers came from. There was never any mention of my people and culture, except as savages who needed to be educated by the 96|P a g e 
Europeans for us to be accepted into their colonised world and that we should aspire to be as good as them. We were seen as second-class citizens to their history.

This was not what I was looking at when I saw the show at the Centro. What I saw was that there were people just like me fighting and struggling to be heard above the roar of colonialism. I saw the artists fighting for our own history as a people in the Americas, fighting for our right to be heard, fighting for the right to live our lives without fear of punishment or prejudice, fighting for equal representation in the laws that govern society. Still this was not the first time I had come in contact with this fight.

The first time was in my early teens when the people of Barrio Logan banded together to fight for a park in their neighbourhood. This event became a landmark event in Chicano history. An event that became known around the world and gave birth to Chicano Park (Delgado 1998 Winter: 1). At that time in my life, I was too mixed up with general everyday life issues, school, and working in a family business - in my family, our priority was the family business and to put food on the table- to get involved, but this event had a strong influence on my life.

When David Avalos invited me to his show, it ignited a spark in me that set me on this path today. Right away I had all these ideas and thoughts going through my head but did not know how to express them. I wanted to be part of this. The Centro became my spiritual home for my education in Chicano rights and the arts.

This 'dreaming' period is still part of me today. It opened up a whole new world for me, a new way of being. I started creating work that looked at the issues that were affecting my people and the people around me. I started to look at how to use my art to create dialogue that could lead to changes in the status quo for the betterment of all. As Laenui says, "This phase is the most crucial for decolonisation. Here is where the full panorama of possibilities are expressed, considered through debate, consultation, and building dreams on further dreams which eventually becomes the flooring for creation of a new social order"(Laenui 2000: 4). This also marked the end of my mourning period as I had found a way to help create social change for my people through a creative art practice. 


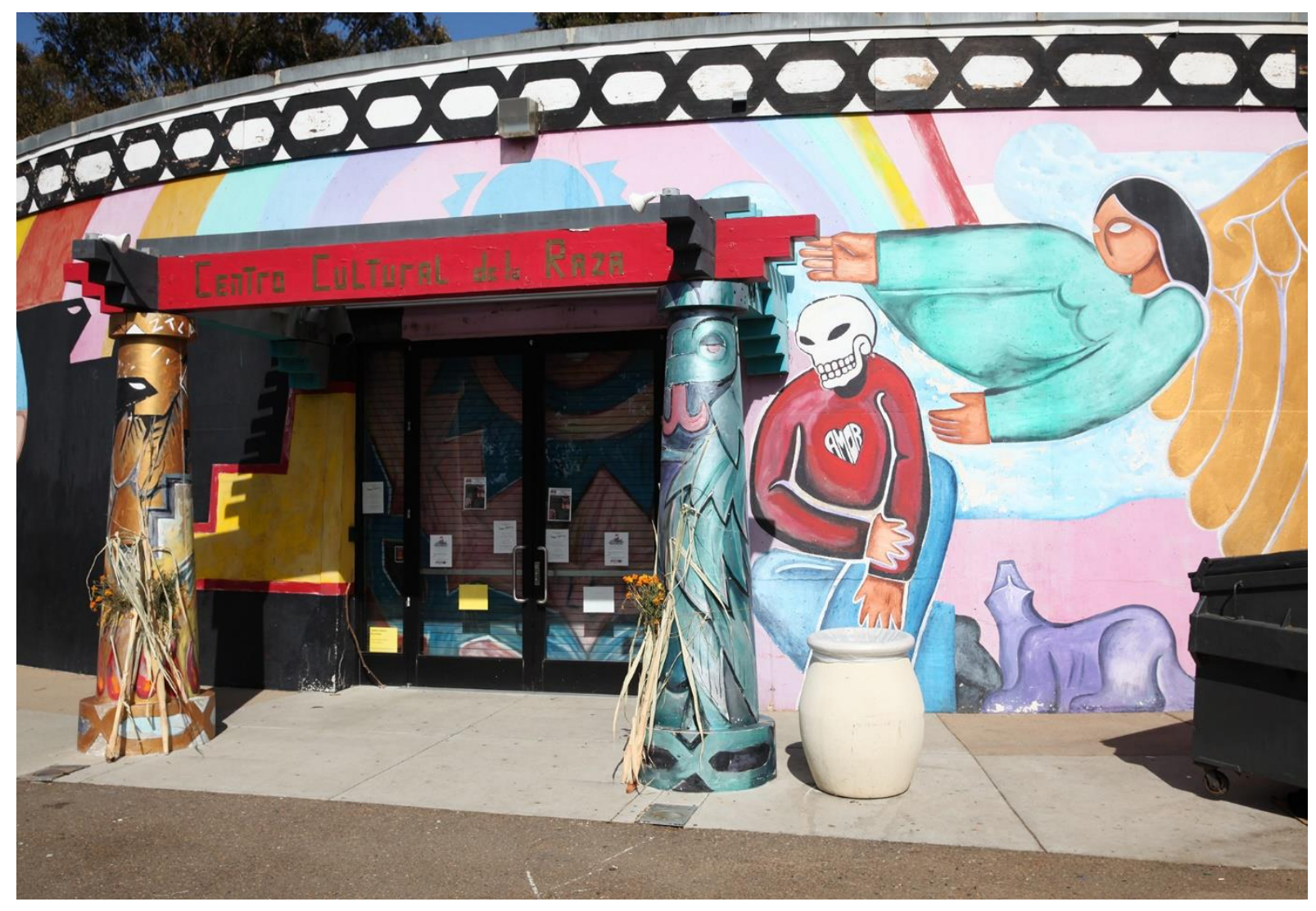

Image 12 Front of Centro Cultural de La Raza (Photo by William Franco)

\section{Border Art Workshop/Taller de Arte Fronterizo (BAW/TAF)}

After that first visit to the Centro with David and my decision to become involved in the Centro, David and a few of the other artists at the Centro were very kind and helped educate me on how to think about art and then to create the artwork that was in my head. This happened at a fortuitous time for me and in the history of the Centro. The BAW/TAF had just been formed and was on its way to becoming one of the most influential Chicano art groups in the Americas. This exceptional group of artists helped bring Chicano art to the world. Their work was exhibited in major galleries and museums around the world. These same artists taught me about contemporary art history and how their work was there to change contemporary art culture and society, to quote David Avalos: they were using art to "reconceptualize social relations through the application of extraordinary art practices" (Grynsztejn 1993: 67).

As I talked about in chapter two, these artists were instrumental in my development as a Border Artist. With their support, I started my artistic career using the skills that I had learned while growing up, which included carpentry and photography. This was supplemented with the knowledge I received while attending community college classes in video and film production, and art. I started making work using all these techniques: video, sound and constructed objects to $\mathbf{9 8 | P}$ a g e 
talk about the social issues that were affecting me and the people around me. This is when I finally felt that I had "released myself from the shackles of colonial patriotism"(Laenui 2000: 5) and entered what Laenui calls the 'commitment phase' where I was "ready to commit to a single direction in which the society must move" (Laenui 2000: 5).

For the last thirty years I have been in Laenui's 'action phase', creating work that looks at changing society for the betterment of all. Part of being a Chicano Border Artist is that life is not stagnate, that I am are not stagnate. I am constantly changing and growing. Part of this growth is revisiting the 'dreaming phase' from time to time, thinking of what could be and how do we get there. These phases continue to this day as part of my Chicano sensibility and my Chicano Border Methodology. This sensibility is embedded in everything I do, including in this thesis. In the next section, I discuss the continuation of my 'dreaming and action phases' as I continue to grow and expand my horizons around the issues of borders and the world around me.

\section{Borders and beyond}

The idea of borders has changed for me over the years. As a result, my practice and thinking has changed over the years with the new knowledge that I learned along the way. This has led me to embrace Border Thinking (W. D. Mignolo 2006: 206). Where once I was completely focused on the La Frontera, as articulated by Chicana/o writers and thinkers such as Gloria Anzaldua (1987) and Jose David Saldivar (2007), I now have been able to expand my art practice to look at all kinds of different Fronteras around us, from the borders between people, cultures, governments and laws to borders between life and death to the borders between people and technology, and technology and the environment. My work has been about the borders that govern the way we engage with the world around us. Looking at the human race, as individuals, we are all islands floating in a sea of air. We all have our own biological border that separates us from the rest of the world. Forever separated from each other, we are constantly looking for ways to connect with the world around us. In doing so, we are constantly negotiating these borders between us. This evolution of my Border Thinking is the outcome of years of research and exploration within my practice.

I, as a Border Artist, am writing this thesis. In doing so, I am crossing a border- the border from the everyday world of political activist community-based art into the world of academic writing. From the Chicano standpoint, the academic world can be perceived as being elitist, formal and disconnected from our everyday reality, while my political activist community-based art is based 
on the realities of our everyday life at the cultural interface. By straddling this border, I hope to create dialogue and communication between these two cultures. By writing in plain English and using personal narrative, I want to bridge the gap between the world of the academic and the world of the general reader, making my processes and concepts accessible to a greater audience.

\section{Looking for home in Aotearoa}

For me to create a project or piece of artwork, I need to have a reason to do it. Every work is personal. Something must push me to create. To borrow a term from the second feminist wave in the 1960s and 70s, "the personal is political"13. I think this term, while coined by the feminist movement, is applicable to many other situations in life where people feel oppressed or feel the need to speak out from a personal point of view.

This vested interest in the topic is the driving force behind my work whether it is Chicano rights, police violence, global warming, factory farming, GMO corn for my tortillas, or the feeling of displacement and loss in a new land. I have to be passionate about the subject matter. The goal with my art is to start discussions about the subjects in my art, bringing them out into the open, into the light, looking for solutions along the way. I try to create art that does not offend people, that respects the place where the art is presented, but creates a place for the communities to talk about subjects in the work. I strive to create a place that stimulates dialogue about the subject matter. The Illustrated Chicano is a good example of this.

This is my first time living for an extended amount of time away from my homeland, Southern California, living in a foreign country where the customs and language are very different from my own place in the world, working in a space inhabited by another Indigenous group (Māori) whose culture and language are very different than mine but who are fighting the same battles for identity, culture, knowledge and existence that I am. For me as a Chicano, I see similarities between us. Some are battles that we have fought and don't have to fight again, some are battles that we have already fought but we are in the process of fighting again, and some battles that have not yet happened.

\footnotetext{
13 Through my research there seems to be a consensus within the feminist movement of the $60 \mathrm{~s}$ and $70 \mathrm{~s}$ that no one should take credit for coining the phase "the personal is political".
} 
Where do I fit in this place and how do I find my home here? I have a strong connection with the Māori here, but they are not like Chicanos and Chicanos are not like Māori. We have a lot in common fighting for our rights as a colonised Indigenous group. The Māori are fighting their battles differently than the Chicanos but we are both fighting for the some of the same things, the right to be recognised, to exist and for land and resources.

Living in a foreign country, I have the benefit of looking at the struggles of Chicanos from a distance rather than being in the middle of the fighting. This gives me a unique perspective on topics that I have not examined before. Being away from my family, friends and art contemporaries is a very isolating and lonely experience. How do I create work from the position of outsider in another country where the battles are not mine to fight, a place where the sensibilities about art and politics are very different than where I came from?

What are my battles? What are my causes to fight for? Do I abandon my cultural battles for ones that are more global? Do I become a nomad with no cultural ties? Do I become colonised and have no culture except western culture? Or do I continue to fight for my people only while living a diasporic live style? What I have decided to do, is to continue my fight for my people while addressing issues that are related to the experiences of my people and the similar experiences of others around the world.

I had produced several projects here in Aotearoa. All of them collaborations with Māori and Pākehā: No Näianei/From this moment and Museum piece, looking at issues of colonisation; He rawe tona kakahu/She wore a becoming dress, addressing issues on gender, 7 Generations, addressing issues of family relationships and sexual abuse. These projects are all projects that continue my ongoing decolonising process. The most recent example of my continuing decolonisation process is my creation, exhibition and articulation of The Illustrated Chicano thesis.

\section{The Illustrated Chicano}

In 2015, I was looking for a piece to create for my thesis, a work that would be an example of my methodology used outside a collaboration, a work that would allow me to discuss how I use my Chicano Border Methodology in detail. After a long process examining how I felt living here in Aotearoa, I came up with The Illustrated Chicano, a solo exploration into my feeling of being out of place, not settled, looking for home in a foreign land, a work dealing with the concepts of place and home. 
In The Illustrated Chicano, I reflect upon my experience as an Indigenous person who has moved to another country, and started a new life away from my people. The Illustrated Chicano is a conceptualised expression of these issues. The Illustrated Chicano is dealing with all these issues in a contemporary art setting that is also pushing for the inclusion of Chicano Border Methodology in academia and Chicano art practices in the contemporary art world.

The Illustrated Chicano installation is a decolonised work because I use a decolonising methodology to create the installation. Every object and element included within the installation was specifically chosen through the lens of the decolonising methodology. Each element is the artefact of the decolonising methodology which is why I included detailed description of each element of The Illustrated Chicano. This means that the installation itself was decolonised through the process of using the decolonising methodology.

Aotearoa New Zealand is dissimilar to the Americas. Unlike the Americas it is an island with a smaller total population than the city I grew up in. We share the same ocean but our histories are different. The Americas started being colonised in 1492 with the arrival of Christopher Columbus. Aotearoa's first European contact was in 1642 with the sighting by Abel Tasman. Māori have a different language with different customs and beliefs. I had been here for eleven years and I still feel that I have not found my place yet. How do I express this longing for my place and home to those for whom this is their homeland? I'm in a Māori department, learning about Māori customs and traditions, tikanga (Māori customary practices) and trying to relate them to my culture. Some of the concepts are similar to the way my culture views the world, such as having a connection to the land. Others are not, like our rituals around death. For example, Chicanos celebrate death and the afterlife by making of sugar skulls that represent our relatives and then eating them, while Māori would never mix food and death. How do I navigate this place?

One of the first things that I wanted to get across to the people who came to see the installation was "What is a Chicano?" When I tell people that I am a Chicano, they really don't know where we sit in the cultural dynamics of North America, or as some Native Americans call it Turtle Island. Turtle Island is taken from a Iroquoian creation story about the Great Mother Aataentsic, who fell onto the back of a turtle that became what Europeans later called the North America continent (Pearce 2005). Native Americans did not have a word for continent. I realised that one 
of the first issues I have to present in my installation was a definition of a Chicano. How do I represent this to Māori and Pākehā in a way that is engaging and informative?

Another major consideration I needed to address was the social context of the installation. I wanted to create a place where Māori and Pākehā could come and engage with the Chicano experience without upsetting or contradicting local customs and traditions. An example of one is the Māori customs of noa (commonality) and tapu (sacredness) (H. M. Mead 2003: 45-50; Shirres 1982) which is a complex set of concepts for outsiders to understand. I know that some items in Māori culture should not be mixed together and would be considered offensive or an insult to Māori, e.g. having a body (or a copy of a body) on a table where kai (food) could be prepared. The body is very tapu in Māori culture. Māori Professor Rawina Higgins states that "a person's individual body and all associated qualities (such as blood and bodily fluids) were deemed tapu with the head being most tapu. Any disrespect shown towards a person's head could cause many inter-tribal wars (Higgins 2004: 54). But in my culture, we would not have any problems mixing items in this fashion. How do I present objects that may offend people here in Aotearoa but are critical to my work? This is just one example of the many considerations of the local context I had to take into account. The awareness of the local community and the effects that my actions have on them is a very important part of my methodology.

\section{Artifact}

The item in question that could potentially cause the most controversy was the centrepiece of my installation, a body cast of myself lying face down on top of a large plinth covered in Zapotec designs. I wanted to pay homage to another Indigenous artist and friend, James Luna, who in 1987 presented himself on a table in a museum for a few hours a day for a week as a living “artifact” (Ceseña 2013: 206). This was to protest to how Native Americans are portrayed in American history and culture. 


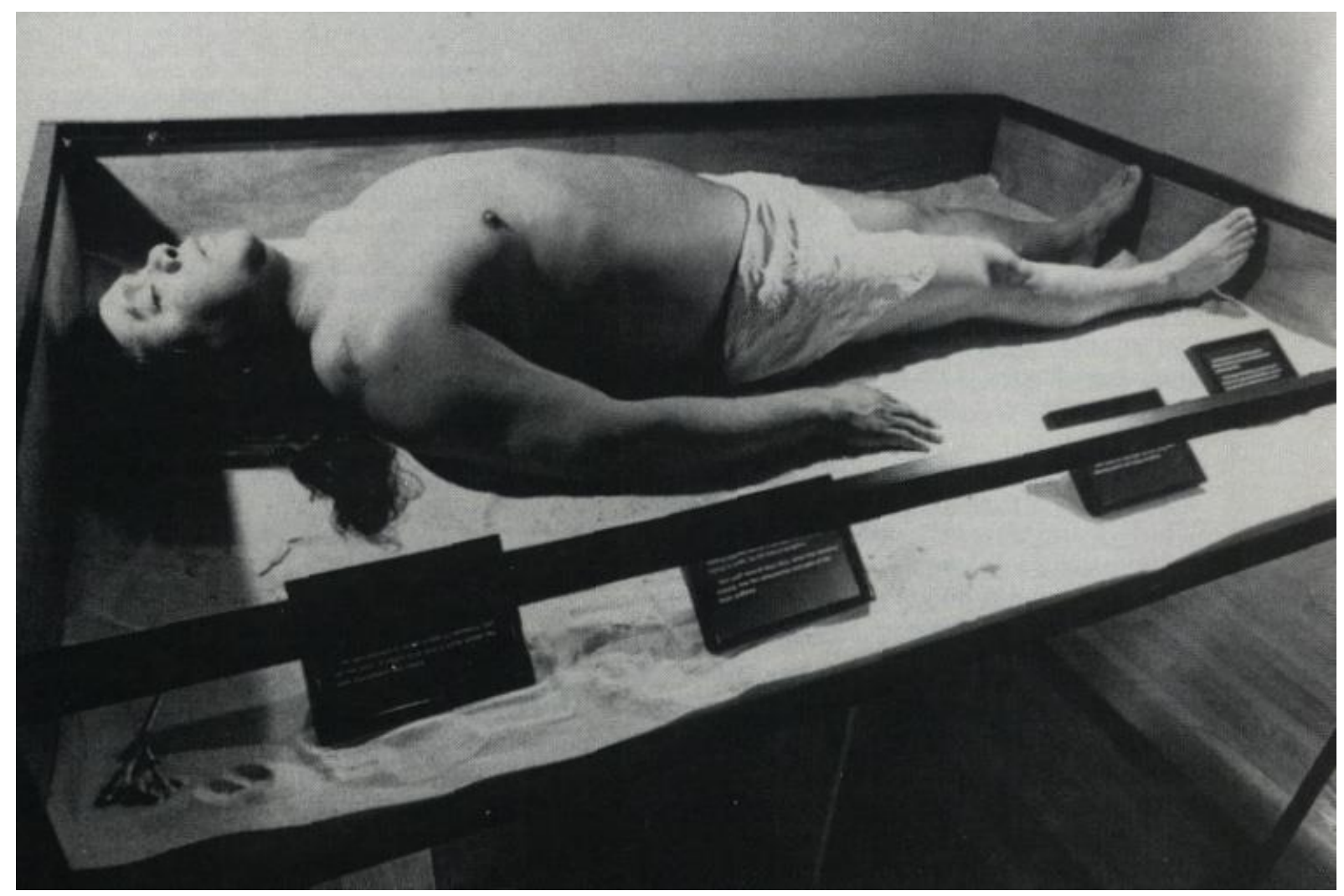

Image 13 “artifact” Museum of National History San Diego (Photo by James Luna)

Using Luna's work as a point of departure, I decided to make the body cast of myself and use the cast as a storytelling device by projecting images onto it to tell the story of me being a Chicano. Landscapes would be projected onto the body cast and plinth top to show the connection between body and land, the way Chicanos and other Indigenous peoples feel about the environment. These landscapes would then give way to my actual nude body being projected onto my body cast with tattoos starting to appear on my body. These tattoos would travel around my body and settle into specific places. The idea of tattoos reference the importance of tattoos to Māori who call their tattoos "moko" and have specific historical and cultural significance, as detailed in Higgins thesis He Tanga Ngutu, He Tiiboetanga Te Mana Motubake o te Ta Moko Wabine: The Identity Politics of Moko Kanae (Higgins 2004). To make the work interactive, the viewers would be invited to touch the tattoos. When a viewer would touch a tattoo, it would become a video that represented the visual interpretation of that tattoo. Some would have sound accompanying them. Others just video. After five minutes, the body cast and plinth top would go to black and then the process would start all over again.

As I mentioned above, consideration of the local is an important part of my Chicano Border Methodology. What I did a few months before I created the body cast for the installation was to 
visit several of the Māori kaumātua (elders in Māori society) and other Māori from the local iwi and told them what I wanted to do and asked what I needed to do to present this body cast in a way that would not cause offence to the local Māori community. They gave me suggestions how to deal with the issue and appreciated the fact that I had taken them into consideration before I had presented the work in a public space. Since these were people in the community, if anyone had asked if I had consulted with anyone before presenting the work, I could say yes and this is what they told me.

\section{Place}

Another part of my Chicano Border Methodology is the recognition of place. That means the recognition of the historical and social context of place where the work is to be presented and my position as a Chicano from Turtle Island/North America in this place. I installed The Illustrated Chicano in the gallery at Thistle Hall in Wellington. As part of this project I wanted to create a space in Aotearoa where the customs, rituals and aesthetics of the Chicano experience would not disrespect or compromise the sensibilities of the local Māori and Pākehā communities.

This quote by Hunkpapa Lakota Sioux artist Dana Claxton reflects my feelings toward the gallery space.

Many Aboriginal artists become historians in some capacity, uncovering the truths of Aboriginal experience that are buried under layers of colonial histories. Bringing these insights into the gallery space, which has a history of excluding Aboriginal artist, inevitably transforms the 'whiteness' of the space. (La Flamme 2008: 49)

Thistle Hall was built in 1907 on Cuba Street in downtown Wellington Aotearoa New Zealand. Thistle Hall has always been a centre for the community. It started out as a grocery and tea store, then became a dance hall, a playground, a movie theatre, classrooms, studios and now a community centre with a performance space and downstairs gallery (White 2007: 1).

Before the Europeans colonised this area, there was a Māori settlement along the stream called Kumototo that ran through this area. In the stream there were tuna (eels) and ngohi (fish) and along its banks were mahinga kai (food gardens). The area has a very long history for Māori as many of the tribes moved through this area on their way to Te Waka/South Island. The area has a strong Māori spiritual presence. After the Europeans pushed the Māori out and took over the area to found the city of Wellington, Kumototo and the other streams in the area were paved 
over. Kumototo stream now runs under the city where no one can see it. The stream, tuna, ngohi and gardens are no longer visible but they are still here, so I needed to honour them.

One of the ways I honoured the history and spirit of the land and decolonised the gallery space was to introduce some Indigenous rituals and symbols into the space that removed the colonial baggage that is inherently attached to the institution of a white box art gallery (O'doherty 1999; Sheikh 2009). One of the first things I did was to do a sage or smudging ritual. The purpose of this ritual is to engage with the spiritual aspect of life and place, to connect with the old spirits of the place and to show respect and to honour them. I used it to ask permission from the spirits to temporarily to change the space into a Chicano Native American space for the duration of the show. I did this alone in the gallery out of the public view. For me rituals are not for public entertainment or showcasing. As James Luna once told me, rituals are not to be done for public consumption as entertainment. What Luna does when he performs is to do something resembling a ritual but has no real meaning, so that the audience gets a sense of ritual but it is not a re-enactment of a ritual. Intentionally there is no documentation of this event for this thesis, but I will give you a generic description of the smudging ceremony.

The smudging ceremony is a custom of Native American and other Indigenous cultures. One of its many uses is for cleansing and purifying a space, to remove negative energy and connect with the spirit world. Smudging is a way to create a cleansing smoke bath that is used to purify the body, aura, energy, ceremonial/ritual space or any other space and personal articles. Our bodies and environments are not only physical but vibrate with invisible, silent energy. The four elements needed for the ceremony are: a shell or clay bowl which represents water; the herbs and resins which represent the earth; a feather and wind it creates which represent air; and the flame used to ignite the herbs which represents fire (Ahisninaabemoaa 2017; Altieri 2014) .

I burned sage during the length of the exhibition to keep it as a safe space and to remove any negative spirits that tried to enter the space as well as a sensory reminder to the audience that they were in another space. Once I finished the smudging ritual, I was able to move onto the next step in the process of installing The Illustrated Chicano. I divided the gallery space into three main areas: the transitional space, the contextual space, and the interactive storytelling space. 


\section{The transitional space}

The transitional, or liminal, space was the entrance to the galley where the visitors travelled from one world to the other, where they first encountered the sweet smell the sage and saw the colourful surveyors tape, where they made the transition from being in Wellington to being in a Chicano space.

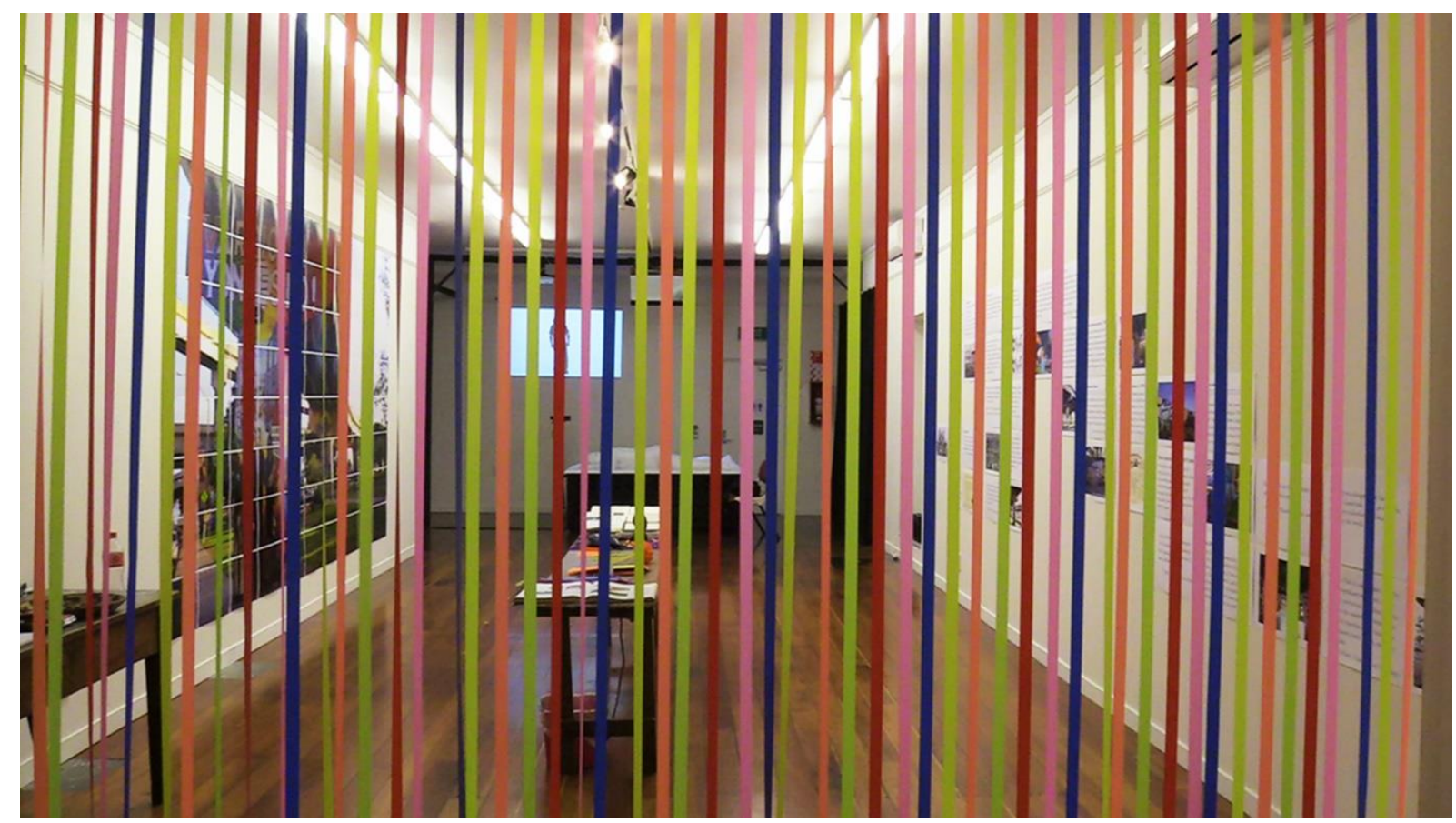

Image 14 Surveyors Tape Curtain (Photo by William Franco)

I wanted to create a transition from the outside world to the inside world of the Chicano, to create a line of demarcation, something that was physically and visually inviting to the public as they walked by the gallery, something that the visitors needed to transverse to enter this other world. I wanted them to cross La Frontera/The Border from the world of Wellington to my world of the Chicano, and I was looking for a material to be a connection between the Chicano North American context and the Aotearoa New Zealand context.

While I was at my residency at the Banff Centre in Canada, I noticed that a few of the Indigenous artists used $25 \mathrm{~mm}$ strips of brightly coloured tape in their work. This immediately got my attention, something was striking and familiar about it. I asked them what were the strips made of? They said surveyors tape. I said of course, I should have remembered. Surveyors tape has a long history in the Americas and other places around the world that were colonised. Surveyors tape is one of the many tools used by the colonisers to take away the land of the Native 
Americans and it was used here in Aotearoa to do the same thing. In Giselle Byrnes' book Boundary Markers, she writes about how surveyors "were charged with extending the boundaries of empire: advancing colonisation on the ground, at the frontier of theory and practice. Although physically located on the margins of the settler society, land surveyors operated, quite literally, at the cutting edge of colonisation" (Byrnes 2001: 5). They were part of the machinery that was used to take land away from the Indigenous populations in colonised lands. In Aotearoa they became part of the Land Purchase Department. "From 1854, land surveyors were included on the staff of the Land Purchase Department (which was incorporated into the Native Department in 1885), specifically established to deal with the acquisition of Māori land” (Byrnes 2001: 4).

The surveyors' main interest was how the land could be developed for commercial use to benefit the colonist. From an economic view, what was the best land to use for commercial expansion of the colony. "That surveyors read the land with explicit commercial motives in mind is hardly surprising: the primary task of the land surveyor in colonial New Zealand was to prepare the path for orderly colonisation and settlement. Surveyors read the land strategically, invoking the colonial agenda at every opportunity" (Byrnes 2001: 4).

There is one Māori historical event that symbolises the importance of surveyors tape and flags here in Aotearoa New Zealand and that is the famous Parihaka affair. Dick Scott wrote about it in The Paribaka Story, first published in 1954, then re-edited into Ask That Mountain in $1975 . \mathrm{He}$ tells the history of Parihaka, where passive resistance was used to slow down the British confiscation of Māori land (Scott 1975). It is mentioned in the book how the surveyors would come during the day and lay out their flags marking off the land. Then at night the Māori would pull the flags up or plough them under as a form of passive resistance, slowing the surveyors' progress. This eventually led to the arrest and jailing of most of the population of Parihaka and is often cited as one of the worst and shameful events in Aotearoa New Zealand history.

Therefore the surveyors tape is a powerful symbol of colonisation on both sides of the Pacific. This was the connection I was looking for the installation, a historical cross-over, that common thread and bond between two Indigenous worlds, thousands of kilometres apart, that experienced the same trauma and pain of colonisation, two peoples who are still living with the ramifications of that process in 2018, that subconscious understanding of what that surveyors tape represents and the feelings and emotions that it still carries hundreds of years later, that "generational trauma" (Evans-Campbell 2008), the trauma and feelings held by the Native 
American populations over the entire North and South American continents, feelings that Māori can understand here in Aotearoa.

So I have this powerful symbol. What was I going to do with it? The core tenet of Chicano Border Methodology is that we use a plurality of knowledges to solve or make changes to the environment around us. We use all the different knowledges around us to make things our own, to reclaim and re-appropriate from the colonisers what was given and what was taken away.

What I chose to do was to reclaim this tool of colonisation and to retool it into something positive, the same way the Chicanos of Barrio Logan reclaimed the pillars under the San Diego Bay Bridge and created Chicano Park to reflect Chicano culture and history. I reclaimed the symbol of the surveyors tape from the colonisers and made it my own. I turned it into a border but one that was inviting and colourful that begged to be crossed and entered. Unlike many of the borders around the world that restrict entry and serve as a barrier between nation-states and communities, my border was porous and invited crossing, but at the same time this border was the line between the world outside the gallery and the Chicano world inside. It was the liminal space of transformation into another time, place, sensibility, mindset, a different reality. For once visitors crossed La Frontera, they entered the world of the Chicano, where neither Māori tikanga, including noa (commonality) and tapu (sacredness), were applicable nor the rules of the colonisers. This was a Chicano space.

\section{The contextual space}

Once the visitors passed through the transitional space, they entered the contextual space. The contextual space was the space of learning and understanding. It was the passing on of knowledge, a place to learn how to read and understand the symbols in the space. It was their first contact with the new world.

As the visitors passed through La Frontera/the surveyors tape curtain, they also passed through a light curtain of smoke from the sage that was constantly burning in the space, cleansing the visitors and removing any negative energy as they entered the space. The sage was a clear reminder that they were in a different space. 


\section{Knowledge Table}

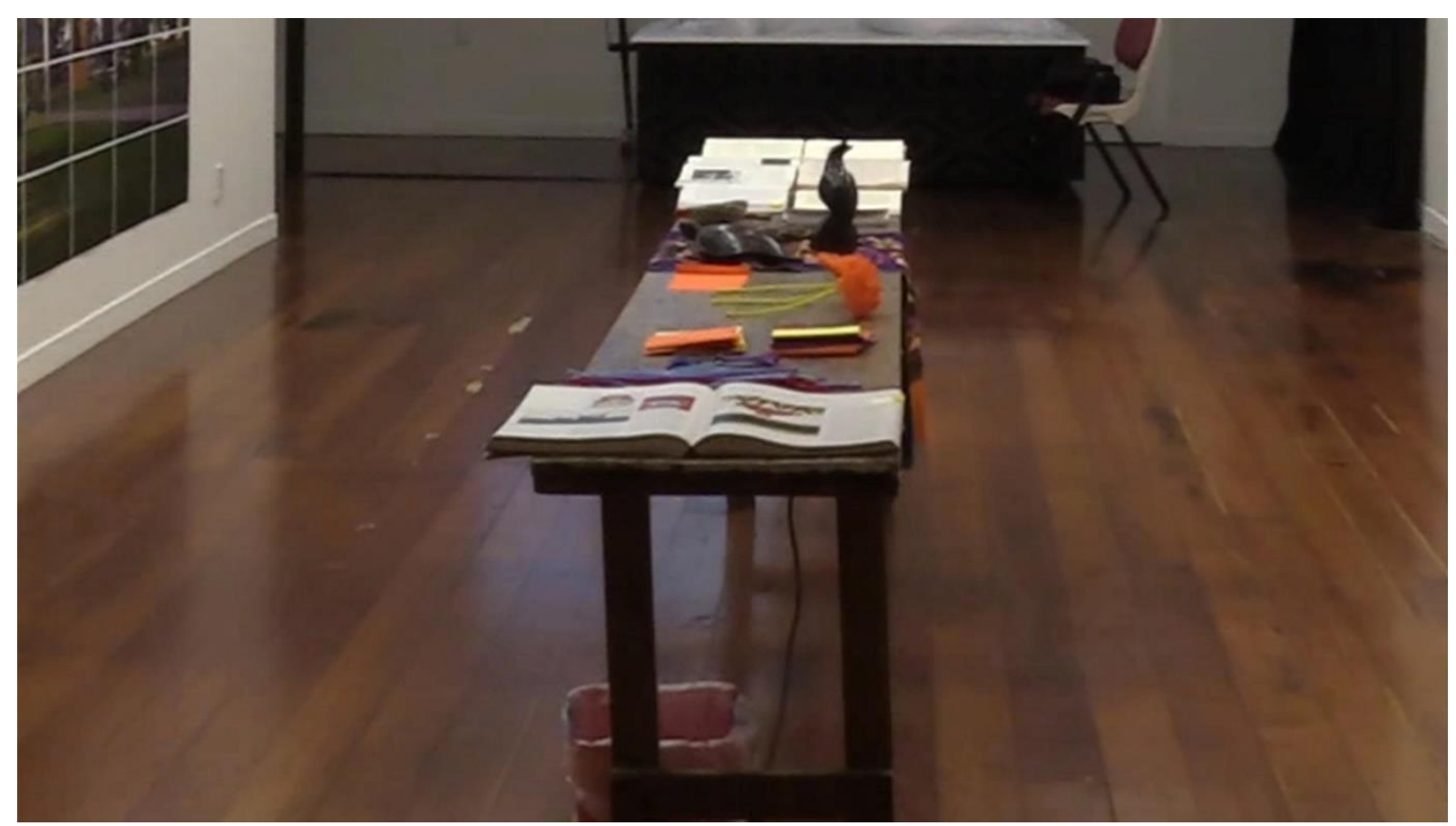

Image 15 Knowledge Table (Photo by William Franco)

Upon entering the contextual space, one of the first things the visitors saw was a long wooden table with books and other objects. This was the Knowledge Table where the visitors were able to learn more about the Chicano experience through books on Chicano history and Chicano art.

These books talked about art history and the connection the Chicano artist has with the Mexican muralists of the 19th and 20th centuries, like Diego Rivera (Aguilar-Moreno and Cabrera 2011). They showed how the work of the Mexican muralists was important to the development of the national and political identity of Mexico. The Chicano artist followed the Mexican muralists lead to create art that furthered the development of a Chicano identity. They did this by creating murals in many of the Chicano barrios (communities) that reflected the Chicano experience and that remain there to this day. They are monuments to the culture and history of Chicanos in North America. Chicano artists were at the forefront of the Chicano movement in the 1960s and 1970s, creating murals and art works that looked at the issues of civil rights and immigration. These artworks are now considered national treasures by the US government. In some cities they have become international tourist attractions, such as the Great Wall in Los Angeles (Baca 1980: iii) and Chicano Park in San Diego.

Also on the table were a few Chicano artifacts. These included a toy red lowrider car that could jump up and down like the real ones back home, and iron wood sculptures made by the Siri $\mathbf{1 1 0} \mid \mathrm{P}$ a g e 
Indians of the Sonora desert. One was a turtle, another was a small plump bird called a quail, and a snake. The Siri Indians were decimated by colonisation. I met them during my travels throughout Baja California and Mexico. There were less than a hundred of them left when I last visited in 2000 .

There was also food to share with the visitors, including raw cocoa beans that are used to make chocolate and other treats. Cocoa came from the southern part of North America and, at one time, was so valued that the beans were used as currency. As stated by G.A.R. Wood in his book Cocoa, "Cocoa beans had far more significance than as the main ingredient of a drink. Cocoa beans are easy to count and the tributes were paid in 'cargas' or loads of 24,000 beans weighting 22.5-27 kg"(Wood and Lass 2008: 2). They were also used in the many different rituals and ceremonies by the Mayans who felt that the beans had significant medicinal uses. Now cocoa is a global industry with plantations all over the world. Along with the cocoa beans, there was some corn chips and salsa to snack on while the visitors experienced the exhibition. Lastly there were tissue paper, wire, tape, scissors and instructions for making Mexican paper flowers.

\section{History of Chicano Park}

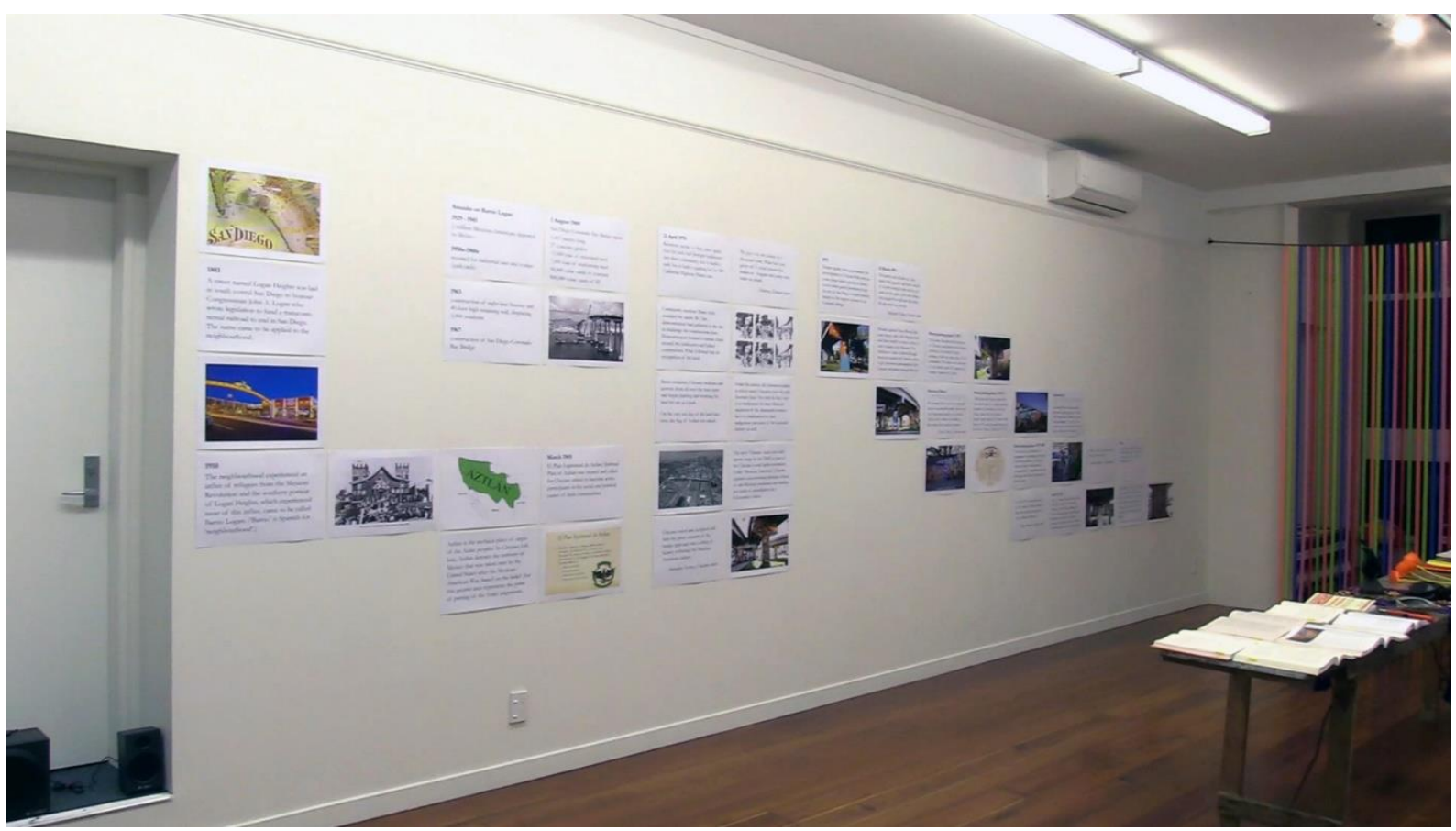

Image 16 Chicano Park Wall (Photo by William Franco)

On the right side of the gallery was a large four-meter-wide wall with a series of information panels on it. These panels, designed and installed by artist Miki Seifert, told the story of Barrio 
Logan, a historical Chicano neighbourhood close to where I grew up and is a good example of one of the major influences in my development as an Indigenous Chicano artist. The panels told of the struggles and traumas that forged the identity of this barrio (community), focusing on one major event that took place in 1967: the founding of Chicano Park.

In San Diego, the city decided to build a bridge from one side of the Coronado Bay to the other. This bridge would be built through Barrio Logan and would forever divide the community in half. The community fought to stop the construction and lost. The bridge was opened on 3 August 1969 . One of the promises made to the community by the city during the negotiations about the bridge was that the city would build a community park under the bridge. However, the city was not sincere in its promise to the community.

We gave you our culture of a thousand years. What have you given us? A social system that makes us beggars and police who make us afraid.

-Alurista, Chicano poet

On the morning of 22 April 1970, the residents of Barrio Logan awoke to find, once again, that the state had brought bulldozers into their community, not to build a park but to build a parking lot for 300 California Highway Patrol cars. Community member Mario Solis sounded the alarm. By 7am demonstrators had gathered at the site to challenge the construction crew. These demonstrators formed a human chain around the bulldozers and halted construction. What followed was an occupation of the land. As the word spread, more and more people showed up. Barrio residents, Chicano students and activists from all over the state came and began transforming the land into a park. On the very last day of the land take-over, the flag of Aztlan was raised. This was the founding of what is known today as Chicano Park (Robles 1996).

From this action, the historical context in which many Chicanos view the park becomes clear. Not only do they view it as vindication for their Mexican ancestors of the nineteenth century, but it is vindication for their indigenous ancestors of the sixteenth century as well.

During this time, Salvador Torres, a Chicano artist and long-time resident of Barrio Logan, had just returned to Barrio Logan and discovered that his family house was one of the houses that was destroyed to make room for the bridge. Like everyone else, he was very distraught at what had happened to his community but at the same time he marvelled at the pylons underneath the bridge (Robles 1996). In his article in the "Journal of San Diego History", Kevin Delgado recounts: 
At the time urban wall murals were still rare in the United States. On the night of 22 April 1970, at a community meeting to discuss plans for the development of Chicano Park, Torres stood up and proclaimed, 'Chicano artists and sculptors will turn the great columns of the bridge approach into a thing of beauty, reflecting the Mexican-American culture.' In retrospect, this may sound like a miraculous prophecy, yet Torres himself was inexperienced with mural painting. (Delgado 1998 Winter)

In 1969 Torres created the Chicano Park Monumental Public Mural Program. Not much was done until 1973 when, with no financial help from the government, a group of about a dozen artist received permission to start painting murals on the foundations underneath the Coronado Bay Bridge. Torres remembers the day, “23 March 1973. The paints were all laid out. And there's this gigantic wall there, and all of us just looking at this wall. So, we pour out the paint, took some rollers, and attacked the wall with the rollers. We put colour everywhere" (Delgado 1998 Winter).

They were following the lead of Mexicans masters like Diego Rivera, Jose Luis Orozco, and Alfor Siqueiros who used their abilities to paint murals that helped shape the Mexican identity. These Mexican masters used their talents of as a form of social activism to change and comment on the times and history of their young nation state. The young Chicano artists who started painting the murals on the Bay Bridge wanted to carry on this legacy and replicate this same style of social activism to promote and inspire as well as give a physical representation of the Chicano movement.

The Chicano Park murals were created to commemorate the struggle to create the park and to reclaim the space for the neighborhood. They depict different aspects of Chicano culture, including historical events, Mesoamerican influences, and mythology. The first phase illustrated the dominance of Chicano nationalism in the imagery portrayed, possessing the park, marking it with the placa (logo) of the community. (Delgado 1998 Winter)

The first group of artists were members of Las Toltecas and El Congresso de Artistas Chicanos en Aztlan. In the following years, other Chicano artists and non-Chicano artists have come to Barrio Logan to contribute to Chicano Park. It is now the largest collection of Chicano murals in the world. The park is recognised worldwide. It is often cited as a prime example of excellent contemporary art. The history of Chicano Park and the murals are used in many visual arts and 
Indigenous studies departments as a prime example of the power of art as social activism that continues to have a long-lasting effect on a community. For example, Dr. Alberto Pulido, who is the founding chair of USD's Department of Ethnic Studies, organises tours of Chicano Park and is on the Chicano Park Steering Committee.

Tourism has starting to become a part of the new history of the park as more and more people hear about the park and its history. Tourists come from not just the United States but from all around the world to see this park. The murals in the park are considered to be some of the finest murals outside of Mexico City. In March of 1980, Chicano Park was officially designated a San Diego Historical Site and the artists have received funding from the city of San Diego to restore and maintain the murals. Guillermo Rosette, one of the Chicano artists, said, "In history, we are the first artists to restore our own murals" (Delgado 1998 Winter).

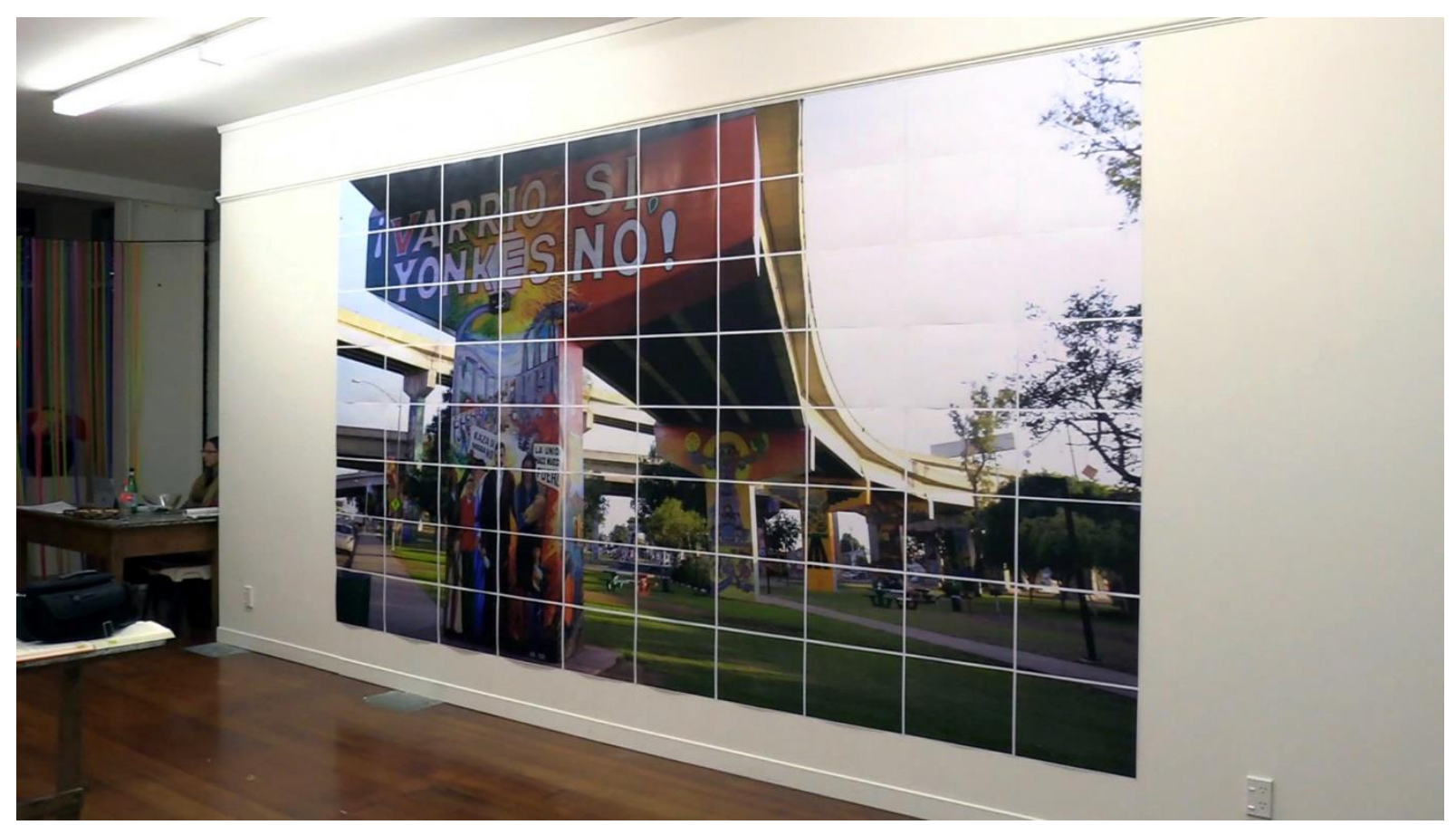

Image 17 Chicano Park Mural (Photo by William Franco)

Across the gallery on the other wall was a four meter by three meter blow up of one my photos of the Chicano Park murals printed on eighty pieces of A3 paper. They were mounted to the wall to give a hint of the scale and size of the murals in Chicano Park to the visitors. Each A3 print had a thin white border. This thin frame created enough of a separation between each print so that the viewer could focus on one small section of the image at a time and see the detail and complexity of the image before moving onto the next. When the visitors stepped away from the wall, the thin borders would disappear, creating a complete image that gave the sense of the scale $\mathbf{1 1 4} \mid \mathrm{P}$ a g e 
of the murals in the park, giving pause to think about the amount of work required to produce work on such a large scale.

\section{Aztlan the mythical land of the Aztecs}

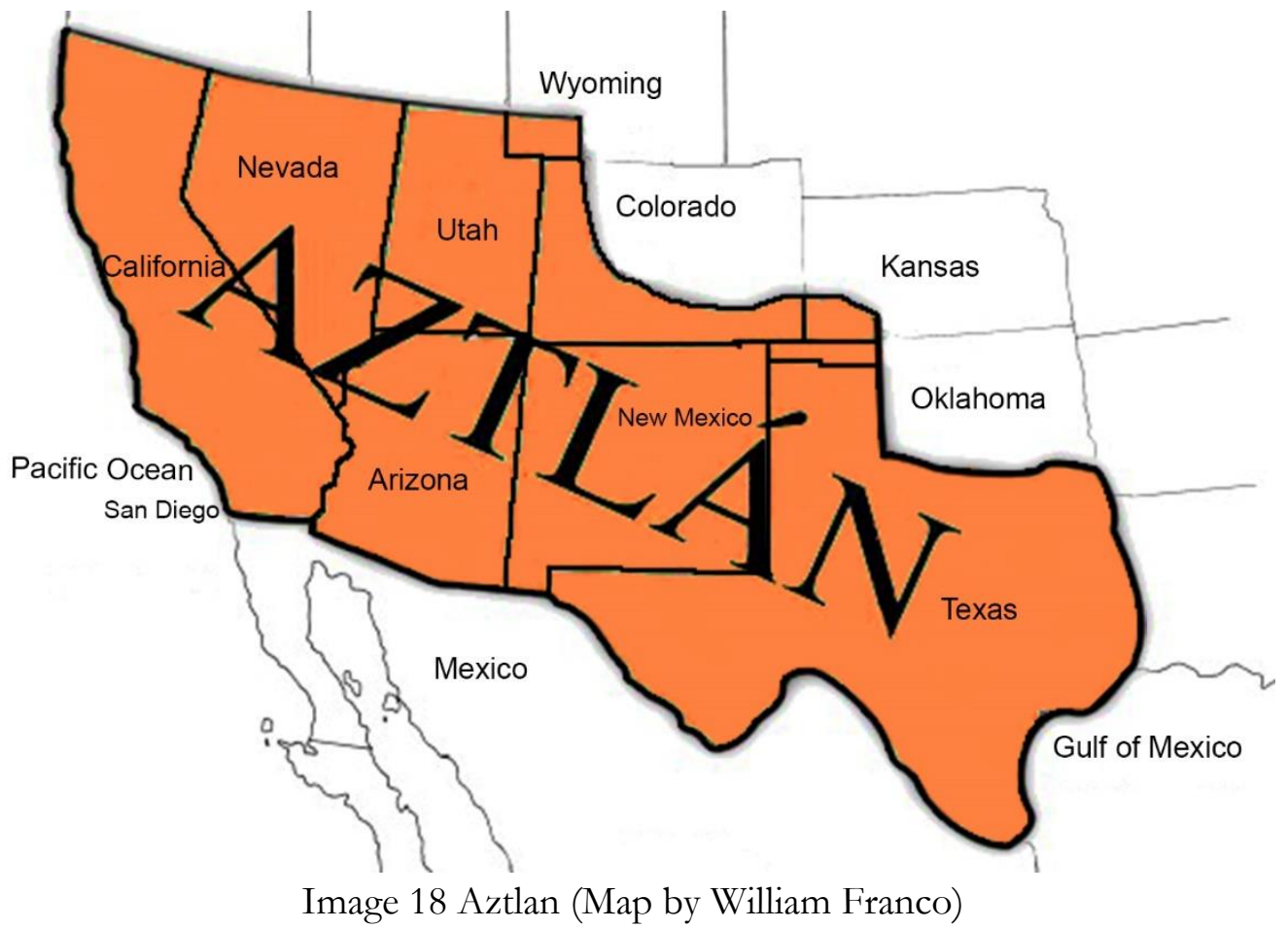

I have previously mentioned the word Aztlan in chapter two and earlier in this chapter. Aztlan is the mythical place of origin of the Aztec peoples. The word 'Aztlan' is derived from two Nahuatl words: aztatl and tlan(tli) meaning 'heron' and 'place of. 'Tlantli' is used to denote settlements, or place names. It also means tooth. A characteristic of a good tooth is that it is firmly rooted in place and does not move. In Aztlan, a land far to the north where the Aztecs originated, the Mexica ancestors dwelled in Chicomoztoc, a place with seven caves, each corresponding to the Nahuatl tribes who would later leave Aztlan and reach, in successive waves, the Basin of Mexico. These tribes were the Xochimilca, Chalca, Tepaneca, Colhua, Tlahuica, Tlaxcala and Mexica (M. E. Smith 1984).

In Patrolling Borders (Beltran 2004), Cristina Beltran states that Luis Leal (1989: 8) tells us Aztlan has multiple meanings. First it is that the story of Aztlan was a pre-Cortesian myth of origin and when the Chicano movement started, Aztlan represented the geographic region encompassing the southwestern part of the United States that Mexico ceded to the US in 1848 in the Treaty of Guadalupe Hidalgo. Beltran finds that the most important statement Leal makes is that Aztlan 
came to symbolise "the spiritual union of the Chicanos, something that is carried within the heart, no matter where they may live or where they may find themselves" (Beltran 2004: 600) Beltran continues and refers the story of Aztlan as a mirror to the Chicano experience: "Like Chicanos themselves, Aztlan is from but not in Mexico, in but not of the United States. Aztlan is portrayed not as a return to Mexico but as the spiritual and territorial embodiment of Chicano aspirations" (Beltran 2004: 601).

Aztlan entered the conscious of the Chicano Movement in the late 1960s when Alberto Baltazar Urista Heredia—who took the penname Alurista during the fall of 1968—talked about Aztlan in a class for Chicanos held at San Diego State University. As Leal notes, prior to 1969, "no one talked about Aztlan"(Leal 1989: 11). Aztlan officially entered Chicano cultural discourse when Alurista's El Plan Espiritual de Aztlan (The Spiritual Plan of Aztlan) was introduced and read aloud at the Denver National Chicano Youth Liberation Conference in March 1969. In El Plan, the Chicano is called on to recognise his Aztec origins and claim Aztlan as the Mexican territories lost to the United States in 1848 (Leal 1989: 11). By the early 1970s, Aztlan was fully integrated into the Chicano cultural and political discourse. As the strong opening statement of this poem says, "Aztlan belongs to those who plant the seeds, water the fields, and gather the crops and not foreign Europeans"(Leal 1989: 11).

One of the important notes about Mesoamerica, the area that extends from the northern part of Mexico—some say the lower part of the US—-southward through Central America to El Salvador, is that it is the only area of the new world that Indigenous cultures had written historical records before the European colonisers arrived to the New World. The four different groups of traditional histories that developed were written in Mayan, Zapotec, Mixtec, and Nahuatl. The histories of central Mexico written in Nahuatl were some of the best documentation of the culture and were the most studied and understood due to the connection to the Aztec conquest by the Spaniards who took great pains to understand the writing to better understand the social and economic structures that governed the central Mexico region (M. E. Smith 1984: 154).

Over the years there have been many studies (Brown 1973; Davies 1973; Henry B. Nicholson 1971b; M. E. Smith 1984) and articles about whether the mythology and the actual history are the same behind the Aztlan stories. "Some of these [stories]survive today (see Nicholson 1971:45-49 for a discussion of the major examples), but most of our knowledge of the Nahuatl histories comes from what Nicholson (p.48) calls 'textual histories'. These are descriptions and 
transcriptions of native chronicles (both written and oral) recorded in Spanish and Nahuatl in the sixteenth century"(M. E. Smith 1984: 154).

\section{The interactive story telling space}

\section{The Illustrated Chicano video}

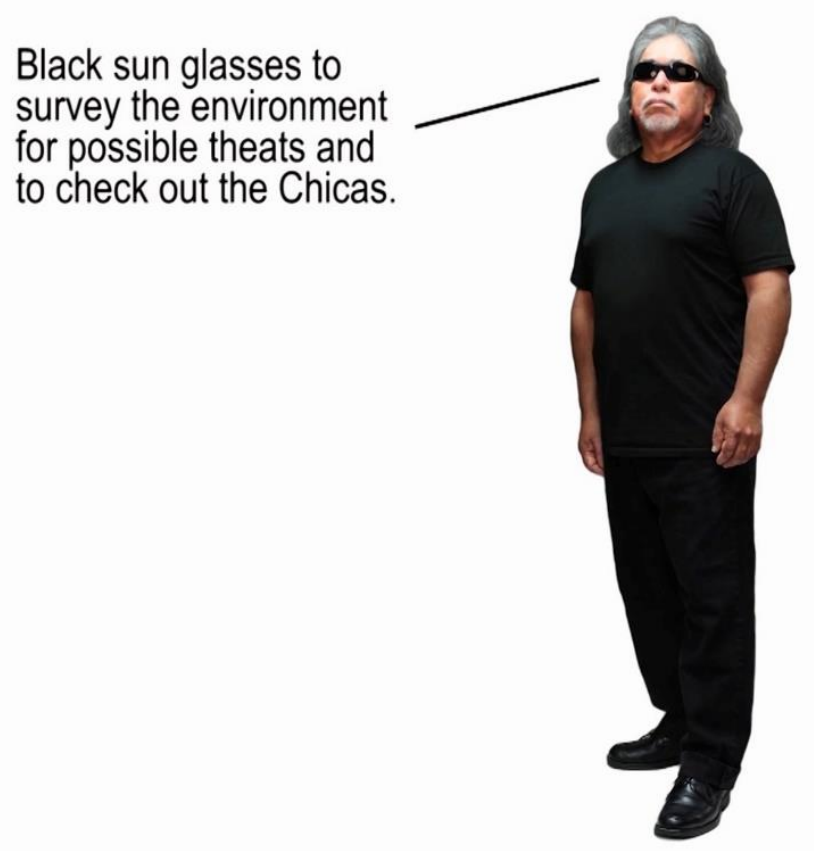

Image 19 The Illustrated Chicano video still (Photo by William Franco)

The video component of The Illustrated Chicano was a humorous way to describe what a Chicano is in a visual form. The setting for the video is a static $16 \times 9$ white-frame. I am in a standing pose as the illustrated Chicano. The video shows an image of me rotating 360 degrees around and around on an invisible platform, periodically stopping to reveal one of many small facts about what it is to be a Chicano:

- Typical Mixtec Native American nose

- Chicano stance weight on back foot leaning back in a laid back but dominant style

- Black sun glasses to survey the environment for possible threats and to check out the Chicas

- Usually seen in black clothing because we look cool in black and can slip away into the shadows

- A few Nahuatl words used in the English language: guacamole, avocados, cacao, chocolate, chili, coyote, mezcal, peyote, tomato, shack (yes shack). 
- Speaks at least three languages: Nahuatl, English and Spanish. Commonly known as Spanglish

- Within the identity politics of North America, the Chicano sits in a unique position

- We are Native Americans

- We are Indigenous of North America

- We have our own languages

- A history that goes back several thousand years before being 'discovered' by Europeans

The video played continuously during the exhibition and was projected on the wall behind the body cast, so that the audience would be drawn to the rear of the exhibition where they would encounter the body cast situated just in front of the projection.

The video was a fun way of delivering critical information to the visitors in an accessible manner easy to understand and enjoy. The image with the text and lines made it easy for the visitors to follow and connect with the content. Along the way, the visitors were gathering new information on a culture that they may not have previous knowledge about, except for what they had seen in movies or on social media. The storytelling in the video made the transition to the storytelling on the body cast easier for the visitors to accept, understand and engage with.

The Illustrated Chicano video was made at the Media Services Department at Victoria University of Wellington. It was created the old fashion way with no digital effects. At first, I was going to be put on a platform that was computer controlled and was used to shoot 3D images of artifacts for the National Museum of New Zealand and other places. The platform was set up to rotate three degrees, stop for ten seconds while the camera took a still image, and then rotate another three degrees to the next point. This process would continue for two rotations around the object, and the images would be assembled into a 360-degree video of the object.

I saw several problems with this method. First, I am a human being, not an inanimate object. I would have to start and stop 120 times per rotation which meant my body would be jerking around on the platform the entire time. I would have to find a way to stay in the exact pose each time the platform moved. That would be impossible. Second, each session would take forty minutes to complete before I could see a result. Thirdly, since it was not a continual shot, there would be only one optimum speed for the video to play back smoothly; otherwise there would be 
a jerkiness to the video when played back. I wanted to have the option of changing the speed of playback without any jerkiness.

To solve this problem, I had the technicians disconnect the rotation mechanism from the platform. I then had one technician rotate me manually. I had another technician shoot the manual rotation on $2 \mathrm{k}$ video at 50 frames per second. This allowed me to vary the speed of playback without any of the jerkiness. Each session took five minutes and we were able to see the results right away. We were able to complete a good take on the second try. I removed the technician's hands from the video using After Effects software. I edited the video in Premiere Pro where I added the text and downsized the video to HD 1080i and rendered the video.
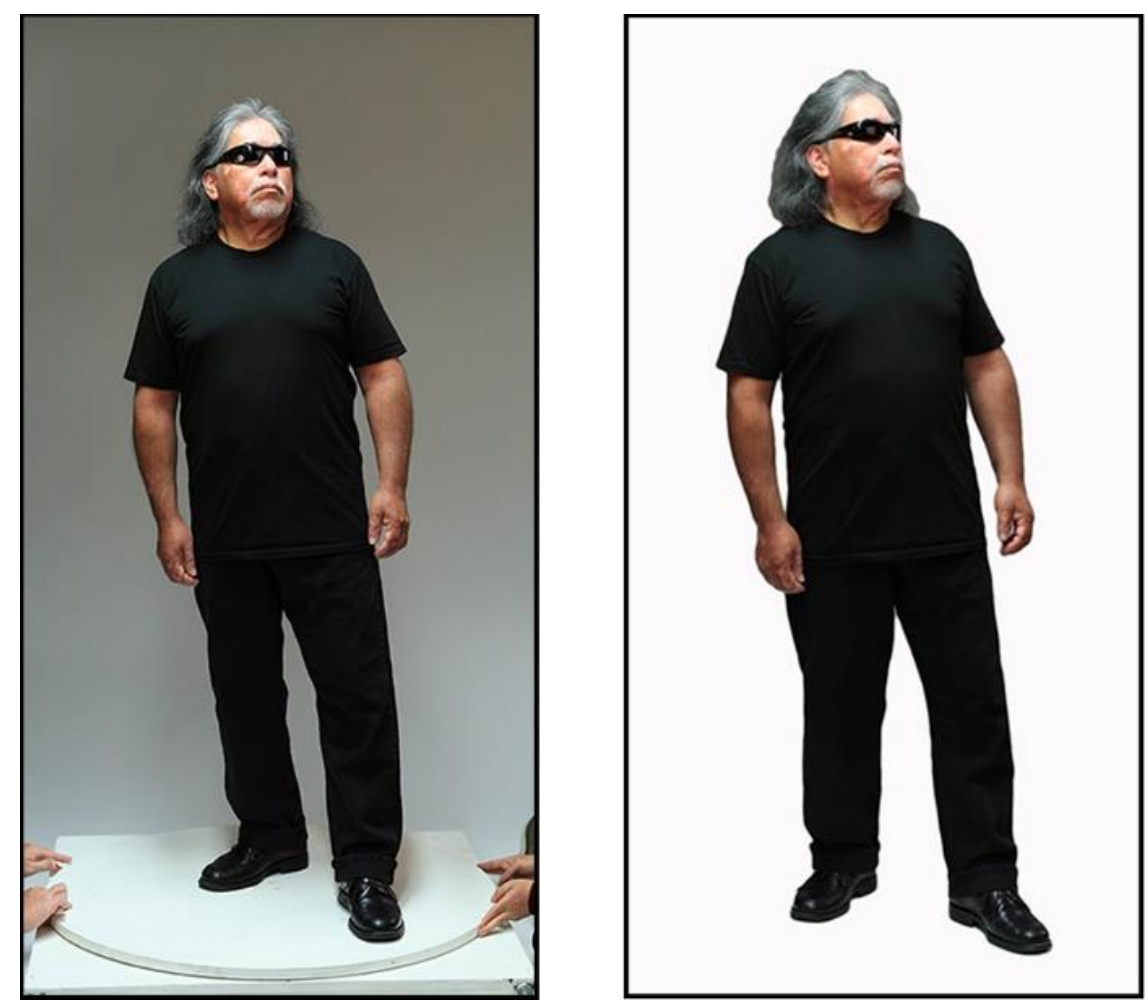

Image 20 The Illustrated Chicano before \& after (Photo by William Franco)

To play the video for The Illustrated Chicano wall projection, I used a Raspberrie Pi 3 Model B mini-computer with a video looping program called the Looper. The computer was the size of a cigarette case and ran on a Linux operating system. I had to install and program the Linux operating system. This mini-computer was set on top of the projector during the installation where it ran all day and night for the duration of the installation. 


\section{The Illustrated Chicano}

The centre piece of the exhibition was The Illustrated Chicano. The Illustrated Chicano consisted of several parts that formed an interactive whole. I will first briefly describe the different parts of the Illustrated Chicano and then I will go into detail about each part, describing its function, meaning and creation.

- The Body Cast was an actual body cast of me. The body cast was made of plasterimpregnated gauze used for making orthopaedic casts.

- The Plinth on which the body cast rest was a platform made of wood, vinyl and paint. It was decorated with Indigenous designs form Mesoamerica. It was similar to other gallery plinths except for the inclusion of the indigenous designs.

- The videos which were projected onto the body cast had specific meanings to help tell the inside story of the illustrated Chicano.

- The Kinect Sensor that was set behind and above the body cast was used to facilitate the interactive experience between the body cast and the visitors.

- The computer system that controlled projection system had software that was written so that several different computer programs could communicate to facilitate the interactivity.

- The projection system that mapped the videos onto the body cast was custom made for the gallery space, taking in all the aesthetics considerations of the space and how the visitors would view the technology and its integration with the piece.

- Special projection coating for the body cast amplified the video image on the body cast, making it clearer and more visible in normal gallery lighting.

- The sound helped to set the stage and atmosphere for the exhibition and the sound system employed to transmit the sound. 


\section{The Body Cast}

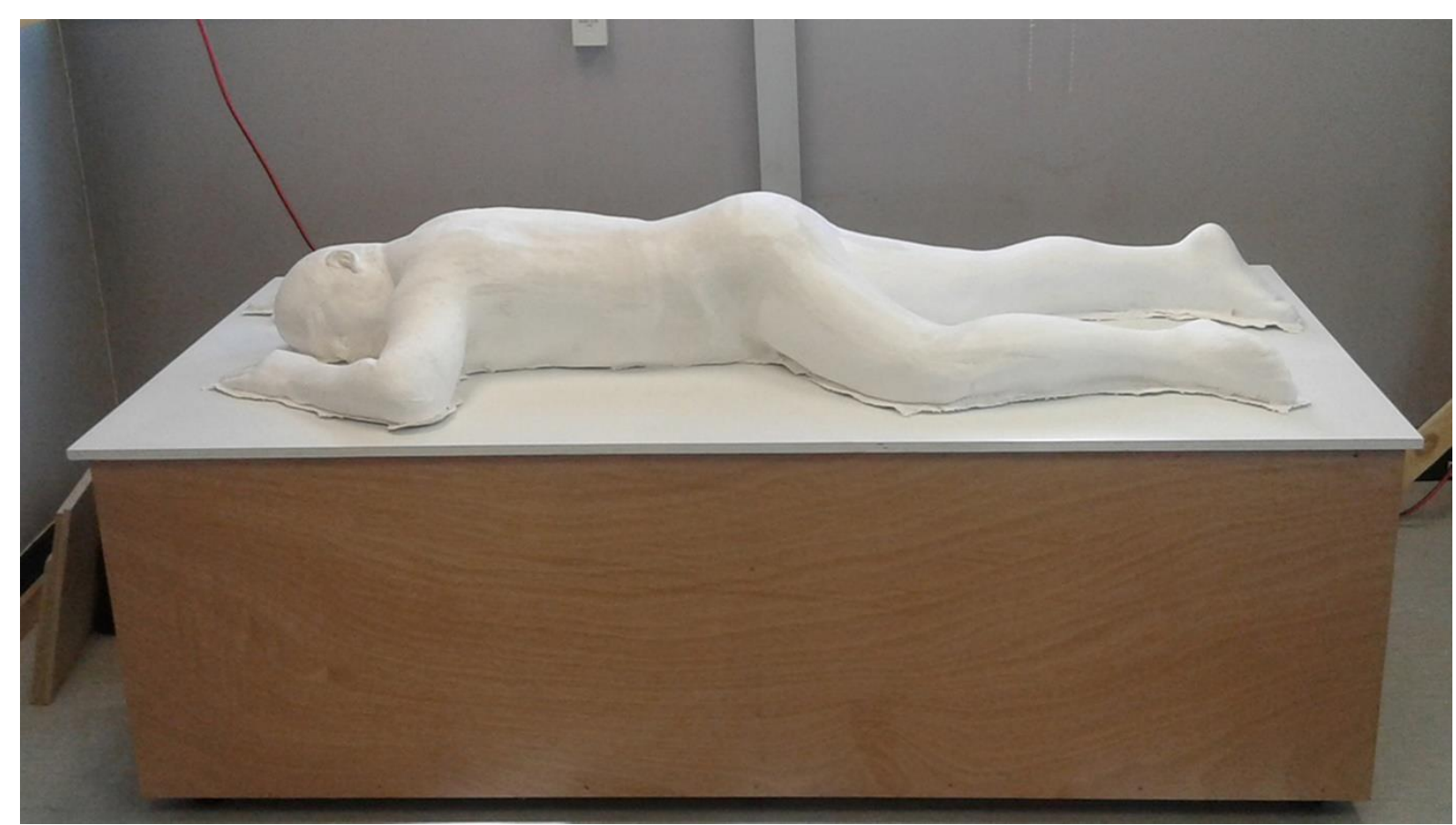

Image 21 The Illustrated Chicano Body Cast Raw (Photo by William Franco)

The body cast was made of plaster-impregnated gauze. It is similar to the material that is used to make casts for people when they set a broken arm or leg. The use of this as an art material was first popularised in the 1960s by George Segal who became known as the father of plaster casting (Schmahmann 1998: 1). He used the material to make life-size models of people in common everyday situations for his art installations. His work was shown around the world in all the major exhibition spaces. I have used a similar technique to create the Illustrated Chicano.

The reason I used plaster-impregnated gauze instead of more contemporary materials, such as silicone, latex, foam or plastic gel, is that these materials show the hyper-detail in their finished products. The resulting form from the plaster-impregnated gauze shows detail but not the fine detail. Also, the plaster-impregnated gauze has a specific texture to it when it dries, a kind of rough and unfinished feel. When applied correctly, the resulting body cast shows a good amount of detail of the human form but still retains a sense of an organic other worldly object with its nooks and crannies and flaws that gives the work a sense of aliveness and soul that I find hyperdetailed materials lack.

The top of the plinth was also covered with the plaster-impregnated gauze. I did this to create a unity to the whole piece. This brings a symmetry to the piece, showing the connection between 
both parts. The plinth top represents the earth and world we inhabit. The body cast represents me and my Chicano-ness. Each element blends into one another, becoming a single piece showing that no separation between the two, showing not only a physical connection but also a spiritual connection.

I wanted the body cast to represent the Chicano form while at the same time being able to double as a landscape and the world. This duality of meanings can be read many different ways. It demonstrates the complexity of the Chicano experience in the world by showing that we are an integral part of the North American landscape, that just like the land we may change over time but we will never disappear, that we Chicanos have been here for thousands of years. We are constantly morphing and changing with the world around us. It is showing the similarity between my culture and other indigenous cultures with our connection with the land, water, air and fire of the world around us. It explores the concept of our oneness with the world. The lack of fine detail in the body cast can be read as a metaphor that illustrates the difficulty of finding one meaning or definition for the object, representing many things to many people.

\section{The plaster-impregnated gauze}

The plaster-impregnated gauze has its own story and history. Made from gypsum, and more commonly known as Plaster of Paris because of the gypsum mining in Montmartre in the Paris district in the 1700s. Gypsum has been used by humans for hundreds of years. Gypsum has been found on the inside of pyramids in the Middle East (Sharma and Prabu 2013). From its origins in the earth, the gypsum for the plaster is mined and transported to the factory. There it is impregnated to the cotton gauze bandages. Gauze was first produced in the 13th century. Gauze is said to have been traditionally woven in Palestine and the English word is said to derive from the place name for Gaza (Arabic: غزة ghazza) from Webster's 1913 dictionary, a centre of weaving in the Middle East region. Gaza may be more familiar to people today as the Gaza strip next to Israel. Gauze was originally made of silk but today it is made of cotton.

We created the plaster body cast in Wellington. The plaster gauze was submerged in warm water for a moment to activate it and applied to my body. For a few minutes the plaster and I were bonded together as one. Body, spirit and earth, reliving that physical and spiritual connection between the Earth and I, as the chemical process of crystallisation heated up the plaster, causing it to harden to form a shell. A shell that now carried my history, my mana and my spirit as well as the history and spirit of the plaster, gained through thousands of years changing from rock to the 
powder. Both of our histories are now carried within the body cast as well as on it. My DNA is carried within the material. Wherever the Illustrated Chicano goes, so does our shared histories.

\section{The position}

The body cast was laying in a prone position, resting on its front, face turned to the side with one leg slightly lifted, the other straight, arms on either side of my head as if sleeping or resting but not dead. I choose this position because I wanted the body cast to be in a non-threating position to the visitors. Even though frontal nudity of the male body is used in contemporary art, it is still one thing to look at a male nude from a distance and another thing to ask the general public to touch a male nude, let alone one that has its genitals on display. I didn't want to offend anyone entering the gallery by being too graphic with the male form. This position, negotiated before the body cast was created, gave me the luxury of not having to acknowledge and wrestle with the justification of the element of male sexuality in the installation. Since the work is not about male sexuality but finding place and home, the prone position was the best choice, implying a sleeping body on a table. Thus, rendering the body cast as just another piece of art that resembles a human or a landscape. This positioning made the piece more accessible to the general public

\section{Creating the Body Cast}

The process of creating the body cast was interesting. It was a multi-step process that took several days of work. This was the first time my partner Miki Seifert and I had made a body cast here in Aotearoa. It was also the first time making a body cast for my crew, Darryl Haddon, Tristen Rodway, and Fern Pakamon Karun They had a small tutorial in the process before we started. In the end we actually made two body casts. The first one did not work correctly. Miki and I are used to making body casts in Southern California where the average humidity is around 25 to 50 percent. With the humidity so low the plaster would dry very quickly. It was a very fast process. The process here in Aotearoa turned out to be very different because of the 80 to 100 percent humidity.

The first step was to find a studio space that was big enough for my crew and the table, and that was private. Once we found the studio, we needed a table that met the requirements for the work. It needed to be sturdy enough to hold my body and the wet plaster material. On the day of the cast making, I arrived with the crew and supplies to make the cast. First step was for me to climb onto the table and find the position that worked best for the cast. After that the crew drew an outline with reference marks of my position on the table and my corresponding body parts so 
that I could replicate the position over and over again. The crew left while I stripped naked and then assumed the position on the table again.

I had a camera rigged above the table, simulating the position where the projector would be located for the installation. We took a series of high-resolution photos of me from the overhead position. One of these photos was to be used as the master image to project onto the body cast during the installation.

Miki applied the petroleum jelly that was used as a releasing agent to my body. This helped release the hardened cast from my body as well as stopping my body hair from sticking to the plaster. Wherever the plaster-impregnated gauze was to be placed on my body, that area had to have the jelly. After applying plastic wrap and more petroleum jelly to my private parts, we called the crew back in. The next step was the hardest step. While covered in plastic wrap and petroleum jelly, I had to stay still for an hour and a half while the crew applied the plasterimpregnated gauze.

Miki and I had a lot of experience working with the material, but it was the crew's first time working with Plaster of Paris, so they were not sure if they were doing it right. They were learning as they went. The crew applied the three layers to my entire body, creating one cast, and waited for it to dry. After an hour they pulled the semi-hardened cast off me. It looked great, but it still wasn't dry. After an hour it started to collapse onto itself. After another half hour it was totally useless. The air was too moist to let the Plaster of Paris dry. We sent the crew home, feeling dejected since we failed. Miki and I looked at the process and figured out that the humidity was too high and the water was too cold. We went home, got our blow dryer and kettle, and returned to the studio and started the process again with just the two of us.

I had to stay still again for an hour and a half. This time Miki applied one layer of the plasterimpregnated gauze at a time. Each layer was dried with a blow dryer before the next layer was applied. After the third layer was dried, she pulled the hardened cast off me. The process of drying and adding the next layer allowed most of the body detail to bleed through the plaster. She also cross-hatched the gauze material on me which created a strong support structure so the dried Plaster of Paris had a strength and flexibility to retain its shape. This allowed the cast to be removed from my body without destroying it. This time we also decided to make the cast in three pieces: the legs, torso and head. The head was created a week later and the whole-body cast was assembled into one piece the next day. After the body cast dried for another day, we flipped the $\mathbf{1 2 4} \mid \mathrm{P}$ a g e 
whole cast over and reinforced the inside. I also attached wooden blocks for mounting the body cast to the top of the plinth.

I chose not to make a positive from the inside of the cast. I wanted to use the original casting so the visitors would be looking at the negative cast rather than the positive inside mould. It has a nicer more organic texture and feel to it.

\section{The Plinth}

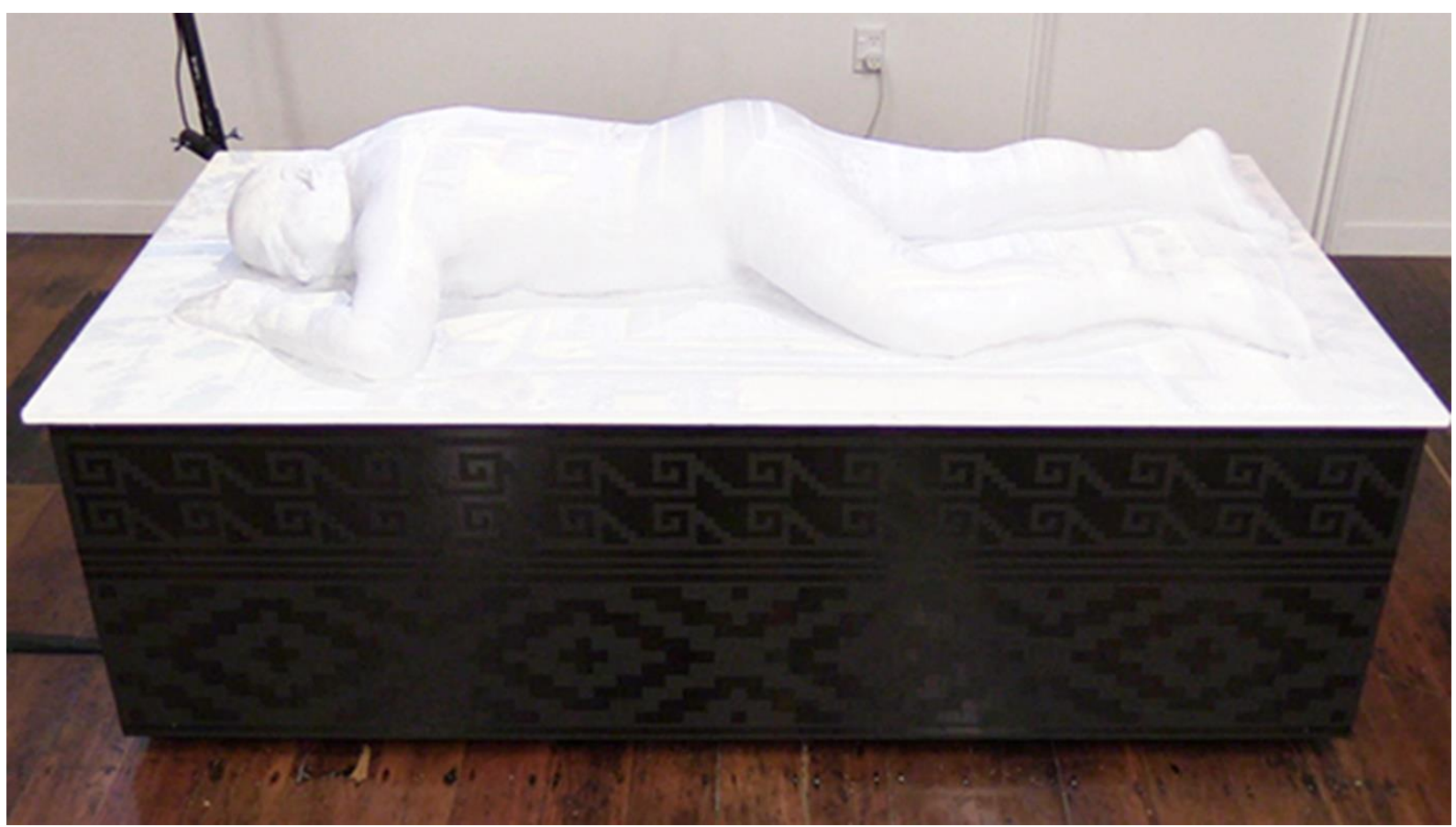

Image 22 The Illustrated Chicano Plinth with Designs (Photo by William Franco)

The plinth was $700 \mathrm{~mm}$ tall by $2050 \mathrm{~mm}$ wide by $1000 \mathrm{~mm}$ deep, made up of solid wood, paint, vinyl and plywood. The top was made of $22 \mathrm{~mm}$ plywood covered with white primer and then covered with plaster-impregnated gauze. The body cast was attached to the top with screws so that it was one unit for travel. The four sides were covered by $12 \mathrm{~mm}$ plywood. The plywood was covered with vinyl decals of Indigenous designs from the Zapotecs of Southern Mexico where my original tribe is located. The symbols represent the earth and water. They were referenced from the ruins of Mitla in Oaxaca Mexico. The geometric designs on the top section of the plywood represent the waves, water, or rain. Caso, Alfonso, and Ignacio Bernal interpreted the step-fret as a stylised representation of the deity Quetzalcoatl (Caso and Bernal 1952). Quetzalcoatl was primarily thought of as a wind and storm deity whose actions brought the rain (M. E. Miller and Taube 1997: 141-42). The geometric designs on the lower half represent 
stylised mountains and valleys of the earth. These symbols are seen all over Mesoamerica. Even though the symbols can represent deities such as Quetzalcoatl, I am not representing myself as Quetzalcoatl. What I am doing is showing that the designs are indigenous ways of showing knowledge. By using these designs, I am sharing the knowledge of my ancestors with the visitors. Also, I am showing the similarity between cultures and the way we use symbols to represent the world around us. To Māori the symbol for Quetzalcoatl is similar to the koru (the fern) which represents the lifecycle and the stylised mountains and valleys are similar to the Māori poutama (stairway to heaven).

The main background of the panels was a charcoal coloured vinyl. On top of the background in a glossy black vinyl were the Zapotec designs. The glossy black designs against the charcoal background gave the plinth a bit of elegance to the work by highlighting the off-white body cast on top. The frame of the plinth was made up of $45 \mathrm{~mm}$ sq. pine railing, screwed together for easy disassembly and travel.

\section{The video projections}

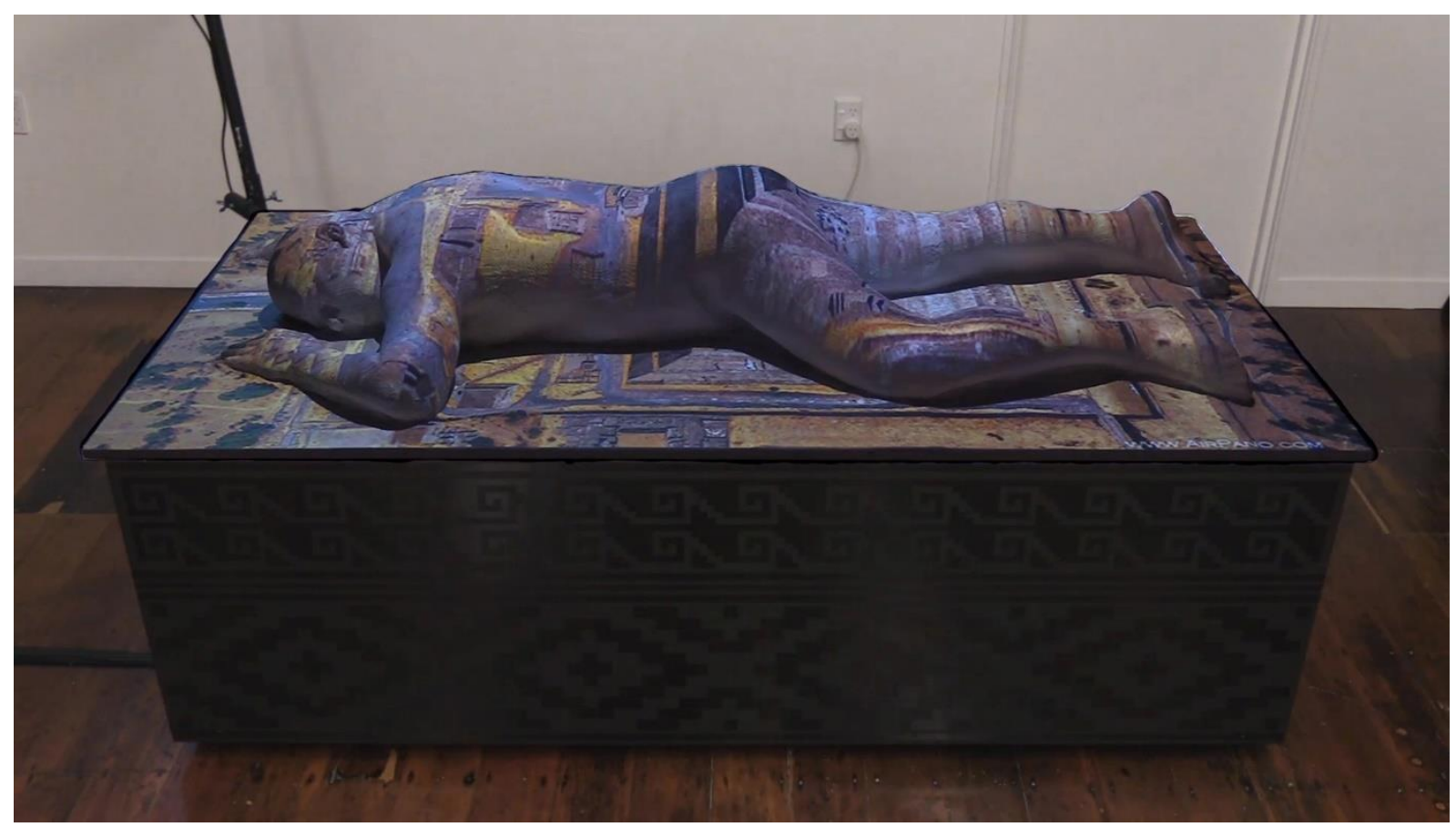

Image 23 The Illustrated Chicano Body Cast with Projections (Photo by William Franco)

The videos that were projected onto the body cast have specific meanings. The first video tells the story of my journey from my homeland of origins, La Frontera/US-Mexico border region, to my new homeland, Aotearoa New Zealand, through landscapes. Each image represents a 
different aspect of my journey, from my cultural origins in Southern Mexico to the US-Mexico border across the ocean to my new home in Aotearoa New Zealand.

The video starts off with fast moving clouds traveling through space, setting the tone of the piece by showing that a journey is starting. The image changes to a medium shot of a sandy landscape of rippling waves of sand with bits of green growth. The image is from a sand dune area in Southern Baja California that I often visited. It reminds me of the flow of life with all its different highs and lows, and the many changes in direction encountered in life. From there the scene changes to a pan of a rock wall in Joshua Tree National Park in the California desert where I used to spend time camping with family and friends. Some of these rocks have petroglyphs from the Indigenous tribes that live in the area. The next image is of the Palomar Mountains which I grew up was close to. Palomar is a Spanish word that means "pigeon roost". The local Luiseno Indian's name for Palomar Mountain is Paauw and the high point is called Wikyo (Stedman 1908). There are no actual English or Spanish translations for these words.

Some of my fondest memories are of my father taking the whole family up to the mountains for the day. I'd stare at the giant trees as we drove along the winding mountain roads. We'd stop for lunch and run around the trees for a few hours before heading back home to the coast. Sometimes he would take us to see the snow, but most times it was in the fall when we would buy apples from the farmers along the road. The mountains were a magical place to run and play as a child.

The video then transitions to an image of sand dunes along the US-Mexico border, showing some of the harsh but beautiful landscapes that people travelled through to get to the US along with closeups of the cholla cactus from the area.

Following this image is an image of my local mountain, San Miguel, the highest mountain in San Diego County. It stands at 2,567 feet high and can be seen from anywhere in San Diego. It was always there looking over me, protecting me on my journey through life. It is the mountain I mention in my mihi (Māori greeting and introduction) when I do presentations in Aotearoa New Zealand. It is my spiritual contact to the earth.

The next image is of Ocean Beach at sunset where I spent most of my time growing up until I moved in my forties to Los Angeles to work in the film industry. The ocean has always felt like a 
mother to me. Swimming or just floating on the water was always comforting to me, no matter what else was going on in life. I was always energised when I came out of the ocean.

The next section of the video gets into my cultural background and connections, starting with showing various images of the cultural ruins from the area of my ancestors: Tzintzuntzan, place of hummingbirds, in the Mexican state of Michoacán; Teohuacan, the city of the sun in Mexico City; Danipaguache (Zapotec for sacred mountain of life) commonly called Monte Alban in the state of Oaxaca, Mexico; and finally ending at the sea where the La Frontera/US-Mexico border ends in the Pacific Ocean.

The video then transitions into a time-lapse of the skyline of my hometown San Diego, which I shot in 2007. The Zapotec symbol for the God Mother Earth is super-imposed onto the skyscape as time rushes by. This image changes into rushing ocean water, symbolising the journey across the ocean to Aotearoa New Zealand. This dissolves into a time-lapse of Wellington harbour where I landed when I came to Aotearoa. The image of Papatūānuku, the Māori Earth Mother, is super-imposed on this cityscape. The super-impositions show the connection and similarities between the two cultures. The video then shows the different types of flora, fauna and coastline of this new land, illustrating and contrasting the two different worlds that I live in. This first video then goes to black.

The second video fades up from black and shows the Zapotec designs that surround the outside of the plinth. It is projected onto the top of the plinth, adding a cultural texture to the top of the plinth that connects the plinth to the body cast. The body cast has no video projected on it as this time.

\section{Tattoos}

While the second video continues playing, a third video of my body in the same prone position as the body cast, is projected onto the body cast, creating the illusion that my body is lying on top of the table. After a few moments, tattoos appear on the body cast. They float around traveling across the body cast in all directions until settling down on different parts of the body. Each tattoo represents a different aspect of being a Chicano and living here in Aotearoa New Zealand. Below I have broken down the meaning of each tattoo. 
Border fence: This represents the border crossing, a place I crossed at least once a week with my family when I was a kid to go shopping for Mexican goods, driving straight through from the US into Mexico in five minutes without worrying about getting searched or being asked for papers. (I wrote about this in detail in Chapter 3.) Now there are over 90,000 vehicles per day crossing between Tijuana and San Diego, and is expected to raise to over 160,000 by the year 2020 (Garnica 2010: 2). It's a two, three, up to five hours wait to cross as every car is searched and passports are requested. There are cameras everywhere tracking everyone who enters or leaves the zone, looking for criminal activity.

Abandoned crosses: There are several cemeteries near La Frontera/US-Mexico border where in unmarked graves are the bodies of hundreds of people who have died trying to cross into the US from Mexico and South America, looking for a better life, running away from the results of US policy in Latin America. The graves are for people who have not been identified and so are buried in graves which have a simple clay marker that says John or Jane Doe and a number. These cemeteries stretch across from the Pacific Ocean to the Atlantic Ocean, the whole length of La Frontera/US-Mexico border. A group of priests and lay people have been going to these forgotten cemeteries for years and placing white crosses on the unmarked graves. Each cross bares the inscription "No Olvidado" which loosely means "Not Forgotten" in Spanish. I travelled with this group in 2002, as well as on my own for several years, to plant these crosses on these graves, only to return and find them in piles in the rubbish behind the cemeteries. This group of activists continue this ritual today.

Made in Aztlan: This collection of images showing different positive aspects of Chicano culture that are common in US and Mexican culture from our music to our clothing and our food.

Chicano Park: I have discussed Chicano Park in detail in a previous section of this chapter.

Chicano Power: These are images of Chicano political history, including the Chicano rights marches, the Brown Berets (Los Boinas Cafes), the United Farm Workers Union (UFW), and other political events from Chicano history.

Lowriders: The lowrider is an iconic symbol of the Chicano experience that shows how we changed something that was not of our making and added our own sensibilities to it, creating a new and bold expression of who we are, one that was unmistakably Chicano, a look and style that has been copied around the world including Aotearoa New Zealand. 
Dia de los Muertos: Dia de los Muertos was a dying indigenous celebration in Mexico until the Chicanos in the Chicano Movement in the 1960s brought it back to life in the border region as a way to create community and to generate a sense of pride for our cultural background (Marchi 2009). It was also a way to build a political movement, as more and more Chicanos became aware of their history and joined in the celebration, the more they became politicised and were willing to speak up and be counted. Dia de los Muertos is an Indigenous day of celebration for our dead ancestors. It is a day to remember and honour them. We go to the cemeteries, clean up their graves, lay fresh flowers, and then if the weather is good, we sit and have dinner with them. We also build altars for them in our houses. We burn sage and put marigolds on the altar to help them find their way home to us. We put all their favourite things on the altar. We put food, pictures, records, whatever they liked, as well as a toothbrush, fresh water, soap, a razor for the men, makeup for the women, so that they can clean up from their long journey back from the other side. We then have dinner with them and talk about the good and bad times we had with them. Originally it was a monthly occurrence but when the Spanish colonisers came, they restricted it to two days in November that coincided with the Christian holidays of All Souls Day and All Saints Day. They were hoping that the Indigenous would forget their rituals and become Christians, but that didn't happen. Today there has been a resurgence in the celebration in Mexico. It is now bigger than it ever was (Marchi 2009).

Aztec dancers: The Aztec dancers are a staple of our celebrations in the Chicano world. They are a direct link to our past and no celebration would be complete without them. They are the proud representation of our strong warrior past and help us connect with that past in the present. This is similar to the Māori haka dancers who perform at pōwhiri's showing the historical strength and courage of the Māori warriors to defend their iwi, hapū and whānau,

Several of the Nahuatl/Aztec gods are represented:

Xipe Totec: One of the oldest deities is the great god Xipe Totec, the god of spring and fertility (Torres: 145). He was responsible for the breaking through of spring to a new season, as well as the transition of young men into manhood. He was a curer of sicknesses, especially those of the eyes. One rite in his honour was when his impersonators wore the skins of the victims who were killed in gladiatorial fights during his festival (Thompson 1957). 
Centeotl: Centeotl was the goddess of maize and agriculture, and was known, according to Clavigero, by the title, among others, of Tonacajohua, meaning "she who sustains us". Corn originated in the Americas and now is a staple food around the world and we call ourselves the children of the corn (Sturtevant 1885).

Chalchiuhtlicue: Chalchiuhtlicue was the Aztec water goddess and was closely connected to rivers; the mountains are said to be hollow reservoirs of water from which rivers flow.

Chalchiuhtlicue is believed to be responsible for the birth of the first man and woman. A statue of her on exhibit at the National Museum of Mexico depicts her as a river goddess lying on her back with a nopal cactus growing out of her body that symbolises the human heart (Altman 2002: 20).

Huitzilopochtli: Huitzilopochtli was a solar god and the god of war. More than this, he came to embody the feats and aspirations of the Aztec-Mexica people themselves. At the Templo Mayor, the Great Temple in the heart of Tenochtitlan, Huitzilopochtli was worshiped alongside Tlaloc, the god of rain and, indirectly, of agricultural fertility, who had ancient roots in Mesoamerica. Together the cults of Tlaloc and Huitzilopochtli reflected the economic basis of the empire: agriculture and war/tribute (Boone 1989: 2).

Mayahuel: Mayahuel is the Aztec goddess of the maguey (or agave) plant and represents the maguey plant and all of its products, including the fermented drink pulque. Mayahuel is also the goddess who brought love to mankind. As the story goes, Quetzalcoatl fell madly in love with Mayahuel, the granddaughter of one of the terrible night-demons called tzitzimine. Quetzalcoatl stole her away to Mesoamerica where the two expressed their love by turning into an entwined two-fork tree. Mayahuel's enraged grandmother tracked her down. Mayahuel was torn to pieces by her grandmother and a host of tzitzimine who fed on her flesh. Weeping, Quetzalcoatl buried the goddess's remains. His tears saturated the earth. In time the remains of Mayahuel grew into the maguey plant from which men and women learned to make pulque from the plant's milky sap (Torres: 143).

Quetzalcoatl: Quetzalcoatl is the Plumed Serpent andis also known by the names of his avatars, or nahauls: Tlahuizcalpantecuhtli, Lord of the House of Dawn, or Morning Star, or Venus, Ehecatl, Lord of the Wind, Ce Atl (One Reed) and Xolotl (Monster), and White Tezcatlipoca to contrast him with the black Tezcatlipoca. An ancient Mesoamerican deity, he is one of the main gods worshipped by many Mexican and Central American civilizations, including the Olmec, the 
Mixtec, the Toltec, the Maya and the Aztecs. The Mayans call him Kukulkan and the Quiche Gukumatz. He is the god of life and fertility. He is the creator of humans, for whom he invented agriculture and to whom he gave the calendar. He gave people maize (corn), having stolen kernels of corn by changing into an ant and stealing them from the ants that had hidden it. He is the patron of many arts and industries. He is also the patron of twins, himself being a twin god (Torres: 138).

Tezcatlipoca: Tezcatlipoca is known as the Trickster and Supreme Deity, whose name is a linguistic apotheosis of Aztec conceptual thought, "Lord of the Smoking Mirror" and "his abode was everywhere in the land of the dead, on earth, [and] in heaven" (Henry B Nicholson 1971a: 412). Like the wind, he is invisible. Like a shadow, he moves across the land (ibid.,book 1; 5). In other words, Tezcatlipoca crosses spatial and mythical boundaries with impunity as a truly shaman-like transformative figure (Saunders 1990).

Coatlique: Coatlique, the Earth-Mother Goddess, is called the Snake Woman or One with the Serpent Skirt. She is also known as Tonantzin, which means "Our Mother." Coatlique is the mother of Huitzilopochtli, the god of war. This goddess brings adverse things like poverty and ruin. She is known to devour everything around her (Torres: 142).

Tepeyollohti: Tepeyollohti, the most important of the jaguar gods, is the god of earthquakes, echoes and is associated with the night, caves and the Underworld. He is related to Tezcatlipoca. He is depicted as a jaguar leaping towards the sun (Torres: 142).

Huehuecoyotl: Huehuecoyotl, known as the Old Coyote, the Trickster, and god of deception, is a prankster who loves to pull pranks on people and on the gods. Sometimes he unwittingly pulls pranks on himself. He is a shape-changer, able to turn himself into any shape, animal or human (Torres: 142).

Tlaloc: Tlaloc is the god of rain. The 16th century Franciscan Bernardino de Sahagun writes of Tlaloc: "This god called Tlaloc Tlamacazqui was the god of rain. They said he gave them the rains to irrigate the earth and that these rains caused all the grasses, trees, fruits and grains to grow. It was he who also sent hail and thunder and lightning and storms on the water and the dangers of the rivers and sea. The name Tlaloc Tlamacazqui means that he is the god who resides in the terrestrial paradise and gives to men the subsistence necessary for life" (Moctezuma 1985). 
Tonatiuh: Tonatiuh is the Aztec god of the sun. Tonatiuh means He Who Goes Forth Shining (Brundage 1983: 7). The Aztecs were vigilant observers of the heavens. Their ancestors, the wandering Chichimecs, considered the sun to be their father, and they drew attention to this affiliation by wearing on their backs an appropriate emblem, generally a sunburst of yellow parrot feathers. The sun was that celestial object excelling all others in lordliness and in the daily drama of his appearances and his exits. He was therefore a focal point of Chichimec mythology.

\section{Interactive projection system}

The interaction system consisted of several different elements that worked together to create the interaction with the body cast: the Kinect sensor, WATCHOUT projection software, and two high speed computers.

I developed a routine that I followed every time I set up the Illustrated Chicano in a new space. I would set up the body cast in a room and then setup the Kinect sensor in the same room. The Kinect was setup so that the field of view of the Kinect's hi-res colour camera and three infrared cameras included the entire body cast and the room. I would then enter the room. The Kinect would recognise me and start tracking my body. Through the writing of specific coding, the Kinect would focus on the position of my fingertips. I would walk over to the body cast and position my index finger where I wanted to register a specific point of reference on the body cast. I would have my assistant log this position with a specific name and number into a separate file. I would then move onto the next reference point. I did this until I had the entire body cast covered with twenty reference points. The next step was to go back and test each point for accuracy and then assign the point a tolerance level making it easier to find the reference point. These reference points were the key to the interaction with the audience. These points were used by another software as triggers points. Whenever a person entered the room the Kinect would start tracking them and their index fingers. If that person connected his or her index finger with one of the reference points on the body cast, it would then trigger an event on the body cast. This interaction could be repeated until all the trigger points on the body cast were engaged, creating a seamless and organic interaction between the two different worlds.

\section{The Kinect sensor}

The Kinect sensor was a key component to the Illustrated Chicano. It was the interface between the human world and the technological world. It was the invisible bridge between our reality and 
the digital reality, the instrument that created the environment which allows the organic interaction of the audience with the work.

The Kinect sensor was originally developed by Microsoft for their Xbox 360 gaming consoles. The sensor was introduced to the public on June 1, 2009 at E3 2009 under the code name Project Natal and on June 13, 2010 at the E3 conference at Galen Centre, the sensor was officially given the name of Kinect. (Corden 2018: 1)

The main reason I used the Kinect in my project was that the system has the ability to do full body skeletal mapping of up to six people at a time. This skeletal mapping can not only identify a human subject but was capable of recognising body parts heads, shoulders, arms, legs, torso, feet, as well as fingers and finger tips. The fingertip recognition was the part that I was interested in.

The Kinect system was able to track a person's fingertip in 3D space: X, Y, Z, height, width, and depth within a three-meter space in front of it. The Kinect was able to do this through a complicated set of algorithms developed by Microsoft software engineers that is too complicated to lay out here for my thesis. It is a thesis on its own. This ability to track a single fingertip through space and to assign numbers to the position of the fingertip at any given moment was critical to my project. These numbers were very accurate and could be logged and found again and again. This meant that I could find a specific point in space and use that point as a reference point time and time again as long as the Kinect was not moved from its location in the room.

In this project I only used one of the many different ways that the Kinect can be used for creating interactive installations. The way I used the Kinect sensor in The Illustrated Chicano is the only known instance of the device used in this manner, to trigger events on a three-dimensional surface. Most uses of the Kinect sensor as an interactive device have been to use it on twodimensional surfaces, such as a wall, screen or table top. My application of the Kinect on a threedimensional surface like my body cast is a first.

\section{The computer system}

The computer system I used was part off the shelf, part custom-made. I needed to use two computers for the body cast. Because of the different software being used in the computers to create the interaction with the body cast, the two computers had to be running on two different operating systems. The Kinect, because of its high processing speeds and power requirements, 
would only run on a Windows 10, 64 bit system, while the WATCHOUT Projection Display software would only run on a Windows 7, 64 bit system. (Since the completion of The Illustrated Chicano, WATCHOUT has been upgraded and can now run on a Windows 10 system.)

\section{The projection system}

The projection system was run by a software called WATCHOUT created by Dataton. WATCHOUT is a multi-display software program used around the world in stadiums, arenas, theatres and concert halls for controlling and programming video projections. I have been using it for ten years now, but this is the first time I have used it in connection with an interactive device. This ability to integrate an external control device that can be used as an interactive link with WATCHOUT software has been a newly developed by WATCHOUT in the last few years.

This is the sequence of events that occurs when a visitor engages with the technology used for the Illustrated Chicano. When a person enters the space, the Kinect sensor recognises the person and starts to track them. The sensor reads the position of the person's index finger in the threedimensional space and tracks the index finger. When the finger comes in contact with one of the reference points on the body cast (A), a "yes" signal is generated that references this specific point (A). This "yes" signal is sent to another software written by me that transcodes the "yes" point (A) signal from the Kinect into a language that WATCHOUT can understand; "yes" becomes "GO" point (A). When the WATCHOUT production computer receives the transcoded point (A) "GO" signal, WATCHOUT sends it to a processer that looks for an event that references point (A), when the GO signal is applied to reference point (A) an event takes place. In this case WATCHOUT is telling a specific video to start playing at this specific place on a specific screen. This event play signal from the WATCHOUT production computer is then sent to the WATCHOUT display computer which starts the corresponding event which is sent out to the corresponding projector to be output through the projector onto the body cast. After a pre-determined time, all the reference points reset to start the process again.

\section{Special projection coating}

The final piece of the Illustrated Chicano is the coating on the body cast. Working with projections is working with light. Light can be affected by many different things. It can be easily defused and washed out. Unfocused light has no detail. While this is good for general lighting situations, it is unwanted when working with projections. The goal with projections is to bring as 
much detail and clarity to an image as possible. Projections require an image that is recognisable to an audience.

To do this, projections requires three things. One, a space where the light level can be controlled. Two, a bright projector that emits a strong focused ray of light. Three, a surface that can reflect as much focused light as possible. With the Illustrated Chicano I solved the first problem by installing in the gallery space of Thistle Hall where I could control the light. For the projector, I was able to borrow a 3000 lum projector from Circuit Artist Film and Video Aotearoa New Zealand, an organisation in Wellington run by Mark Williams. I had a space where I could control the light and a focused light source.

The last part of the puzzle was the highly reflective projection surface. The body cast was made out of plaster-impregnated gauze. Plaster is a white dull surface that does not reflect a lot of light, instead it absorbs light. How do I turn a surface that absorbs light into a highly focused reflective surface? After doing research online and talking to other projection specialist, I came upon a company called Goo Systems Global, who produce a product called Screen Goo. Screen Goo is a spray on projection surface.

As explained on their website, Screen Goo products are specially formulated, colour corrected, screen coatings in liquid form. They are designed to achieve the highest performance levels possible for a given display situation. Wall paint is designed and engineered principally to cover an underlying surface and to provide colour in a room. By contrast, Screen Goo has been specifically engineered to accurately reflect and disperse the complex coloured light patterns produced by video projectors. To that end, Screen Goo starts by employing a premium acrylic dispersion with very low light absorption characteristics and excellent durability. To minimise light loss and to ensure colour fidelity, Screen Goo uses much greater concentrations of pigment than those found in house paint. These pigments are carefully chosen to accurately reflect the full spectrum of colour produced by video projectors as opposed to house paints where the goal is to reflect that portion of the light which produces the single desired colour. In addition, Goo Systems employs proprietary dispersion and pigment treatment techniques to maximize the reflective properties of the pigments employed. These techniques require custom built machinery and are very time and labour intensive.

Lastly, unlike wall paint which involves the application of a single product, a Screen Goo application consists of two different products. Screen Goo Reflective Coats provide an ideal $\mathbf{1 3 6} \mid \mathrm{P}$ a g e 
reflective surface to which a diffusive, colour correct Finish Coat is added. It is the combination of the Reflective Coat and the diffusive Finish Coat which gives a Screen Goo screen its remarkable qualities of high reflectivity, colour accuracy, wide viewing angles and excellent contrast. The icing on the cake is the very special sense of image depth or feeling of looking into the picture that only a Screen Goo screen provides(Global 2018).

It took two days to apply the Screen Goo to the plaster cast and another week for it to dry enough to touch and handle. It made a tremendous difference in image quality. The Screen Goo enabled me to install the Illustrated Chicano in a normally lit room where the visitors could still see the detail work on the body cast, table top and plinth but the projections still retained the crispness and colour saturation that usually comes from screening them in total darkness.

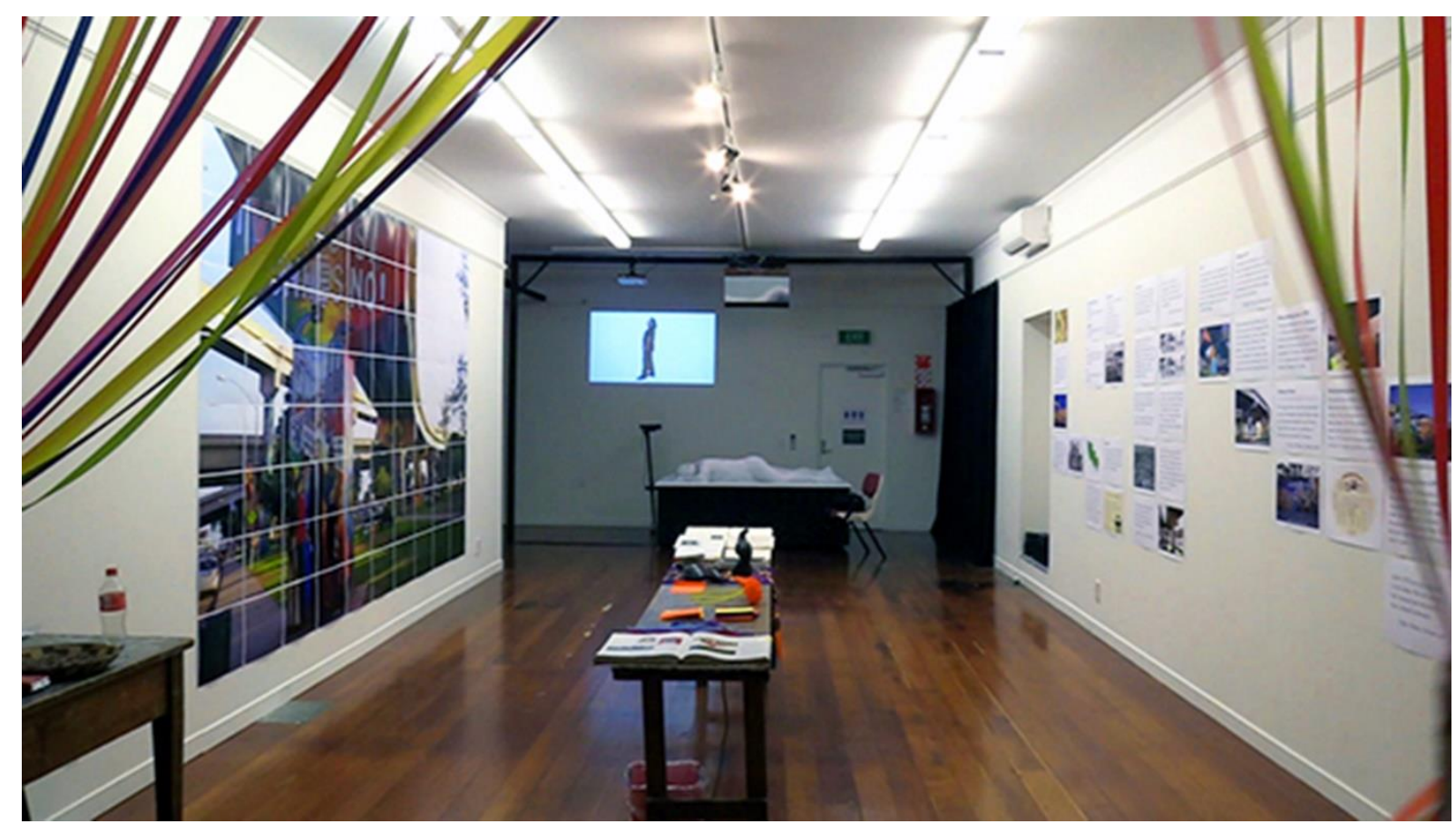

Image 24 The Illustrated Chicano Installation Wide (Photo by William Franco)

\section{Conclusion}

In this chapter, I have shown how I started my decolonising process through my reconnection with the Centro Cultural de la Raza in San Diego where I started to learn more about my culture's history and struggles in the Americas. I have also shown that this decolonising process is not a once and done event but a series of ongoing re-engagements as I continue to perform my decolonising process through with my art practice with artworks like The Illustrated Chicano. 
I analysed how I re-discovered my Chicano identity and learned how to create Chicano art through my many conversations and collaborations with other Chicano, Indigenous and nonIndigenous artists over the years in North America and Aotearoa New Zealand.

I discussed how my concept of borders have changed over the years. From my discovery of Chicano Border consciousness along La Frontera and the evolution from that point of view to the geographical borders, technical, intellectual, and spiritual borders as captured in my body of artwork created over the course of my career.

As part of my practice, I used my Chicano Border Methodology's decolonising method because it provided me the space to look at subjects from my Indigenous viewpoint rather than a western art perspective, thus giving me a freedom to explore issues from a different perspective than what is considered the western norm. The Illustrated Chicano is an example of this. I used the principles outlined in chapter three (page 62) to create the interactive installation in Te Aro Wellington. The principles around community and community engagement were used to invite community interaction not just on a physical level but on a spiritual and intellectual level. Using materials, technology and ritual, I asked my audience to leave the comfort of their world and to look at the world through my eyes for a moment.

Through The Illustrated Chicano, I investigated the topic of finding place and home here in Aotearoa. I found it to be a very complicated topic, full of issues around race, economics, languages, and colonialism, without any clear answers. I found it to be a fertile place to visit and explore, a place that I would like investigate further at a future time.

I then meticulously examined each element in The Illustrated Chicano installation through the lens of my Chicano Border Methodology. I detailed how each of the elements in The Illustrated Chicano was conceived of and why it was chosen as part of this installation. There was nothing used in the installation that was there just because it looked cool or acted cool or was fashionable at the time. Each element was there to help move the story along. An example of this was the surveyors tape curtain that looked inviting but was actually a device used for illustrating the colonisation of Indigenous land.

I talked about how each of these elements crossed some type of border to be part of The Illustrated Chicano, from the physical elements such as the plaster from the land, that by adding water to it, starts a chemical reaction that turns it from a dusty powder to a hard rock element to $\mathbf{1 3 8} \mid \mathrm{P}$ a g e 
make the body cast; the California sage plant that went from an organic life form to a smokie haze as it was burned to purify the space; and the Siri iron wood cravings that came 10,792 km from Baja California to be part of the Knowledge Table. The Kinect sensor crossed technical borders with the special border crossing communication language between it and the Watchout Projection software to make the interaction between the technical world and the physical world possible.

I talked about how I crossed the internal borders of my mind to the external world with the imagery that represented my internal processes as a Chicano male, digging deep inside, looking for images to best represent my Chicanismo (pride of being a Chicano)—images such as the border fence, lowrider cars, Dia de Los Muertos (Day of the Dead) celebrations.

I talked about all of this through the Indigenous lens of my Chicano Border Methodology. In the next chapter, I explore the last element of my re-construction process, the visitors to the installation, their interaction with the artist, and how those interactions transformed them and the artist as part of the Chicano Border Methodology. 
$\mathbf{1 4 0} \mid \mathrm{P}$ a g e 


\section{Aludínce liksponse chapter $\mathfrak{s i x}$}


$\mathbf{1 4 2 | P}$ a g e 


\section{AUDIENCE RESPONSE chapter six}

My goals for the installation are: (1) to demonstrate a successful practical application of my Chicano Border Methodology in a real-world setting and (2) to facilitate a transformational space where people have an opportunity for de-colonisation. To find out if I was successful in researching my gaols, I needed to analyse the responses of the people who attended the installation and that is the focus of this chapter.

I have often noticed that when I enter a gallery, there is this sense of entering a sterile noninviting, alien space that lacks an emotional connection to me. I am forced to find an emotional or intellectual connection with the artwork in the gallery because the gallery does not connect with the location, the work or me the viewer. I will discuss how all these elements-location, work, artist and viewer-are connected under a common theme of a decolonising methodology. I will discuss how the experience of being in a decolonising space can be a transformative experience for the visitor.

To nurture a transformative environment for the visitors, I needed to create a space where knowledge was embodied and active, where knowledge was performed. I achieved this through how I interacted with the visitors and how the visitors were able to interact with the various spaces in the installation. For example, when I was exhibiting The Illustrated Chicano, the entire time that the gallery was open, my partner Miki Seifert and I were in the gallery, greeting everyone as they transitioned into the Chicano space. We were their spiritual and informational guides while they were in the space. We were there to answer questions, share our knowledge and to listen to their responses to the work. As a bonding ritual, we invited people to sit down and make paper flowers while we talked about the work. Everyone was treated as a special guest to our Chicano house.

The Illustrated Chicano was presented 23 - 29 of October 2017 at Thistle Hall in Wellington, Aotearoa New Zealand. The installation was open to the public during the two-day installation period and officially opened for five additional days. Seventeen people watched the installing of The Illustrated Chicano and 196 people viewed the completed installation after the opening.

To be able to talk about the transformation of the visitors, I gathered their responses to the installation. I collected responses to The Illustrated Chicano in two different ways: a simple survey 
and one-on-one dialogues with the visitors. My ethics approval number is 20091. I will start with the written responses from the surveys.

\section{Surveys ${ }^{14}$}

What I have noticed during our installations is the reluctance of people to fill out surveys in a gallery and this installation was no different. People are more open to having face-to-face dialogues about the work. However, six visitors agreed to fill out the survey. Below are the results of these surveys.

The survey was divided into four parts:

- two short answer questions

- five agree/disagree questions

- six multiple choice questions

- two short answer questions

The survey template can be found in Appendix. I have distilled the demographic information into the tables below.

Table 1: age groups

\begin{tabular}{lr}
\hline Age groups & Years \\
\hline $13-19$ & 2 \\
$20-29$ & 1 \\
$30-39$ & 0 \\
$40-49$ & 0 \\
$50-59$ & 1 \\
$60-69$ & 2 \\
\hline Total & $\mathbf{6}$ \\
\hline
\end{tabular}

The survey results suggest that the visitors were at either end of the age spectrum with none from the middle. However, my observations of the visitors were that there was a significant number of visitors from the 30-50 age range who came to the installation. I posit that the younger and older visitors had more time to stay and complete the survey.

\footnotetext{
${ }^{14}$ The survey was included because I was conducting my research within a western academic institution. It is not an integral part of Chicano Border Methodology.
} 
Table 2: gender

\begin{tabular}{ll}
\hline Sex & \\
\hline Male & 1 \\
Female & 5 \\
Other & \\
\hline Total & $\mathbf{6}$ \\
\hline
\end{tabular}

The survey results show that there was a ratio of five women to one man. This is consistent with my observations.

Table 3: cultural background

\begin{tabular}{lll}
\hline Cultural background & & \\
\hline NZ European & 4 & \\
Pākehā & 1 & \\
Māori & 0 & \\
Other & 1 & Scottish \\
Other & 1 & White New Zealander \\
\hline Total & $\mathbf{6}$ & \\
\hline
\end{tabular}

The survey results show that the survey respondents were all of European descent. Given the location of the gallery on Cuba Street, in downtown Wellington, the capital of Aotearoa New Zealand, the seat of government I would expect the visitors to be predominantly European Pākehā (non- Māori). There were others, including Māori, Pacifica, Japanese, Chinese and Chicano, who did visit the installation but did not fill out a survey. What I found interesting was how differently the respondents identified themselves. For example, one visitor checked the 'Other' box and wrote in 'White New Zealander'. This person had the opportunity to check either the box labelled 'New Zealand European' or the one labelled 'Pākehā' but instead they made the conscious decision to mark 'Other'.

Table 4: emotional responses

\begin{tabular}{lccc}
\hline \multicolumn{1}{c}{ Statements } & $\begin{array}{c}\text { Strongly } \\
\text { agree }\end{array}$ & Agree & Total \\
\hline I felt moved or inspired & 4 & 2 & 6 \\
I felt engaged in the experience & 5 & 1 & 6 \\
I was exposed to new points of view or ways of seeing things & 5 & 1 & 6 \\
It made me want to know more about what I was seeing & 4 & $\mathbf{2}$ & 6 \\
\hline It felt relevant to our society and the times we live in. & $\mathbf{5}$ & $\mathbf{1}$ & $\mathbf{6}$ \\
\hline
\end{tabular}

The survey results show that overall the respondents had a very positive interaction with the installation. They were positively affected by the installation and wanted more information about 
the subject matter of the installation. When asked if there was anything, they didn't like about the installation they all answered "No". There were no negative responses in the surveys.

I have listed the responses to the last two short answer questions below. These answers suggest that the way I had designed The Illustrated Chicano installation as a Chicano interactive space worked well for the audience. After looking at the responses, it turns out that the two youngest respondents liked the cultural aspects of the installation more than the technical aspects. The age range was 13-29-year-old, one was female and the other was the sole male respondent. While the remaining four female respondents in the 50-70-year range, were more impressed and interested in the technical aspect of the installation. I can only speculate that the younger generation grew up playing with technology so it was not that interesting or new to them, while the older generation are still experiencing some of the technology and what can be done with it for the first time.

\section{Survey question: What did you like most about The Illustrated Chicano?}

- I liked how it was culturally informative. The way it was presented made it easier to understand and more memorable. I liked that there was a good historical background.

- The variety of different media. The interactive body form. The clarity of the textual aspect.

- The projection of the Illustrated Chicano! A really cool interactive piece.

- The way it informed me both culturally and historically. I knew the history but to learn more about the cultural context was very interesting.

- I liked the lying figure. I loved the projected images and the way the body affected images and landscapes. The idea of the body inside the place and the place inside the body.

- The mixed media approach, touch, Moko, scenes, visual. The mix of surface kinaesthetic experience and intellectual depth.

Survey questions: Is there anything else you would like to share with us about your experience of The Illustrated Chicano?

- Very welcoming and cultural. Presented very nicely.

- I really appreciated the gallery being open late and the artist's openness in discussing the work and its context. 
- It was a great learning experience (:)

- Again, it was interesting to learn about the cultural context of a history of a people.

- Great Inspiring.

- Easy to engage with on both purely aesthetic level and an intellectual level, Thoughtful, emotional.

Regarding the visitors' response to the installation, the difference between the above written answers and the one-on-one dialogues was minimal. So even though it was a small sample of surveys, it seems to be a good reflection of the overall audience response to the work.

\section{One-on-one dialogues}

As I mentioned, Miki and I were in the gallery during opening hours. We made specific efforts to ensure that the visitors knew that we were there to engage with them. We would greet them when they entered the gallery and ask them if they had any questions. We also looked for non-verbal signs, such as puzzled looks, that indicated that they had questions, and would non-intrusively approach them. These efforts gave rise to a number of dialogues. Some were brief while others were more in depth and free-ranging.

This, in the western perspective, can be considered anecdotal evidence of the success of the exhibition because it is based on personal accounts rather than scientific research. But in the context of this thesis, and as discussed in the chapter four, this information is factual, valid, research material and knowledge that can be included as research within this thesis. This is similar to post-performance question and answer periods that dancers and actors have that are included as part of the project outcomes in practice-led research thesis. This research material was more informational and supplied me with more candid and authentic responses than I could get from an anonymous paper survey. It also reflected more the transformational effects of the exhibition that were not captured in the written surveys. I discuss audience responses to the installation and how they were transformed in the three different areas of the installation: Transitional Space, Contextual Space and Interactive Space.

\section{Transitional Space: surveyors tape}

The surveyors tape was the first thing people saw. Several visitors mentioned that they were walking by the gallery when the brightly coloured curtain caught their eye and they had to come in and have a look. They said that it was inviting them to walk through. It was very colourful, 
tactile, and fun. They could feel the tape as it gently caressed their body as they entered and exited the gallery. They had the feeling that they were walking into something different, that something was happening to them as they walked through the tape, something enjoyable. This was the first of the transformation spaces in the installation. It was a tactile transformation that people could recognise and feel on their bodies.

There was a lot of curiosity about the curtain at the entrance of the gallery. The visitors asked about the significance of the colourful tape curtain. I would explain to them that it was a symbolic border they were crossing from Aotearoa New Zealand into Aztlan, the homeland of the Chicanos, a place where Chicano rules apply. I explained that this is how addressed the question of Māori tikanga regarding a sculpture of a body lying on a table. I also pointed out that I was re-appropriating the surveyors' tape and making it my own. I told them that surveyors tape has been part of the colonial machinery that takes land away from Indigenous peoples around the world.

When I explained why I used it, they understood. When I told them what it was made of, they were surprised. Most of the people who entered the gallery did not know the significance or history of surveyors tape until I explained it to them. They had never thought of surveyors tape in that way before. It was an experience that they were not expecting when they entered the gallery. People thought it was a great way to use surveyors tape and they could relate to the idea of surveyors tape being associated with colonisation here in Aotearoa.

A couple said that the use of surveyors tape to form the border between Aotearoa New Zealand and Aztlan fit perfectly with the piece. This is where the performance of sharing my knowledge changed their perception and understanding of surveyors tape. Everyone who entered and left the gallery space had access to this information as part of the installation experience. This is an example of how performing knowledge, e.g. the action of going through the surveyors tape, facilitated transformation.

\section{Contextual space: knowledge table and Chicano Park}

The story of Chicano Park resonated with the visitors and allowed them to find a point of commonality with Chicanos and help the visitors to be able to transforms their unfamiliarity with Chicanos and find a sense of kinship with them. The visitors shared their own stories of similar events as Chicano Park that they knew of and had happened in Aotearoa. 
One visitor saw similarities between the founding of Chicano Park and the Māori protests at Bastion Point in 1977.

An attempted subdivision of disputed land at Bastion Point in Auckland led to the occupation of the site by protesters united under the Banner of the Orakei Māori Action Group. The history of this land is one of confiscation in contradiction to the terms of the Treaty of Waitangi. After 506 days of occupation, the protesters were finally dislodged by a large contingent of police and army personnel. The group lost the battle but won the war, as ten years later the government made a formal apology and returned the land to the Ngati Whatua tribe with compensation (Leask: 204).

At Bastion Point there was a history of confiscation of land belonging to the Māori community. The fact that the Māori community rose up to fight the government confiscation was a key moment in the history of Aotearoa New Zealand. Because of a similar history of resistance, the visitors who came into the gallery could feel a comradery with the Chicanos of Barrio Logan. I think it is important to note that there was a significant point of difference. The land in Barrio Logan was already a thriving community with houses and businesses built on the land. Also, the government never apologised for this treatment. Still the community remains.

Another visitor related it to Wellington's controversial Vivian Street by-pass project, just a block down from the gallery. The initial plans for the by-pass went through the city council to build a highway off-ramp. "There was protest from the Wellington community but the construction went on as planned" (O'Neil 2015). Even though the community protested and took a stand, the construction of the by-pass went ahead after a protracted time of planning. With the construction of the San Diego Bay Bridge, the community was left to pick up the pieces. Unlike the Vivian Street by-pass, the Barrio Logan community were able to reclaim some of the land and built a park without assistance from the city government. It wasn't until a few years later that the city government helped support the construction of Chicano Park, as well as the painting and maintenance of the internationally recognised murals. The park then became the centre for community activity.

One of the main similarities between these events in Aotearoa and Barrio Logan that everyone who visited the gallery saw and acknowledged, was that they were all instances of the power of 
community activism. Some actions were more successful than others, but they all made a difference to the communities involved.

There was one response to the story of Chicano Park that I found of particular interest. After reading the material detailing the history of the park on the wall of the gallery, a woman remarked that the whole event was an example of institutional terrorism. I had not heard that term before. But upon researching the topic later, I came across a book by William D. Perdue titled, Terrorism and the State: A critique of Domination Through Fear, where he talks about terrorism and institutional terrorism. Perdue describes it as:

From an institutional perspective, the means of domination through fear may be embodied in the modern nation-state... It holds a monopoly on many forms of lethal force, including that exercised by the military and the police" (Perdue 1989: x).

"Accordingly, it confers upon those who control it, whether directly or indirectly, the power to intimidate or coerce both domestic and international opponents and to do so efficiently and continuously over time (Perdue 1989: x).

I had always looked at the founding of Chicano Park from a Chicano activist point of view, how one small community fought the giant US government and had a small win. I had never looked at it from a different angle as a planned governmental exercise in terrorism but I think it does apply to Barrio Logan and Chicano Park. This community had endured this subtle form of on-going terrorism for many years as was explained in the text of the wall panels. Similarly, another woman who referred to herself as a feminist said that the Chicano Park event was abuse by the state.

\section{Interactive space: the Illustrated Chicano video}

The video of me rotating around in circles stopping to reveal an aspect of what a Chicano is, generated tremendous responses. I would be in a different part of the gallery and would hear a burst of laughter coming from the direction of the video. I would turn around and see a group of people watching the video. I had several brown men come up to me afterwards and say, "Yeah bro, I know what you mean." Or they would point out to me what they were wearing, showing off their dark sun glasses and dark clothing. Both women and men would laugh, as some of the statements in the video were done in a self-effacing manner, poking fun at how I view my Chicano myself. For instance, saying why I wear sunglasses day and night: “just because I look cool and to check out the Chicas". Most visitors saw the humour even in the statements that were directed towards Chicanos in general, like the way we stand. Using humour to disarm 
visitors proved a successful approach. They were more open to the more serious comments about colonisation and being Indigenous after having a laugh.

\section{Interactive space: body cast}

When visitors first saw the body cast, they were not sure of what to do. Were they just supposed to view it and watch the images play through? How were they supposed to interact with the body cast? I wanted them to feel free to touch and explore the cast. This was important to me because this exploration is not allowed in most galleries and museums.

Before coming to Wellington, I worked at the Museum of Contemporary Art in Los Angeles (MOCA) as their AV technician. I would wander around the museum all day setting up exhibits and checking that equipment was working correctly. I would watch the way people acted around the sculptures. If there was someone else in the room who looked official, they kept their distance from the sculptures. If they thought they were alone or that no one would see them, they would start to touch and explore the sculptures, enjoying the curves and textures of the works. Once other people entered the room, they would back away. I understood their reaction completely.

Thirty-five-years ago, I visited a major museum with a sculptor friend of mine. She went around touching all the sculptures and commented on how they felt and what the artist was trying to say with the work. She told me that sculptures were meant to be touched. How else could you get the same feeling and meaning out of the work without experiencing the sculpture from the artist's point of view? However, people are now told not to touch sculptures and so they have lost that tactile interaction with sculptural art works. I wanted people to get that tactile interaction back with the Illustrated Chicano.

This was one of the reasons why I was in the gallery the entire time the work was on display. I wanted the visitors to see how I interacted with the work. I wanted them to understand that their tactile interaction with the body cast was an expected part of the experience. So when they saw my interaction with the body cast, they realised that they had license to interact with it on their own. This non-verbal communication instantly transformed the way the visitors acted in the space. Once they realised that they were allowed and encouraged to touch the body cast, they actively engaged with the body cast. 
I was concerned that people might have an issue with touching the body cast of a naked man. This is the reason I chose a prone position. However, most visitors had no problem with this. As a matter of fact, the young kids between three and seven years old were the ones who seem to get the most fun out of touching the body cast. They enjoyed the fact that something happened when they touched it. They had no concerns touching an object that resembled a male figure. One woman told us that she enjoyed the texture of the body cast and the feel of the material so much, that she had spent a half-hour wandering around the table touching it. This license to touch and feel the Illustrated Chicano transformed the audience's sensibility and relationship to sculpture as it was presented in the gallery.

\section{Interactive space: video projections}

The visitors quickly picked up the idea of place and home as they explored the installation. I had dialogues with around 40 visitors about immigration, place and home. The question of place and home seemed to resonate with people here in Aotearoa New Zealand. As this world gets smaller, this question of home is getting more important in people's lives.

The installation transformed a gallery space into a communal and community space, where discussion and debate about immigration, place and home could take place. It transformed the gallery into a place where people felt comfortable to share their own, or their families, experiences immigrating to Aotearoa New Zealand. They shared their feeling of displacement and loneliness in a foreign country with us and other gallery visitors. One visitor from the US said that Aotearoa felt familiar but different-simple things like which side of the road to drive on, rubbish (Aotearoa) versus trash (US), sitting in a theatre having ice cream and wine; Pavlova and Marmite, paying rent weekly (Aotearoa) rather than monthly (US), and yeah, yeah, no. Another visitor talked about how they had difficulty fitting in. They mentioned how their families had to struggle to find a place to call home. We shared our difficulty with a new culture and language. A visitor from Columbia mentioned how US English is easier to understand than New Zealand English which is very British-influenced.

\section{Interactive space: tattoos}

Many visitors commented on how they liked the tattoos and their associated videos on the body cast. The tattoos were a great storytelling device. They were an effective way to externalise the internal and show the internal thought process of me as a Chicano man. From a cultural perspective, because it was a Chicano piece and I used my own designs and designs from my own 
tribe, and since I was not using or appropriating Māori designs, no one had any problems with the way I used the tattoos. In fact, they served as a point of reference and commonality between cultures, something Māori and Pākehā could identify with.

\section{Interactive space: plinth}

Visitors noticed how the Zapotec designs on the plinth resembled Māori designs, except they were more geometric, squarer, not as flowing as the Māori koru designs. Because of this, visitors were able to connect with these images, finding a commonality with them. One visitor commented on how the designs from various Indigenous groups around the world seem similar even though they were thousands of miles apart. Many Indigenous designs are representations of nature. As I had mentioned in chapter five, the designs I had chosen for the base were Zapotec designs for land, mountains, and earth as well as designs representing water and waves, flowing across a lake or sea. I used these commonalities as a way to transform feeling of the 'Other' to feeling of kinship.

\section{Interactive space: technology}

There was strong positive feedback on the technology used in the installation. I had several discussions with two software developers from the Wellington area who kept coming back to the installation, bringing friends with them. The two were interested on how I was able to integrate the different systems required to make the installation function. They had never seen the Kinect technology used in an interactive environment before and didn't known that the Kinect sensor was so versatile and programmable. They thought it was a brilliant use of the technology. They were very interested in the code writing required for the communication between the various pieces of hardware used in the installation.

Other visitors commented on the viewability and resolution of the projected image on the body cast. They were impressed with the clarity of the image in the bright gallery light. Two visitors said they had seen other projected work in regular gallery lighting and they had looked dim and without much detail in the image. Others mentioned seeing projections in black voids where the sole focus was the projection. 


\section{Two stories}

To conclude my discussion of the visitor's response to the installation, I would like to share two conversations that sum up for me what installation was able to achieve. The first was with a small group of Māori and the other was a chance encounter with a young woman from Barrio Logan.

\section{Māori and Chicanos}

Two Māori men and a Māori woman artist came in to see the exhibit. They stayed and talked with me for an hour. They understood what I was doing with the space. They appreciated the fact that I had taken into consideration the cultural context of the piece, that I had taken the time to learn about the area, and that I had thought about how this piece fit within the context of Te Aro. They appreciated that I had done a ritual to ask for permission from their ancestors to change the space into a Chicano space. I find that Māori culture works a lot with this concept of transformation in their rituals, for instance when they change things from tapu to noa or vice versa. They understood the concept of transformation that I was presenting in the installation. They felt and recognised the transformation when they entered the space through the surveyors tape.

\section{Barrio Logan home girl}

On the last day of the installation, a young woman was walking by the gallery and noticed the images of Chicano Park that we had hung on the gallery windows. She said she had to come in to investigate why there were pictures of her community, Barrio Logan and Chicano Park, in a Wellington gallery window. To my surprise, she told me that she had grown up in Barrio Logan. She stayed with us in the gallery for about four hours while we reminisced and talked about home. Later that night she returned to help us dismantle the installation. I asked her if she wanted the pictures of Chicano Park for her house here in Wellington. She was thrilled and happy to take them, and was excited to know that there was someone else who understood her here in Aotearoa New Zealand.

\section{Conclusion}

One of the outcomes of the process in the creation of The Illustrated Chicano was that the installation its self was transformative to the audience who saw it and provided them with the opportunity to decolonise themselves by learning about it. After discussing the responses from the visitors to The Illustrated Chicano in this chapter, I believe the goals of the installation were reached: (1) to demonstrate a successful practical application of my Chicano Border Methodology 
in a real-world setting and (2) to facilitate a transformational space where people have an opportunity for de-colonisation. The responses I received from the visitors, both in the surveys and the one-on-one dialogues, show that the installation and the methodology used to create it was successful for those who came and experienced it.

After sharing my knowledge with people, I was excited that people responded by sharing their knowledge with me. This happened time and time again. Each time this happened was a moving moment for me.

"If I am to find place and home in this land, I must venture out into the community to find it.” Willie Franco, Chicano Artist 2018.

In the next and final chapter, I summarise my thesis and what I have learned along the way in the re-construction of my Chicano Border Methodology and the writing of this thesis. 
$\mathbf{1 5 6} \mid \mathrm{P}$ a g e 


\section{Condlusion \\ chapter $\mathfrak{s e b e n}$}




\section{CONCLUSION chapter seven}

\section{Conclusion}

In the introduction to this thesis, I wrote about the tension I felt being educated in the western academic system. This thesis was a step toward resolving this tension as I re-constructed the development of my Chicano Border Methodology. The format of a critical personal narrative was instrumental in giving me the space in which to talk about the creation of my Chicano Border Methodology. The personal narrative gave me the latitude to move to and fro through different territories, to cross many borders to explain the events that influenced the development of my methodology.

Through the experience of writing about being a Chicano, I have found that my identity as a Chicano is a very complex concept. In this thesis I have viewed my identity through the lens of the physical world as a border-crosser, commuting back and forth across La Frontera, viewing this world on a sensory level, talking about the sights, sounds and smells at La Frontera.

I then transitioned into the historical lens where I talked about where Chicana/os (feminine and masculine) came from. This led me through the colonisation of the North Americas and to the Treaty of Guadalupe Hidalgo in 1848 and into a discussion about Mestizos, Mexican nationalism, Native Americans, and indigeneity.

As in the Māori whakataukī I used in my introduction, I continue to walk backwards into the future with my eyes fixed on my past, as I explored what it means to be a Border Crosser, Border Artist, Border Thinker, Native American, Mestizo, Indigenous person by positioning my Chicano identity at the cultural interface and in a contact zone which gave rise to my Chicano triconsciousness: the colonial worlds of Mexico and the US, and my Indigenous world. A way of being that encompasses the coloniser's and Indigenous worldviews, intermixing them at will to create the unique knowledge space of La Frontera. What started out as a simple discussion of my understanding of who I am and what lies beneath the term Chicano ended up crossing the borders of time, the borders of tri-consciousness, the cultural interface, contact zones, and the borderlands. These border crossings strengthened my sense of who I am in contemporary society and why I want to change the status quo of how knowledge is produced. This discussion was important because it is giving context to my positioning in this thesis and for the recognition of the Chicano as a knowledge producer. 
In my introduction I also discussed the reasons for using a de-colonising epistemological pluralism as the framework for my Chicano Border Methodology. They were to show alternative ways of knowing to counter the positivist structures in academia and de-centre the western hegemony or epistemic sovereignty that is at the centre of western academia. Through this thesis I demonstrated that there is more than one way of being in the world, a way that is inclusive of other ways of knowing such as Indigenous knowledge. Furthermore, I illustrated the validity of different forms of reality, such as the fluid reality of living and working along $\mathrm{La}$ Frontera/Mexico-US border. As an outcome of this.

To this end, I described the main elements of a decolonising epistemological pluralism framework as adapted by my Chicano Border Methodology and applied to The Illustrated Chicano Installation. First, it needs to be performative, as in performing knowledge. The knowledge I performed was the creation of a Chicano space, a decolonised space in a historical Māori location and in a historical European building in Te Aro. Performing knowledge is not limited to the arts. It is practiced in all the disciplines. Western science is performing western knowledge, and it used in disciplines from mathematics, computer design, physics, geology, ecology, humanities, economics, medicine and others. So, this aspect of Chicano Border Methodology could be used in these afore mentioned study areas, such as looking at computer design through a triconsciousness lens.

Second, it needs to be transformative, something needs to change. On one level we had the transformation of the Te Aro gallery space into a Chicano space, but what I discovered during our interviews with the visitors, was that they were transformed by objects and stories being told in the gallery space. Each person's transformation was different, but most talked about viewing the world and Chicanos differently than before they entered the gallery. Again, transforming problems into solutions to benefit society is what western science strives to do. Chicano Border Methodology does this too, just from a localised knowledge space perspective.

Third, it needs to include mind, body and spirit. This is where the major difference between working with Chicano Border Methodology and western science occurs. Western science in general is still sees, body and spirit as separate from mind, where this is one of the core elements of a Chicano Border Methodology. What would it be like to do scientific research where the concept of body, mind and spirit are critical elements of the research project? Using Chicano Border Methodology, The Illustrated Chicano was able to engage on all three levels. The objects in the space were designed to engage the mind, from the entry curtain of surveyors tape to the video 
projections to the Knowledge Table to the large wall murals that told the story of Chicano Park. Each element engaged the mind in a different way.

I also engaged the bodies of the visitors as they were able to use their hands to touch the objects on the Knowledge Table, such as the small Seri carvings, where they got to feel the energy of the pieces through their bodies. Their bodies were also engaged when they touched the interactive body cast and helped determine what videos would appear on the body cast. This was a way for their body to engage with the artwork and to be able to help tell my story of being a Chicano. I brought a spirituality to the space by doing a few rituals where I communicated with the spirits of the space and asked for permission to change the space spiritually for a brief time. I changed the space rich with Māori spiritually to a Chicano spiritual space for the duration of the exhibition and then performed a ritual returning and thanking the spirits for letting me use their space. Each person who visited the installation was a Chicano spiritual space and they were feeling the different spirit inside the gallery.

Along with these principles of a de-colonising epistemological pluralism, there are the practical questions I use when I produce my visual artwork. There are no explicit steps that are required to use my Chicano Border Methodology, instead there are a few core questions to point the researcher in the right direction. Each project may have a few different ones added or removed depending on the circumstances of each research project. Suggested questions are:

- What is the purpose of this project?

- Who is the project for?

- What are the issues that the project needs to address?

- Does the project involve the local community?

- What is the perceived impact that the project will have on the local community?

- What are the potential benefits for the community?

- How is the project connected with the location?

- Why is the location important to the project?

- Can you learn to listen? Listening is a powerful tool.

- Can you learn to talk to a person not through them? 
Along with the questions, Chicano Border Methodology uses guidelines similar to other Indigenous research methodologies. With Chicano Border Methodology, each step of this process is geared toward my communities. Chicano Border Methodology respects and ultimately seeks to validate Chicano worldviews. Chicanos will be able to use the research to further the needs of our community. It is designed for use by Chicano and in Chicano communities. Chicano Border Methodology is responsible to my Chicano community. In Chicano Border Methodology, action is a critical part of the methodology. The research must be action-oriented to finding solutions to problems rather than waiting for them to be solved by the western science. That action can take many different forms depending on the project.

I understand that these are lofty guidelines for this research model. All these guidelines may not be able to be met during a research project using this methodology. However, it is something to strive for while doing research using a Chicano Border Methodology. While I have found this methodology to be robust, I can see the possible limitations of this methodology. For example, the number of collaborators able to work on a research project may not be boundless. To have more than 10 people to commit to working on a decolonising project could be problematic. As the group gets bigger, the micro-borders between people get harder to manage in a large group setting. Another limitation could be finding non-Indigenous people who are confident enough in themselves, who are willing to be part of a decolonising research project. In general, it is easier to find Indigenous people to work on a decolonising research project than to find, say, a white European male.

During my research, I have made some discoveries that I think are important to me as a Chicano researcher and for researchers in general. I've come to have a better understanding of how location can influence what I know, how I know it, how I exist, and how I develop my consciousness because of it. It was something I had considered but did not realise how important it is to my work. Another is that I have been able to articulate the concept of Chicano triconsciousness as a method of knowledge production. This is important as it illuminates a reason why La Frontera is an important place to do research about survival and resistance at the cultural interface and in contact zones. It also helped me resolve a tension I had growing up with the feeling not belonging, being the Other in my homeland. And lastly the realisation that even if it is a localised knowledge space, a localised way of looking at things, it is still a valid new knowledge, similar to how Māori use Māori research to look at issues of importance to Māori. 
During the re-construction of my methodology, I realised that my going through the decolonising process was critical to the development of my decolonising methodology. In fact, decolonising myself was the catalyst for the development of my Chicano Border Methodology. I realised to create a decolonising methodology I had to go through the process of decolonisation myself as an individual. If I had not done this, I would not have understood the decolonising process and if I do not understand the process, I cannot decolonise the system. I think for any Indigenous or non-Indigenous scholar or researcher this is an important question to ask when looking to create a decolonising epistemology or methodology. Am I or do I consider myself decolonised? Yet decolonisation is not a once and done event. It is a process and there are various ways to understand the process of decolonisation, such as Yellowbird and W...'s and Laenui's. In this thesis, I talked about how I went through and I am still going through the process of decolonisation. Writing about my process of decolonisation has shown me that I cannot say I am decolonised without truly looking at myself.

Through the writing of this thesis, my Chicano Border Methodology, which was originally an internal methodology developed as a survival mechanism for living at La Frontera, I was able to externalise it as a methodology for collaborations across the hyphen. Through applying it to the creation of The Illustrated Chicano, I was able to re-internalise this methodology and use it for a solo project without collaborators. The Illustrated Chicano demonstrated my Chicano Border Methodology in action in a real-world environment.

Going forward, it is my hope that Chicanos will use my methodology to produce knowledge that can be used to address issues along La Frontera. Also, that we can take control of how our knowledge is created by using methodologies that address specialised locations such as La Frontera where many of us live and work.

What other people who live at the cultural interface, in a contact zone, or in a borderland can learn from this thesis is that this methodology can be modified to create a methodology that matches their specific situation, a methodology that can fit their locality that acknowledges the localised knowledge space, a methodology to create new knowledge that is for the benefit of the local community and not just for western knowledge consumption.

Indigenous and non-Indigenous researchers who want to start or continue their own decolonising process can adapt the principles of my Chicano Border Methodology and its decolonising epistemological pluralism framework to create a methodology that fits their own $\mathbf{1 6 2} \mid \mathrm{P}$ a g e 
decolonising research project. Such a methodology could be used for collaborations across the hyphen that has the potential to decolonise each member of the research group as well as the people who interact with the project. Such a methodology could be used in research projects other than the visual arts. These adaptations could lead us further into the world of a pluri-versity system of education, a place where diverse knowledge systems sit at the same table.

I plan to continue to develop this methodology through future research projects and to write more papers about this methodology as I apply it in different circumstances for the foreseeable future. Now that I have finished this re-construction of my Chicano Border Methodology, I can leave you with the old Mayan saying:

In Lak'ech,

You are my other self. 
$\mathbf{1 6 4 | P}$ a g e 


\section{REFERENCES}

Aguilar-Moreno, Manuel and Cabrera, Erika (2011), Diego Rivera: a biography (ABC-CLIO).

Aguirre, Jr Adalberto (2005), 'The personal narrative as academic storytelling: a Chicano's search for presence and voice in academe', International Journal of Qualitative Studies in Education, 18 (2), 147-63.

Ahenakew, Cash (2014a), 'Indigenous Epistemological Pluralism: Connecting Different Traditions of Knowledge Production.', The Canadian Journal of Native Education, 37 (1) (Theme Issue: Indigenizing the International Academy), 148 - 64.

Ahenakew, Cash; Andreotti, Vanessa de Olivira; Cooper, Garrick; Hireme, Hemi (2014b), 'BEYOND_EPISTEMIC_PROVINCIALISM: De-provincializing Indigenous resistance.pdf >', Alternative, 10 (3), 216 - 31.

Ahisninaabemoaa (20128), 'Ceremonies: Smudge - Pkwenezige Pigitinigewin', $<$ http://www.anishinaabemoaa.com/\#/about/ceremonies/Ceremonies >, accessed 15 Nov.

Aldama, A.J. and Quiñonez, N.H. (2002), Decolonial Voices: Chicana and Chicano Cultural Studies in the 21st Century (Indiana University Press).

Alfred, Taiaiake (2005), Wasase: Indigenous Pathways of Action and Freedom (University of Toronto Press).

Alonso, Ana Maria (2004), 'Conforming Disconformity: "Mestizaje," Hybridity, and the Aesthetics of Mexican Nationalism M-Alonso.pdf>', Cultural Anthropology, 19 (4), 459 - 90.

--- (2005), 'Territorializing the nation and 'integrating the Indian':'Mestizaje'in Mexican official discourses and public culture', Sovereign bodies: Citizens, migrants, and states in the postcolonial world, 39-60.

Altieri, Dino (2014), 'Smudging Protocol and Guidelines', in Manitoba Education and advanced learning (ed.).

Altman, Nathaniel (2002), Sacred water: the spiritual source of life (Paulist Press).

Anzaldua, Gloria (1993), 'Border Arte: Nepantla, El Lugar de la Frontera', in Kathryn Kanjo (ed.), La Frontera/The Border: Art about the Mexico/United States Border Experience (San Diego: Centro Cultural de la Raza and Museum of Contemporary Art, San Diego), 107-23.

Anzaldúa, Gloria (1987), Borderlands: La Frontera the New Mestiza (3 edn.; San Francisco: Aunt Lute Books) 258.

--- (1993), 'Border Arte: Nepantla, El Lugar De La Frontera', LA FRONTERA/THE BORDER, Art About the Mexico/United States Border Experience (San Diego, California: Centro Cultural de la Raza, and the Museum of Contemporary Art San Diego), 107-23.

Baca, Judith F (1980), 'The great wall of Los Angeles', (California State University, Northridge).

Barnhardt, Ray and Kawagley, Angayuqaq Oscar (2008), 'chapter 16: Indigenous Knowledge Systems and Education 1', Yearbook of the National Society for the Study of Education, 107 (1), 22341.

Bataille, Gretchen M. and Silet, Charles L. P. (1976), 'The Indian in American Film', Journal of Popular Film, 5 (2), 171-82.

--- (1980), 'Bibliography', Journal of Popular Film and Television, 8 (1), 50-53.

Battiste, M. (2008), 'Research Ethics for Protecting Indigenous Knowledge and Heritage', in Norman K. Denzin, Yvonna S. Lincoln, and Linda Tuhiwai Smith (eds.), Handbook of Critical and Indigenous Methodologies (Los Angeles: Sage).

Belgrad, Daniel (2004), 'Performing lo chicano', Melus, 29 (2), 249-64.

Beltran, Cristina (2004), 'Patrolling Borders: Hybrids, Hierarchies and the Challenge of Mestizaje', Political Research Quarterly, 57 (4), 595-607.

Black, Jason Edward (2007), 'Remembrances of Removal: Native Resistance to Allotment and the Unmasking of Paternal Benevolence', Southern Communication Journal, 72 (2), 185-203.

Boone, Elizabeth H (1989), 'Incarnations of the Aztec supernatural: The image of Huitzilopochtli in Mexico and Europe', Transactions of the American Philosophical Society, 79 (2), i-107. 
Brown, D.E (1973), 'Hereditary Rank and Ethnic History: An Analysis of Brunei Historiography', Journal of Anthropological Research, 29, 113-22.

Brundage, Burr Cartwright (1983), The fifth sun: Aztec gods, Aztec world (Texas Pan American Series: University of Texas Press).

Burdell, Patricia and Swadener, Beth Blue (1999), 'Critical Personal Narrative and Autoethnography in Education: Reflections on a Genre', Educational Researcher, 28 (6), 21-26.

Butler, Judith (2010), 'PERFORMATIVE AGENCY', Journal of Cultural Economy, 3 (2), 147-61.

Byrnes, G. (2001), Boundary Markers: Land Surveying and the Colonisation of New Zealand (Bridget Williams Books).

Cadava, G. L. (2010), 'Borderlands of modernity and abandonment: The lines within ambos nogales and the tohono O'odham nation', Journal of American History, 98 (2), 362-83.

Callery, Maryann; Williams, Alixandra (1991), 'Ramona UCSD flyer.pdf', in UCSD (ed.).

Carroll, A.S. (2017), REMEX: Toward an Art History of the NAFTA Era (University of Texas Press).

Caso, Alfonso and Bernal, Ignacio (1952), Urnas de Oaxaca (2: Instituto Nacional de Antropología e Historia).

Castro-Gomez, Santiago (2006), 'The Social Sciences, Epistemic Violence, and the Problem of the "Invention of the Other"', in Saurabh Dube and Ishita Banerjee-Dube (eds.), Unbecoming Modern: Colonialism, Modernity, Colonial Modernities (New Delhi: Esha Beteille, Social Science Press), 211-27.

Certeau, Michel de (1984), 'The practice of everyday life. Berkeley', (CA: University of California Press).

Ceseña, Maria Teresa (2013), 'Hemispheric Visions and Border Divisions: Differential Decolonizations at the US National Museum of the American Indian', Comparative American Studies An International Journal, 11 (2), 201-19.

Chávez, Ernesto (2002), "i Mi Raza Primero!"(My People First!): Nationalism, Identity, and Insurgency in the Chicano Movement in Los Angeles, 1966-1978 (Univ of California Press).

Conquergood, D. (2002a), 'Performance studies - Interventions and radical research', Tdr-the Drama Review-a Journal of Performance Studies, 46 (2), 145-56.

Conquergood, Dwight (1995), 'Of Caravans and Carnivals: Performance Studies in Motion', The Drama Review, 39 (4), 137-41.

--- (2002b), 'Performance Studies: Interventions and Radical Research', The Drama Review, 46 (2), $145-56$.

Corden, Jez (2018), 'Farewell, dear sweet Kinect', <https://www.windowscentral.com/ode-kinect>, accessed Nov 28, 2018.

Correa, Jennifer G. (2011), 'The Targeting of the East Los Angeles Brown Berets by a Racial Patriarchal Capitalist State: Merging Intersectionality and Social Movement Research', Critical Sociology, 37 (1), 83-101.

Cram, Fiona (2001), 'Rangahau Māori: Tōna tika, tōna pono-The validity and integrity of Māori resaerch', in In M Tolich (ed.), Research Ethics in Aotearoa New Zealand: concepts, practices, critique (Auckland Longman).

Crenshaw, Kimberle (1989), 'Demarginalizing the intersection of race and sex: A black feminist critique of antidiscrimination doctrine, feminist theory and antiracist politics', U. Chi. Legal F., 139.

Davies, Nigel (1973), The Aztecs: A History (New York: G.P. Putnam's Sons).

Day, Ida (2015), 'The Preservation of Indigenous Knowledge in Contemporary Mexico in El cultivo del maize en Yojovi by Javier Castellanos', IK: Other Ways of Knowing, 1 (1), 9-14.

De Castro, Juan E (2002), Mestizo Nations: Culture, Race, and Conformity in Latin American Literature (University of Arizona Press).

Dei, George J. Sefa (2000), 'Rethinking the role of Indigenous knowledges in the academy', International Journal of Inclusive Education, 4 (2), 111-32. 
Dei, George Jerry Sefa, Hall, Budd L., and Rosenberg, Dorothy Goldin (2000), Indigenous knowledges in global contexts : multiple readings of our world (Toronto ;: Buffalo : Published in association with University of Toronto Press) xvi, $282 \mathrm{p}$.

Delgado, Kevin (1998 Winter), 'A Turning Point: The Conception and Realization of Chicano Park', The Journal of San Diego History, 44 (1).

Denzin, Norman K. and Lincoln, Yvonna S. (2008), 'Introduction: Critical Methodologies and Indigenous Inquiry', in Norman K. Denzin, Yvonna S. Lincoln, and Linda Tuhiwai Smith (eds.), Handbook of Critical and Indigenous Methodologies (Los Angeles: Sage), 1-20.

Denzin, Norman K., Lincoln, Yvonna S., and Smith, Linda Tuhiwai (2008a), 'Handbook of Critical and Indigenous Methodologies', (Los Angeles: Sage), xv, 604 p.

--- (2008b), Handbook of Critical and Indigenous Methodologies (Los Angeles: Sage) xv, 604 p.

Dubois, W.E.B. (([1904] 1995)), The Soul of the Black Folks (New York: Penguin).

Dussel, Enrique (2006), 'Anti-Cartesian Meditations', (Poligrafi).

Ermine, Willie, Battiste, M, and Barman, J (1995), 'Aboriginal epistemology', First Nations education in Canada: The circle unfolds, 101-12.

Evans-Campbell, Teresa (2008), 'Historical Trauma in American Indian/Native Alaska Communities:A Multilevel Framework for Exploring Impacts on Individuals, Families, and Communities', Journal of Interpersonal Violence, 23 (3), 316-38.

Facio Elisa and Irene, Lara (2014), Fleshing the Spirit : Spirituality and Activism in Chicana, Latina, and Indigenous Women's Lives (Tucson, UNITED STATES: University of Arizona Press).

Foster, Thomas (2002), 'Cyber-Aztecs and Cholo-Punks: Guillermo Gomez-Pena's Five-Worlds Theory', PMLA, 117 (1 Special Tpoic:Moblie Citizens, Media states), 43 - 67.

Fuchs, Thomas (2017), '17 Collective Body Memories', Embodiment, Enaction, and Culture: Investigating the Constitution of the Shared World, 333.

Garnica, Lynelle Christine (2010), 'Spatial distribution of traffic related air pollutants in the community of San Ysidro', (Health and Human Services).

Gaudry, Adam J. P. (2011), 'Insurgent Research', Wicazo Sa Review, Spring, 113-36.

Ginsburgh, V. and Penders, A.-F. (1997), 'Land Artists and Art Markets', Journal of Cultural Economics, 21 (3), 219-28.

Global, Screen systems (2018), 'Resources \& FAQ', <http://goosystemsglobal.com/resources-faq/\#1>, accessed Nov 252018.

Gray, C (1996), 'Inquiry through practice: Developing appropriate research strategies. No Guru, No Method? Discussions on Art and Design Research, University of Art and Design Helsinki UIAH, Helsinki, Finland, As quoted in: Haseman, B. 2007 tightrope Writing: Creative Writing Programs in the RQF Environment", TEXT: The Journal of the Australian.

Grosfoguel, Ramón (2009), 'A Decolonial Approach to Political-Economy: Transmodernity, Border Thinking and Global Coloniality ', Kult 6, Special Edition.

--- (2011), '<Grosfoguel-Decolonizing-Pol-Econ-and-Postcolonial.pdf>'.

--- (2012), '<Grosfoguel-FM-The Dilemmas of Ethnic Studies in the United States.pdf>'.

--- (2013), '<Grosfoguel-The Structure of Knowledge in Westernized Universities.pdf>'.

Grynsztejn, Madeleine (1993), 'La Frontera/The Border: Art about the Mexico/United States Border Experience', in Kathryn Kanjo (ed.), La Frontera/The Border: Art about the Mexico/United States Border Experience (San Diego: Centro Cultural de la Raza and Museum of Contemporary Art, San Diego), 23-39.

Haseman, Brad (2006a), 'A manifesto for performative research', Media International Australia incorporating Culture and Policy, 118 (1), 98-106.

--- (2006b), 'A Manifesto for Performative Research', Media International Australia incorporating Culture and Policy, February (118), 98-106.

Haseman, Brad and Mafe, Daniel (2009), 'Acquiring know-how: Research training for practice-led researchers', Practice-led research, research-led practice in the creative arts, 211-28.

Haseman, Bradley C (2007), 'Rupture and recognition: identifying the performative research paradigm', Practice as research: Approaches to creative arts enquiry (IB Tauris), 147-57. 
Healy, S. (2003a), 'Epistemological pluralism and the 'politics of choice", Futures, 35 (7), 689-701.

Healy, Stephen (2003b), 'Epistemological Pluralism and the 'Politics of Choice", Futures, 35, 689-701.

Higgins, Rawinia R (2004), 'He tanga ngutu, he Tuhoetanga te mana motuhake o te ta moko wahine: The identity politics of moko kauae', (University of Otago).

Holm, Jeffrey E, et al. (2010), 'Assessing health status, behavioral risks, and health disparities in American Indians living on the northern plains of the US', Public Health Reports, 125 (1), 6878.

Howe, Kerry Ross (2006), Vaka moana: Voyages of the ancestors: The discovery and settlement of the Pacific (University of Hawaii Press).

Hutchings, Jessica (2002), 'Decolonisation and Aotearoa-a pathway to right livelihood', Swaraj Foundation, nd http://www. swaraj. org/shikshantar/Is3 jessica. htm HAYWARD, Janine. "Ngā mātāpono o te tiriti-principles of the Treaty of Waitangi: What are the treaty principles.

Ikeda, Daisaku (2004), The Human Revolution, i (Santa Monica, CA: World Tribune Press).

Irwin, Kathie (1994), 'Maori Research Methods and Processes: An Exploration', Sites, 28, 25-43

Jaramillo, Patricia A. (2010), 'Building a Theory, Measuring a Concept: Exploring Intersectionality and Latina Activism at the Individual Level', Journal of Women, Politics \& Policy, 31 (3), 193-216.

John, R.S. (2012), Line in the Sand: A History of the Western U.S.-Mexico Border (Princeton University Press).

Kelly, Lawrence C. (1975), 'The Indian Reorganization Act: The Dream and the Reality', Pacific Historical Review, 44 (3), 291-312.

Kemp, Amanda (1998), 'This black body in question', The ends of performance, 116-29.

Koch, S.C., et al. (2012), Body Memory, Metaphor and Movement (John Benjamins Publishing Company).

La Flamme, Michelle (2008), 'Dana Claxton: "Reframing the Sacred and Indigenizing the White Cube"', in James H Nottage (ed.), Diversity and Dialogue: The Eiteljorg Fellowship for Native American Fine Art, 2007 (University of Washington Press).

Laenui, Poka (2000), 'Processes of decolonization', Reclaiming Indigenous voice and vision, 150-60.

Leal, Luis (1989), In Search of Aztlan, ed. In Rudolfo Anaya and Francisco Lomeli (Aztlan: Essays on the Chicano Homeland; Albuquerque New Mexico: University of New Mexico Press).

Leask, Rognvald 'What Place For The People Of The Land?'.

Lechusza, Aquallo Prof. (2018), 'American Indian Studies Programs \& Tribal Colleges/Universities', $<$ https://www2.palomar.edu/pages/aaquallo/american-indian-studies-programs/>, accessed 4 Oct 2018.

Lee-Morgan, Jenny (2016), Decolonisation in Aotearoa: education, research and practice (New Zealand Council for Educational Research).

Leval, Susana Torruella (1992), 'Recapturing History: The (Un)Official Story in Contemporary Latin American Art', Art Journal, 51 (4), 69-80.

Logan, Irene (2005), 'History and Origins'.

Luna-Firebaugh, Eileen (2005), 'At Hascu Am O I-oi - What Direction Should We Take: The Desert People's Approach to the Militarization of the Border Contemporary and Comparative Perspectives on the Rights of Indigenous Peoples', Washington University Journal of Law \& Policy, 19.

MacDonald, Victoria-Mar (2001), 'Hispanic, Latino, Chicano, or "Other"?: Deconstructing the Relationship between Historians and Hispanic-American Educational History', History of Education Quarterly, 41 (3), 365-413.

Marchi, Regina M. (2009), Day of the dead in the USA: the migration and transformation of a cultural phenomenon (Piscataway NJ: Rutgers University Press).

Martin, Holly E. (2005), 'Code-switching in US ethnic literature: multiple perspectives presented through multiple languages', Changing English, 12 (3), 403-15. 
Martínez, J.L. (2015), Hernán Cortés (Fondo de Cultura Económica).

McKinley, Elizabeth (2005), 'Locating the global: Culture, language and science education for indigenous students', International journal of science Education, 27 (2), 227-41.

Mead, Hirini Moko (2003), Tikanga Maori: Living by Maori Values (Wellington: Huia Publishers).

Mead, Sidney M. (2001), Ngā pēpeha a ngā tīpuna = The sayings of the ancestors / nā Hirini Moko Mead rāua ko Neil Grove, ed. Neil Grove (Sayings of the ancestors; Wellington [N.Z.]: Wellington N.Z. : Victoria University Press).

Mignolo, W. D. (2006), 'Theorizing from the Borders: Shifting to Geo- and Body-Politics of Knowledge', European Journal of Social Theory, 9 (2), 205-21.

Mignolo, Walter D. (2007a), 'DELINKING; The rhetoric of Modernity, the logic of coloniality and the grammer of de-colonialty', Cultural Studies (21 Taylor and Francis), 449-514.

--- (2007b), 'Delinking: The Rhetoric of Modernity, the Logic of Coloniality and the Grammar of DeColoniality', Cultural Studies, 21 (2-3), 449-514.

Mihesuah, Devon Abbott and Wilson, Angela Cavender (2004), Indigenizing the academy: Transforming scholarship and empowering communities (U of Nebraska Press).

Miller, Mary Ellen and Taube, Karl (1997), An illustrated dictionary of the gods and symbols of ancient Mexico and the Maya (Thames and Hudson London).

Miller, Thaddeus R. (2008), 'Epistemological Pluralism: Reorganizing Interdisciplinary Research', Ecology and Society, 13 (2).

Moctezuma, Eduardo Matos (1985), 'Archaeology \& Symbolism in Aztec Mexico: The Templo Mayor of Tenochtitlan', Journal of the American Academy of Religion, 53 (4), 797-815.

Nakata, Martin N. (2007), Disciplining the Savages : Savaging the Disciplines (Canberra: Aboriginal Studies Press) viii, $247 \mathrm{p}$.

Nakata, N. Martin; Nakata, Victoria; Keech, Sarah; Bolt, Reuban (2012), 'Decolonial goals and pedagogies for Indigenouis studies.pdf', Decolonization: Indigeneity, Education and Society, 1 (1), 120 - 40.

Nicholson, Henry B (1971a), Religion in pre-Hispanic central Mexico (Handbook of Middle American Indians, 10: Archaeology of Northern Mesoamerica; Austin TX: University of Texas Press) 395-446.

Nicholson, Henry B. (1971b), ' In vestigaciones Contemporaneos Sobre Historia de Mexico.', Prehispanic Central Mexican Historiography, 38-81.

NOLO 'NOLO 2018 Immigration Legal Updates', <https://www.nolo.com/legal-updates/2018immigration-legal-updates $>$, accessed.

O'doherty, Brian (1999), Inside the white cube: the ideology of the gallery space (Univ of California Press).

O'Neil, Andrea (2015), '150 years of news: Protests against inner-city bypass exposed deep rift in Te Aro district heritage', The Dominion Post.

Olivares, Paula Domingo, et al. (2014), 'Cente Tlakatl Ke Cente Cintli', Our Sacred Maíz Is Our Mother (Indigeneity and Belonging in the Americas: University of Arizona Press), xv-xvi.

Pearce, Robert J (2005), 'Turtles from Turtle Island: An Archaeological Perspective from Iroquoia', Ontario Archaeology.

Penalosa, Fernando (1980), Chicano sociolinguistics, a brief introduction / Fernando Penalosa (Series in sociolinguistics; Rowley, Mass: Newbury House Publishers).

Perdue, W.D. (1989), Terrorism and the State: A Critique of Domination Through Fear (Praeger).

Pérez-Torres, Rafael (2006), Mestizaje: Critical uses of race in Chicano culture (U of Minnesota Press).

Pérez, Laura Elisa (2007), Chicana Art : the Politics of Spiritual and Aesthetic Altarities (Durham: Durham Duke University Press).

Phillips, George Harwood (1974), 'Indians and the Breakdown of the Spanish Mission System in California', Ethnohistory, 21 (4), 291.

Porter, R. B. (1999), 'Demise of the Ongwehoweh and the Rise of the Native Americans: Redressing the Genocidal Act of Forcing American Citizenship upon Indigenous Peoples', The Harvard Blackletter Law Journal, 15, 107-84. 
Pratt, M.L. (2007), Imperial Eyes: Travel Writing and Transculturation (Taylor \& Francis).

Pratt, Mary Louise (1991), 'Arts of the Contact Zone', Profession, 33-40.

--- (1999), 'APOCALYPSE IN THE ANDES', Americas, 51 (4), 38.

Quijano, Aníbal (1995), 'Raza, etnia y nación en Mariátegui: cuestiones abiertas', Estudios latinoamericanos, 2 (3), 3-19.

--- (2007), 'Coloniality and Modernity/Rationality', Cultural Studies, 21 (2), 168-78.

Rameka, Lesley (2016), 'Kia whakatōmuri te haere whakamua: 'I walk backwards into the future with my eyes fixed on my past", Comtemporary Issues in Early Childhood, 17 (4), 387-98.

Ramirez, Elvia (2013), 'Examining Latinos/as' Graduate School Choice Process An Intersectionality Perspective', Journal of Hispanic Higher Education, 12 (1), 23-36.

Ramos, Genaro Medina (1999), Náhuatl ( : Plymouth State College of the University System of New Hampshire).

Ranford, Jodie (2015), "Pakeha', Its Origin and Meaning'.

Robles, Kathleen L., Griswold del Castillo, P. D. Richard (2018), 'History of Chicano Park Web site', <http://www.chicanoparksandiego.com/index.html.>, accessed 12 Nov.

Rollins, Peter (2011), Hollywood's Indian: The portrayal of the Native American in film (University Press of Kentucky).

Rua, Mohi, Hodgetts, Darrin, and Stolte, Ottilie (2017), 'Māori men: An indigenous psychological perspective on the interconnected self', New Zealand Journal of Psychology (Online), 46 (3), 55-63.

Saldívar, José David (2007), 'Unsettling Race, Coloniality, and Caste: Anzaldúa's Borderlands/La frontera, Martinez's Parrot in the Oven, and Roy's The God of Small Things', Cultural Studies (21: Taylor and Francis), 339-67.

Sanchez, Micaela Diaz (2010), 'Inbetween Nation and Diaspora: Performing Indigenous and African Legacies in Chicana/o Mexican Cultural Production Micaela Diaz-Sanchez.pdf>', (Stanford University).

Santos, Boaventura de Sousa (1998), 'The Fall of the Angelus Novus: beyond the Modern Game of Roots and Options', Current Sociology, 46 (2), 81-118.

--- (2007), 'Beyond the Abyssal Thinking: From Global Lines to Ecologies of Knowledges', Review (Fernand Braudel Center), 30 (1), 45 - 89.

Saunders, Nicholas J (1990), 'Tezcatlipoca: jaguar metaphors and the Aztec mirror of nature', Signifying animals: human meaning in the natural world, 159-77.

Schmahmann, Brenda (1998), 'Casting a Glance, Diverting the Gaze: George Segal's Representation of the Female Body', American Art, 12 (3), 11-29.

Scott, Dick (1975), Ask that mountain : the story of Parihaka / Dick Scott (Auckland [N.Z.]: Auckland N.Z. : Heinemann/Southern Cross).

Seifert, Miki (2011), 'He Rawe Tona Kakahu/She Wore A Becoming Dress: Performing the Hyphen', $\mathrm{PhD}$ (Victoria University of Wellington).

Seifertl, Miki (2018), 'Performing the Hyphen', Rev. Bras. Estud. Presença, 8 (4), 691-718.

Sharma, Hemant and Prabu, Dhanasekara (2013), 'Plaster of Paris: Past, present and future', Journal of Clinical Orthopaedics and Trauma, 4 (3), 107-09.

Sheikh, Simon (2009), 'Positively White Cube Revisited', e-flux journal, 3.

Shirres, Michael P. (1982), 'TAPU', The Journal of the Polynesian Society, 91 (1), 29-51.

Sinmadera, Telodigo (2019), 'The Meaning of Chicano', $<$ http://www.vividhues.com/BSS/chicanomovement.htm>, accessed Jan 4

Smith, H. (2009), Practice-led Research, Research-led Practice in the Creative Arts (Edinburgh University Press).

Smith, Linda Tuhiwai (1999), Decolonizing Methodologies : Research and Indigenous Peoples (London and Dunedin, N.Z.: Zed Books and University of Otago Press).

--- (2000a), 'Transforming the common sense relationship between the words "Maori" "research" and "theory"'. 
--- (2000b), 'Kaupapa Māori research', in M. Battiste (ed.), Reclaiming indigenous voice and vision (Vancouver: UBC Press), 225-47.

--- (2005), 'On Tricky Ground: Researching the Native in the Age of Uncertainty ', in Norman K Denzin, and Yvonna S Lincoln, (ed.), Handbook of Qualitative Research (3 edn.; Thousand Oaks Ca. USA: Sage Publications), 85-107.

Smith, Linda Tuhiwai, et al. (2016), 'Indigenous knowledge, methodology and mayhem: What is the role of methodology in producing indigenous insights? A discussion from Mātauranga Māori'.

Smith, Michael E (1984), 'The Aztlan migrations of the Nahuatl chronicles: myth or history?', Ethnohistory, 153-86.

Stedman, Philip (1908), 'The Culture of the Luiseño Indians'.

Strickland, Rennard (1985-1986), 'Genocide-at-Law: An Historic and Contemporary View of the Native American Experience Lecture', University of Kansas Law Review, 34.

Sturtevant, E Lewis (1885), 'Indian Corn and the Indian', The American Naturalist, 19 (3), 225-34.

Taliaferro, Denise M. (1998), 'Signifying Self: Re-Presentations of the Double-Consciousness in the Work of Maxine Greene', in William Pinar (ed.), The Passionate Mind of Maxine Greene (Bristol, PA: Falmer Press), 89-98.

Terborg, Roland, Landa, Laura García, and Moore, Pauline (2006), 'The Language Situation in Mexico', Current Issues in Language Planning, 7 (4), 415-518.

Thompson, John Eric Sidney (1957), Deities portrayed on censers at Mayapan (Citeseer).

Tomaselli, Keyan G. Dyll, Lauren and Francis, Michael (2008), "'Self" and "Other" Auto-Reflexive and Indigenous Ethnography', in Norman K Denzin, Lincoln, Yvonna S., Smith, Linda Tuhiwai. (ed.), Handbook of Critical and Indigenous Methodologies (Los Angeles: Sage), 347-72.

Torres, James W Salterio 'Aztec Mythology: The Influence of Aztec Mythology on Mexican Culture and History'.

Turnbull, David (1997), 'Reframing science and other local knowledge traditions', Futures, 29 (6), 55162.

Vasconcelos, Jose (1925), 'La Raza Cosmica= The Cosmic Race: A Bilingual Edition, introduction and notes by Didier T', Jaen. Los Angeles: Department of Chicano Studies, California State University, Los Angeles.(Originally published in Spanish.).

Verdaasdonk, Maria Adriana (2007), 'Living Lens: exploring interdependencies between performing bodies, visual and sonic media in immersive installation', (Queensland University of Technology).

Viergever, Marcel (1999), 'Indigenous Knowledge: An Interpretation of Views from Indigenous People', in Ladislaus Semali and Joe L. Kincheloe (eds.), What is indigenous knowledge? : voices from the academy (New York ; London: Falmer Press), 333-43.

Villenas, Sofia and Deyhle, Donna (1999), 'Critical Race Theory and Ethnographies Challenging the Stereotypes: Latino Families, Schooling, Resilience and Resistance', Curriculum Inquiry, 29 (4), 413-45.

Walsh-Tapiata, Wheturangi (2002), 'A question of identity for our rangatahi', Social Work Review, 14 (2), 24-27.

Walsh, Catherine (2007), 'Shifting the Geopolitics of Critical Knowledge', Cultural Studies, 21 (2-3), 224-39.

Walsh, John C (2001), Landscapes of Longing: Colonization and the Problem of State Formation in Canada West (University of Guelph).

Waziyatawin and Yellow Bird, M (2012), 'Introduction: Decolonizing our minds and actions', Waziyatawin \& M. Yellow Bird (Eds.), For Indigenous minds only: A decolonization handbook, 57-83.

White, Georgina (2007), 'ThistThistle Hall 1907 - 2007: 100 Years of Community', (Wellington, New Zealand).

Wickstrom, Stefanie and Young, Philip D (2014), Mestizaje and Globalization: Transformations of Identity and Power (University of Arizona Press). 
Wilson, John (2016), 'European discovery of New Zealand - Abel Tasman', Te Ara - the Encyclopedia of New Zealand.

Wood, G.A.R. and Lass, R.A. (2008), Cocoa (Wiley).

Wooden, Cindy (2019), 'Pope canonizes Junipero Serra, says faith is alive only when shared', CNS News < $<$ https://www.catholicnews.com/services/englishnews/2015/pope-canonizesjunipero-serra-says-faith-is-alive-only-when-shared.cfm>, accessed 23 July. 


\section{PHOTO CREDITS}

Image 1 On a Mission, .............................................. David Avalos

Image 2 Ramona...................................................... Deborah Small

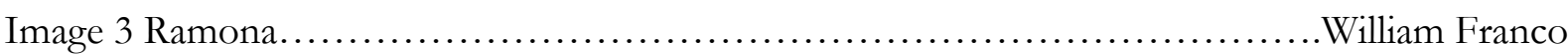

Image 4 Welcome to America's Finest Tourist Plantation......Smithsonian American Art Museum Image 5 To My Sister's Husband: Candy Hearts, Red Slipper...................William Franco

Image 6 Odi's Story: Video still.........................................William Franco

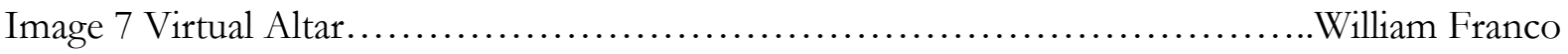

Image 8 Quecholly, (left) wide shot, (right) detail..........................William Franco

Image 9 No Olvidado (left) Art in the Park (right) Calarts......................William Franco

Image 10 No Olvidado: Hotel/Motels.....................................William Franco

Image 11 No Nāianei (left) Butoh Hikoi (Right) Indoor performance..............William Franco

Image 12 Front of Centro Cultural de La Raza..............................William Franco

Image 13 "artifact” Museum of National History San Diego........................ James Luna

Image 14 Surveyors Tape Curtain......................................William Franco

Image 15 Knowledge Table.........................................William Franco

Image 16 Chicano Park Wall.............................................William Franco

Image 17 Chicano Park Mural..........................................William Franco

Image 18 Aztlan Map................................................William Franco

Image 19 The Illustrated Chicano video still................................William Franco

Image 20 The Illustrated Chicano before $\&$ after............................ William Franco

Image 21 The Illustrated Chicano Body Cast Raw..........................William Franco

Image 22 The Illustrated Chicano Plinth with Designs.........................William Franco

Image 23 The Illustrated Chicano Body Cast with Projections...................William Franco

Image 24 The Illustrated Chicano Installation Wide............................William Franco 
MEMORANDUM

Phone $\quad 0-4-4635480$

Email susan.corbettivvuw.ac.nz

\begin{tabular}{l|l}
\hline TO & William Franco \\
\hline COPY TO & \\
\hline FROM & AProf Susan Corbett, Convener, Human Ethics Committee \\
\hline DATE & 15 September 2016 \\
\hline PAGES & 1 \\
\hline \multicolumn{2}{|l}{} \\
\hline SUBJECT & $\begin{array}{l}\text { Ethics Approval: 20091 } \\
\text { Cultural Identity in Experiential and Interaction Digital Installations }\end{array}$ \\
\hline
\end{tabular}

Thank you for your request to extend and amend your ethics approval. This has now been considered and the request granted.

Your application has approval until 31 December 2017. If your data collection is not completed by this date you should apply to the Human Ethics Committee for an extension to this approval.

Best wishes with the research.

Kind regards

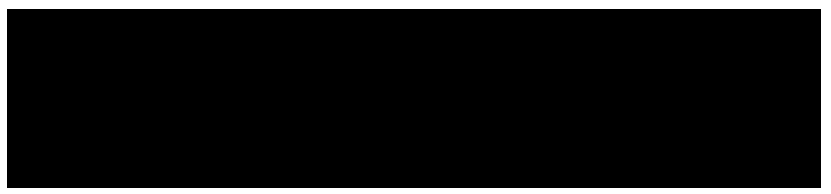

\section{Susan Corbett}

Convener, Victoria University Human Ethics Committee 


\section{APPENDIX 2 - AUDIENCE SURVEY FORM}

\section{The Illustrated Chicano}

\section{Survey and Feedback Form}

Thank you for taking the time to complete this survey. Please be as thorough with your responses as you can be. The responses will be used by William Franco as part of his $\mathrm{PhD}$ in interaction installations from a cultural perspective at Te Kawa a Maui/School of Māori Studies at Victoria University. Responses will also inform the future planning of our arts company With Lime.

Q1) What did you like most about The Illustrated Chicano?

Q2) Was there anything you didn't like about The Illustrated Chicano?

Q3) Based on you experience of The Illustrated Chicano, please indicate whether you agree or disagree with the following statements:

\begin{tabular}{|l|l|l|l|l|l|}
\hline & $\begin{array}{l}\text { Strongly } \\
\text { agree }\end{array}$ & Agree & $\begin{array}{l}\text { Neither } \\
\text { agree or } \\
\text { disagree }\end{array}$ & Disagree & $\begin{array}{l}\text { Strongly } \\
\text { disagree }\end{array}$ \\
\hline I felt moved or inspired & & & & & \\
\hline $\begin{array}{l}\text { I felt engaged in the } \\
\text { experience }\end{array}$ & & & & & \\
\hline $\begin{array}{l}\text { I was exposed to new } \\
\text { points of view or ways of } \\
\text { seeing things }\end{array}$ & & & & & \\
\hline $\begin{array}{l}\text { It made me want to } \\
\text { know more about what I } \\
\text { was seeing }\end{array}$ & & & & & \\
\hline $\begin{array}{l}\text { It felt relevant to our } \\
\text { society and the times we } \\
\text { live in }\end{array}$ & & & & & \\
\hline
\end{tabular}


Q4) How did you hear about The Illustrated Chicano?

$\square$ E-mail

$\square$ Event Poster or Flier

$\square \quad$ Facebook

$\square$ Magazine

$\square$ Newspaper

$\square$ Online Promotion Website(e.g. Event Finda, The Big Idea etc )

$\square$ Word Of Mouth

$\square$ Other (Please List)

Q5) Have you been to a performance or an exhibition by With Lime before?

$\square$ Yes

$\square \quad$ No

$\square$ Not Sure

Q6) How would you rate The Illustrated Chicano overall?
Excellent
$\square$ Good
$\square$ Average
$\square$ Poor
$\square$ Very Poor

Q7) Are you:

$\square \quad$ Male

$\square \quad$ Female

$\square$ Transgender

$\square$ Prefer not to say

Q8)What is your age group?
12 or under
$\square \quad 13-19$
$\square \quad 20-29$
$\square \quad 30-39$
$\square \quad 40-49$
$\square \quad 50-59$
$\square \quad 60-69$
$\square \quad 70+$ 
Q9) Do you identify as:

\section{Chicano \\ $\square$ Maori \\ $\square \quad$ Pacific Islander \\ $\square$ Chinese \\ $\square \quad$ NZ European}

$\square$ Indian

$\square$ Pakeha

$\square$ From a culturally diverse background.

$\square \quad$ Other (Please specify)

$\square \quad$ Would prefer not to say

Q10) Where did you travel from today? Which suburb do you live in? Or, if you are from overseas, whereabouts is your country of origin?

Q11) Is there anything else you would like to share with us about your experience of The Illustrated Chicano?

Thank you for your thoughtful responses, it is very much appreciated.

With Lime

info@withlime.co.nz 


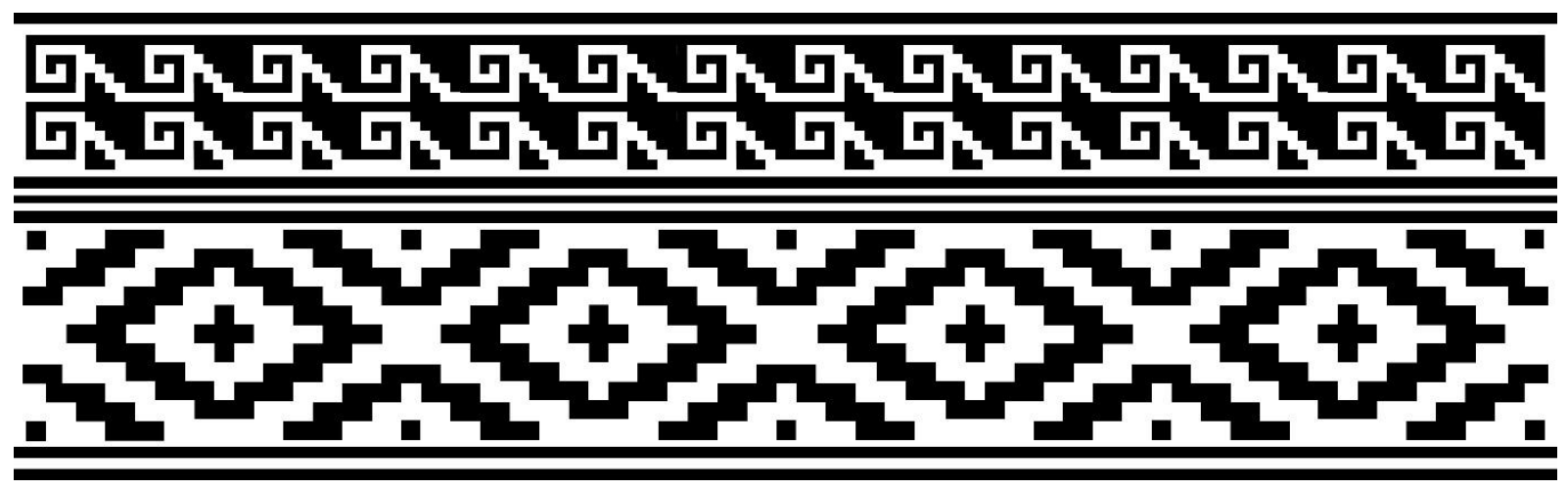

Side Panels

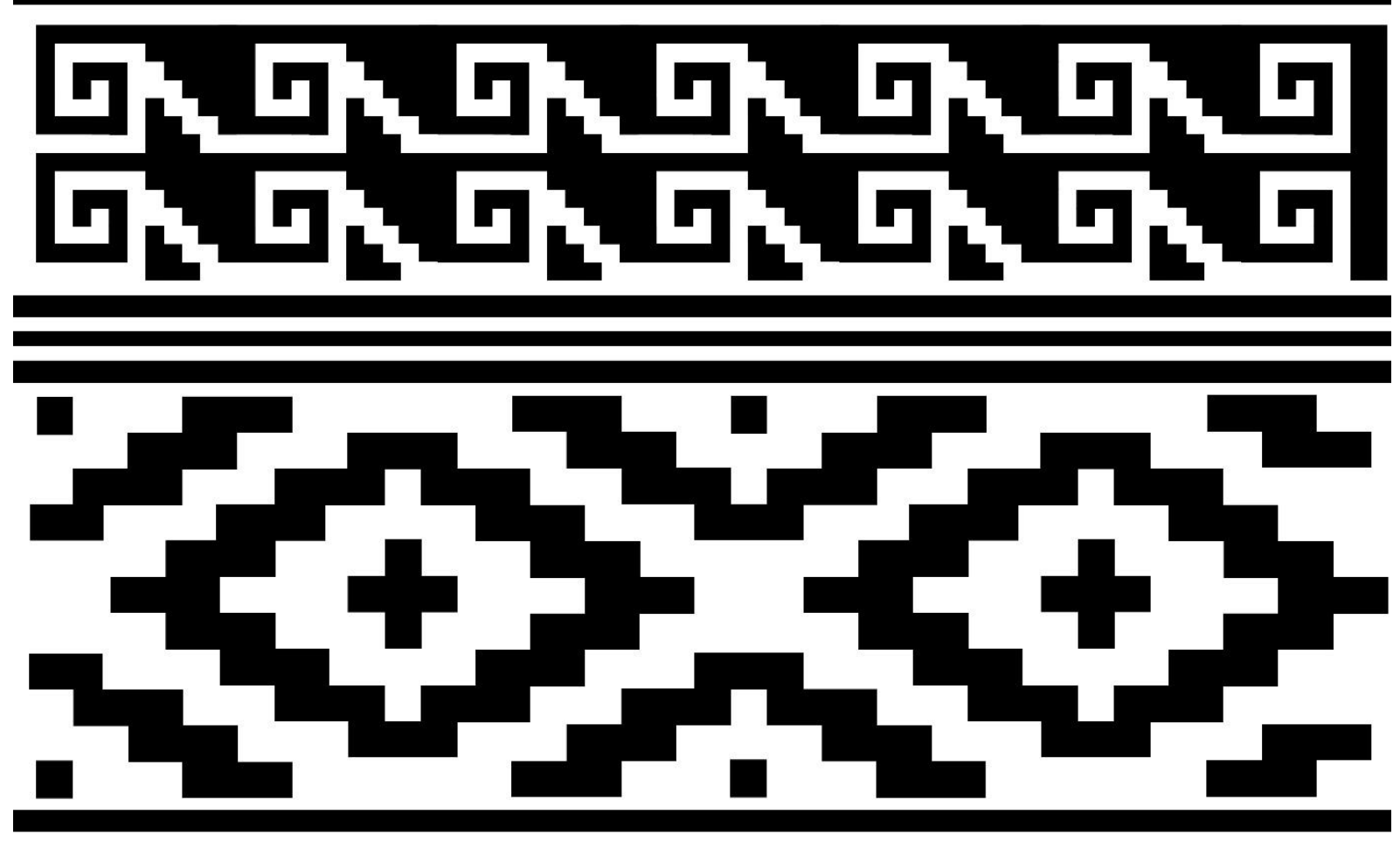




\section{APPENDIX 4 - POSTER}

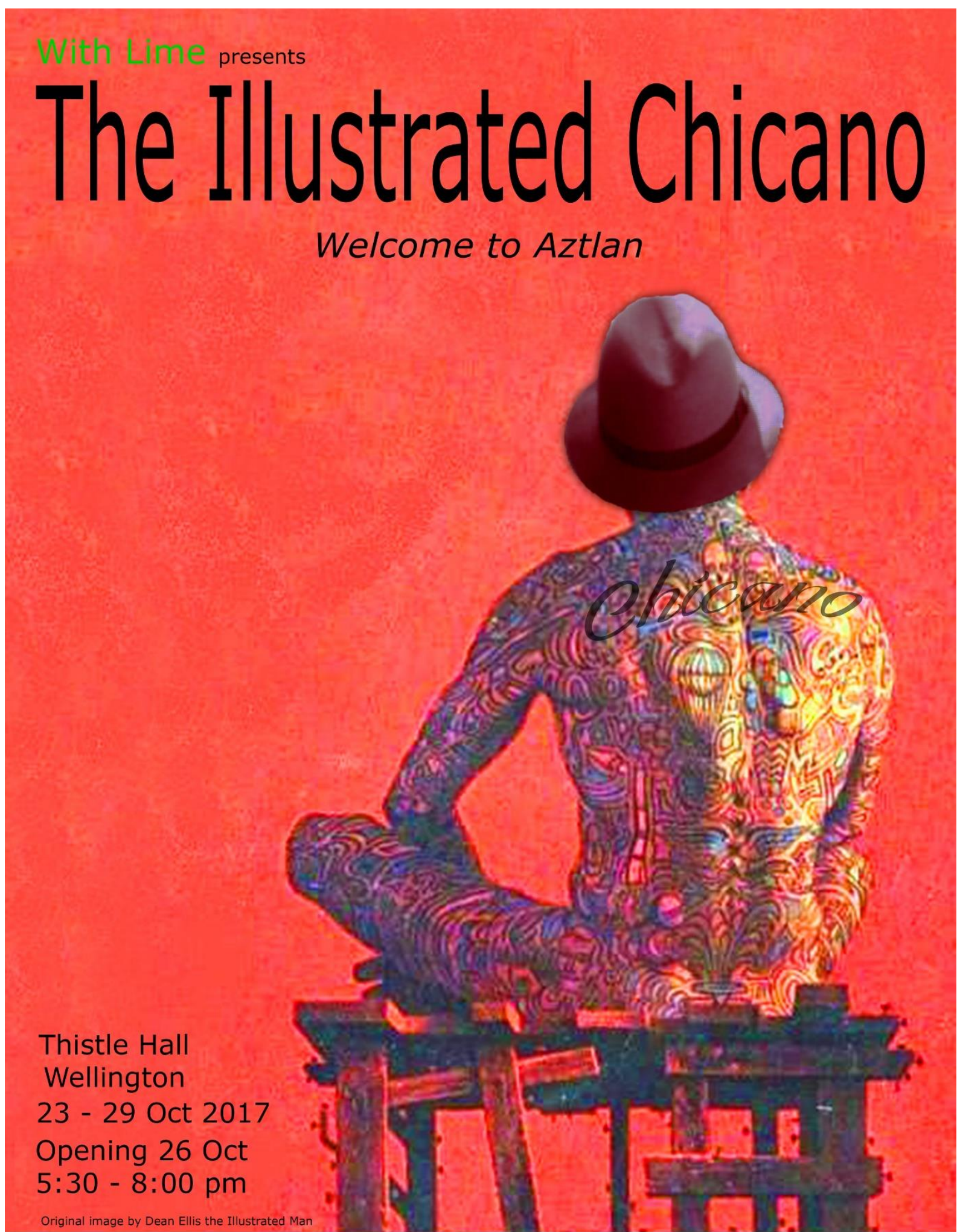

Original image by Dean Ellis the Illustrated Man

Wellington City

Supported by a grant from the FHSS, Victoria University of Wellington
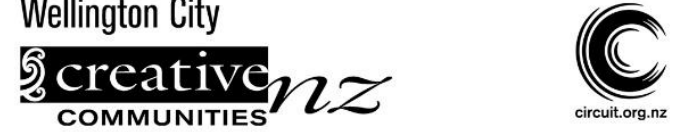


\section{APPENDIX 5 - FIRST DESIGNS}

First design was using four projectors but the project changed to one projector pointing down onto the body cast

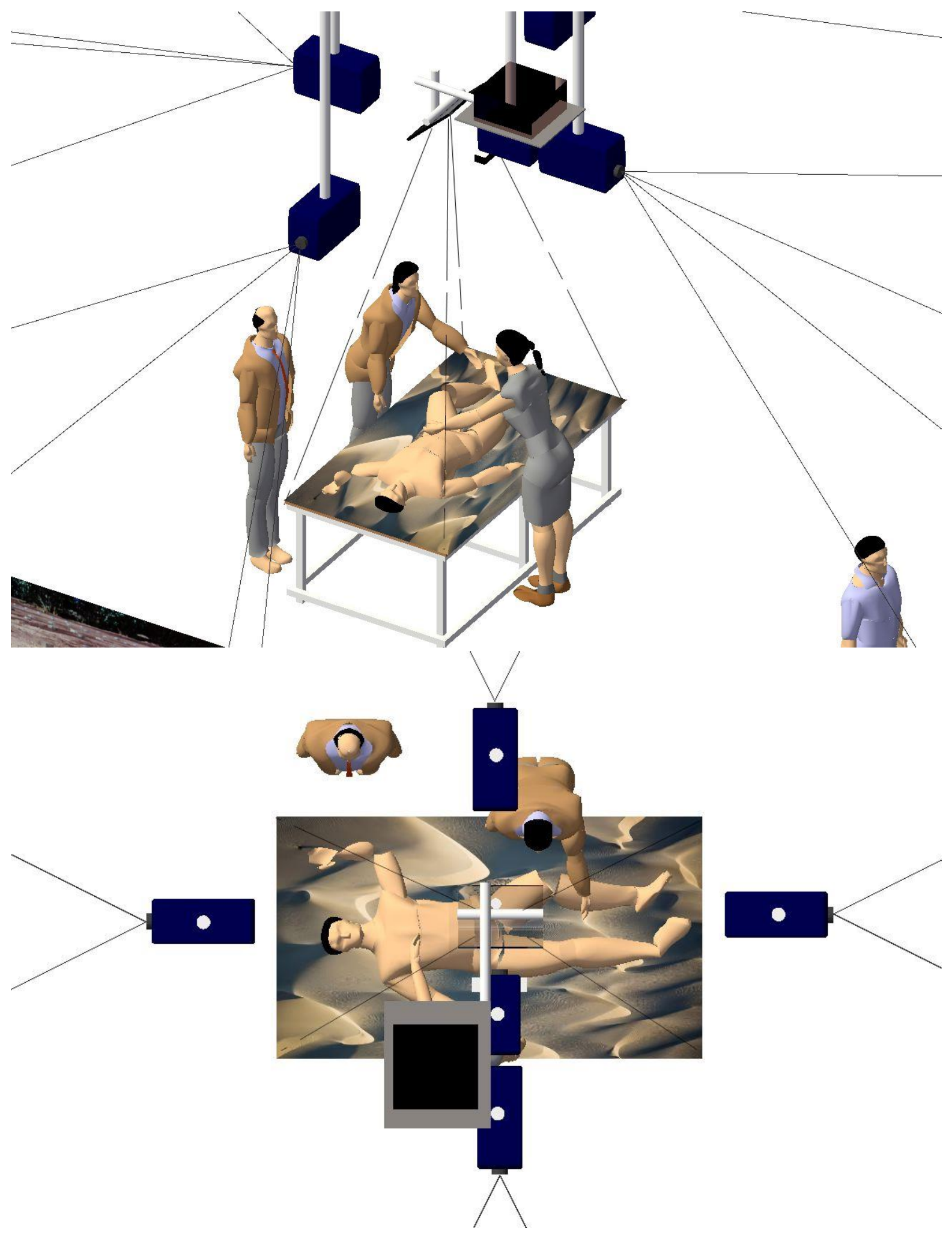




\section{APPENDIX 6 - THE ILLUSTRATED CHICANO INSTALLATION PRESS RELEASE}

\section{FOR IMMEDIATE RELEASE:}

Tattoos will come alive to tell stories of Chicanos as part of an interactive installation, The Illustrated Chicano, at Thistle Hall, Wellington 23-29 October 2017.

The title of the installation is adapted from the Ray Bradbury story, "The Illustrated Man." In Bradbury's story, a white carnival worker is cursed by tattoos that come alive and show the future. Bradbury's story has been repurposed to tell the story of artist William Franco's migration to Aotearoa and his Chicano heritage and identity.

Chicanos are Native Americans whose lands (the Southwestern US and Mexico) were appropriated by the European colonisers. "We've had to change and adapt our culture multiple times," says Franco. "A lot of people in Aotearoa don't know the history or the culture of Chicanos."

For the installation, a detailed plaster cast of the artist's body has been made. The body cast functions as a sculpted canvas onto which projected tattoos flow and dance. Using new developments in real time, 3D digital-mapping technology, the tattoos, when touched, morph into videos that envelope the body cast. The public will be able to come and watch the construction of the installation 23-25 October, and then see and interact with it 26-29 October. "Sculpture is tactile," Franco explains, "but when you see sculpture in museums, you're told not to touch it. We want the public to touch this work, to get to know it, to feel its presence, to feel its life."

The casting was done by William Franco's partner and collaborator Miki Seifert. Together they are the artistic directors of With Lime, an interdisciplinary arts company based in Wellington. They relocated from Los Angeles in 2007.

The pair have previously worked alongside intercultural art luminaries Guillermo Gomez-Pena and James Luna. They are driven by a desire to make compelling and beautiful work that facilitates intercultural dialogue and engages people in issues of social justice.

As an indigenous living and working in the land of another indigenous, Franco has taken Māori tikanga into consideration when designing his installation. In Māori culture, displaying the image of a body on a table and inviting people to touch it, could be seen as disrespectful.

Following discussions with local Māori, Thistle Hall will be transformed into a distinctively Chicano space, decorated with cultural symbols of marigolds, corn, burning sage,. "Reclaiming indigenous space is important," says Franco, "and I need to be aware of how my actions effect the tangata whenua. I need to understand how to keep everyone safe when creating art. People will know immediately upon entering that different rules apply, that this is an alternate indigenous space."

Staying on the edge of technological developments has allowed Franco to talk about culture in new and engaging ways. Technology is a perfect analogy for the sometimes complicated work of communicating between cultures at a time where culture is continually shifting and changing. To make The Illustrated Chicano, Franco has had to get two software programs, Watchout and Kinect, to work together. A process he describes as like an act of translation.

"The work we make lives in a liminal space where technology allows us to adapt to different settings, different cultural contexts." 
Franco may soon need to adapt The Illustrated Chicano with interest being shown from galleries in Los Angeles and San Diego.

In Bradbury's The Illustrated Man, the tattoos show a future that is isolated and violent. Franco's The Illustrated Chicano shows an alternative future based on understanding and respect.

Contact Info:

William Franco, Artistic Director

With Lime Ltd

9/127 Molesworth Street

Thorndon, Wellington 6011

021.100 .5582

williamfranco@,withlime.co.nz

info@withlime.co.nz

(word count 595)

\#\#\# 
APPENDIX 7 - TATOOS SAMPLES
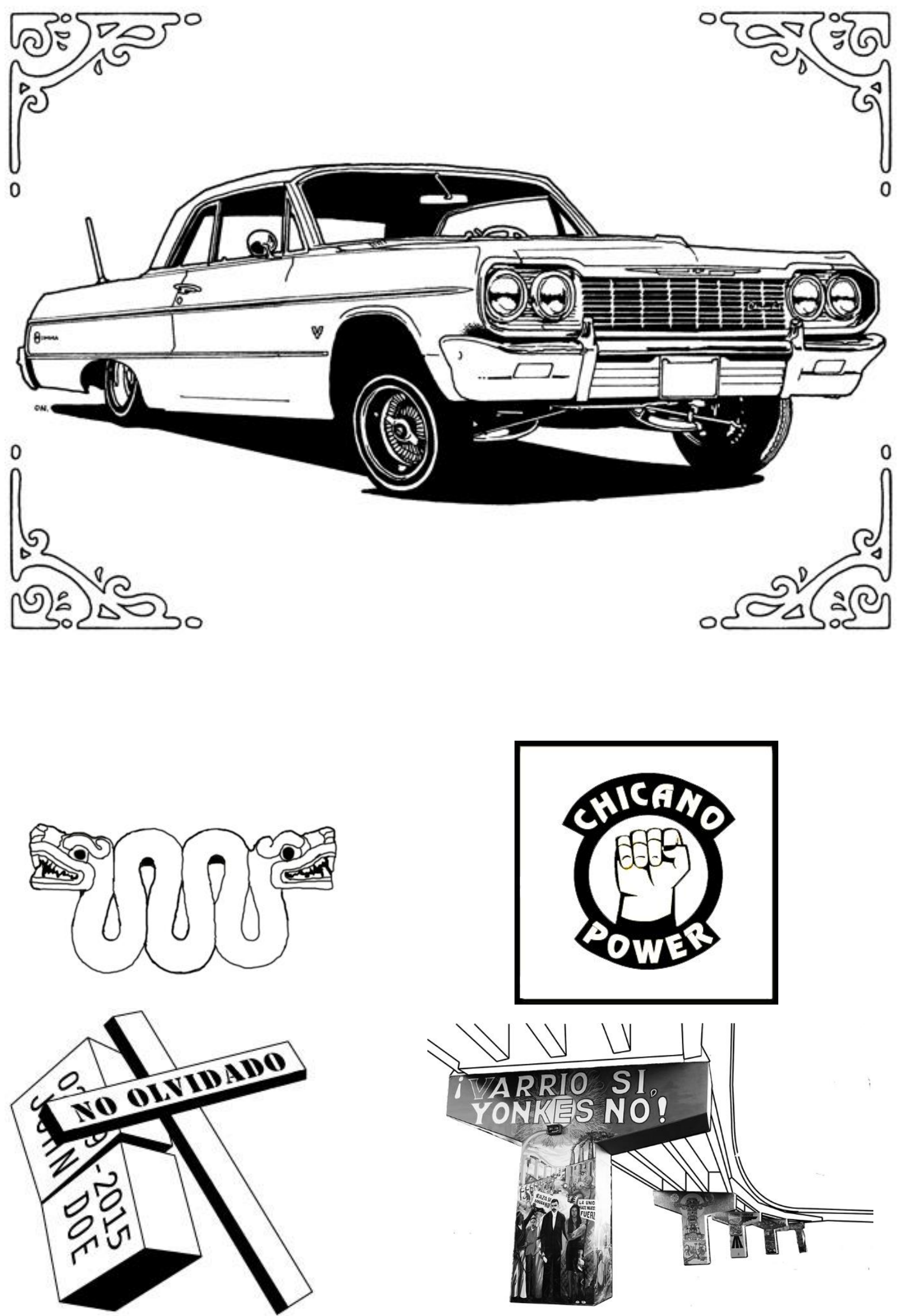
APPENDIX 8 - TESTING AT BANFF CENTRE FOR ARTS AND CREATIVITY

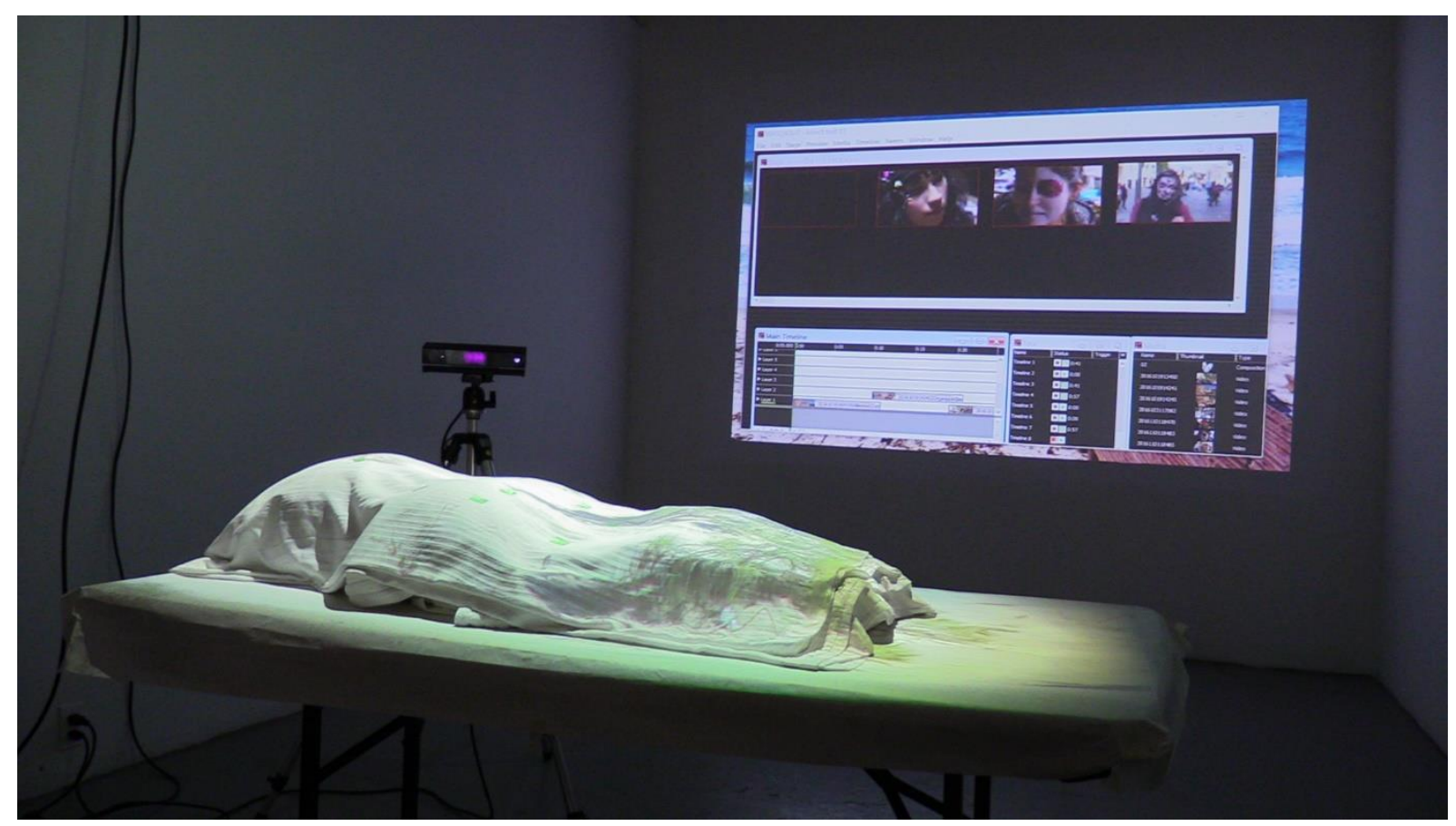


